\begin{tabular}{|c|c|c|c|c|c|c|c|c|c|c|c|c|c|c|}
\hline EEEEEEE & LL & EEEEEEE & \multicolumn{2}{|c|}{$\mathrm{CCCCC}$} & ттттттт & RRRR & $R R$ & \multicolumn{2}{|c|}{00000} & NN & NN & IIIII & \multicolumn{2}{|c|}{$\mathrm{CCCCC}$} \\
\hline $\mathrm{EE}$ & LL & $\mathrm{EE}$ & $\mathrm{CC}$ & $\mathrm{C}$ & TTT & RR & $\mathrm{RR}$ & $\mathrm{OO}$ & $\mathrm{OO}$ & NNN & NN & III & $\mathrm{CC}$ & C \\
\hline EEEEE & LL & EEEEE & $\mathrm{CC}$ & & TTT & RRRR & $R R$ & $\mathrm{OO}$ & OO & $\mathrm{NN} N$ & $\mathrm{~N}$ NN & III & $\mathrm{CC}$ & \\
\hline $\mathrm{EE}$ & LL & $\mathrm{EE}$ & $\mathrm{CC}$ & $\mathrm{C}$ & TTT & RR & $\mathrm{RR}$ & $\mathrm{OO}$ & OO & NN & NNN & III & $\mathrm{CC}$ & C \\
\hline DEI & LLLLLLL & EEEF & & & TTT & RR & RR & & & NN & NN & IIIII & & C \\
\hline
\end{tabular}

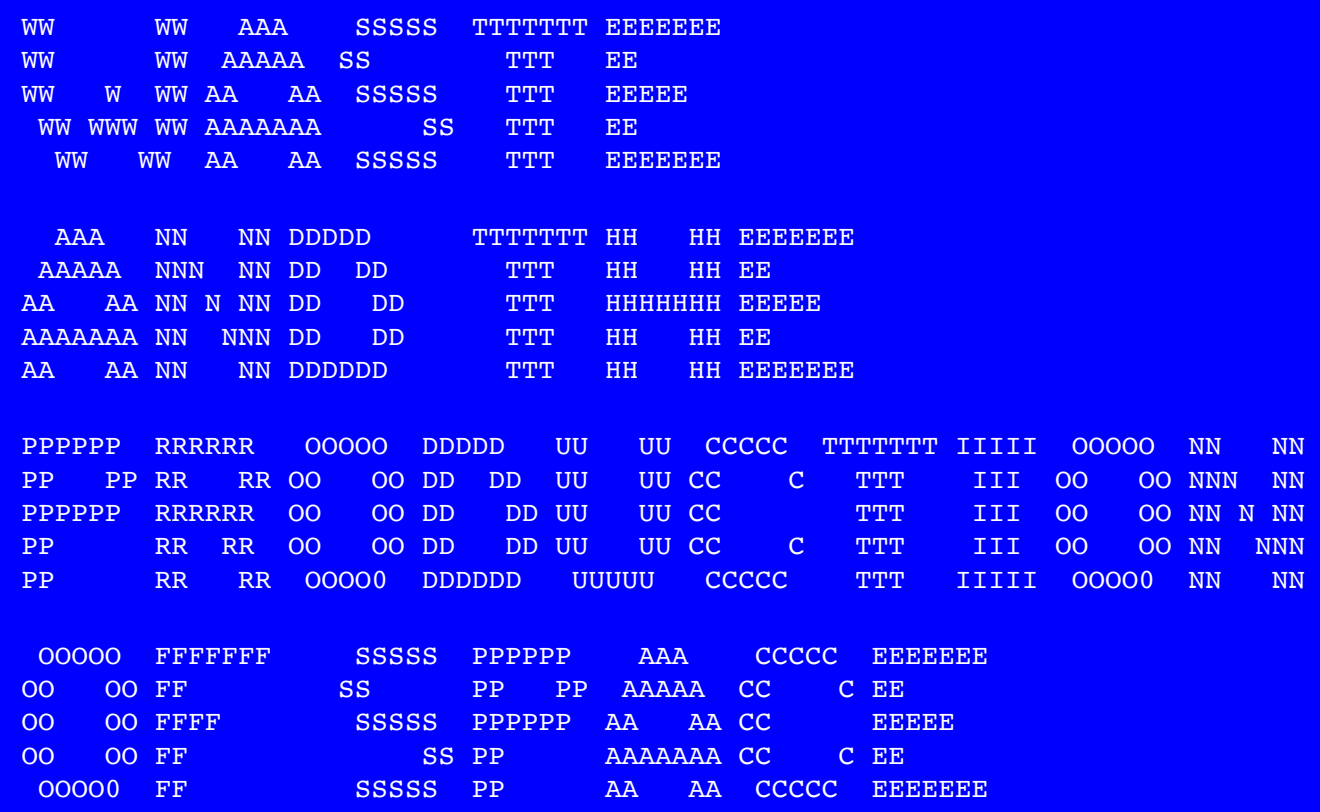





\title{
ELECTRONIC WASTE \& THE PRODUCTION OF SPACE
}

\author{
By \\ Ron Philipp Noble \\ BArchSc, 2014
}

A thesis presented to Ryerson University

in partial fulfillment of

the requirements for the degree of

Master of Architecture

in the Program of

Architecture

Toronto, Ontario, Canada, 2018

(C) Ron Philipp Noble 2018 



\section{Author's Declaration}

I hereby declare that I am the sole author of this thesis. This is a true copy of the thesis, including any required final revisions, as accepted by my examiners.

I authorize Ryerson University to lend this thesis to other institutions or individuals for the purpose of scholarly research.

I further authorize Ryerson University to reproduce this thesis project by photocopying or by other means, in total or in part, at the request of other institutions or individuals for the purpose of scholarly research

I understand that my thesis may be made electronically available to the public. 

Electronic Waste and the Production of Space

Master of Architecture 2018

Ron Philipp Noble

Ryerson University

\begin{abstract}
The future of waste is electronics. The conditions of planned obsolescence combined with our throw away culture of capitalistic consumption has created the largest and fastest growing waste stream responsible for spatially transforming environments. Through the process of reclaiming precious materials contained within our dysfunctional electronics, urban mining becomes a form of resistance to the economics of consumption by recognizing electronic waste as a resource and turning its perceived detritus into value. If waste is central in the processes of capitalist urbanization, can architecture improve the condition of configuring industrial form to create ecology between e-waste, culture, and urbanity? Are there opportunities for e-waste and its architecture to have a public value and legibility in the city? Within this space of speculation, this thesis will explore the untapped architectural possibilities associated with the management of electronic waste and the production of space.
\end{abstract}





\title{
Acknowledgments
}

\begin{abstract}
Albert Smith, thank you for giving me the freedom to explore my own ideas.
June Komisar, thank you for providing clarity at times when nothing made sense. Thank you for truly understanding what it was that I was doing. Thank you for introducing me to a phenomenal understanding of transparency, which really laid the foundation and allowed me to see my thesis with new perceptions.
\end{abstract}

Masha Etkind, thank you for your energy, encouragement and enthusiasm.

Kriztel Dizon, my muse, thank you for your love, loyalty, and support throughout the $10+$ years that we have been together, without which, I would have not been able to accomplish the things that I have. Thank you for being my rock. You are a constant reminder for why I do what I do. 



\section{Contents}

Author's Declaration $\quad$ iii

Abstract $\quad \mathrm{V}$

Acknowledgment vii

List of Figures vii

Introduction 1

\section{Act 1: The Future of Waste}

1 Electronic Waste $\quad 9$

2 Recognizing Electronic Waste as a Resource $\quad 15$

$3 \quad$ Managing Electronic Waste $\quad 21$

$4 \quad$ Waste Producing Space $\quad 27$

$5 \quad$ The Invisibility of Electronic Waste 33

6 A Generic Architecture: The Industrial Big Box 39

$7 \quad$ Electronic Obsolescence $\quad 45$

Act 2 (pt.1): Making the Invisible Visible

$8 \quad$ The Need for Transparency 53

$9 \quad$ A Transparent Architecture of Sign and Symbol 61

$10 \quad$ Electronic Iconography $\quad 65$

11 Electronic Billboards Are All Right 73

Act 2 (pt.2): The Medium is the Message

12 Collage Thinking: Disassemble to Reassemble 81

13 Sampling the Electronic Found Object for Architectural Purposes 86

14 Remixing Architecture $\quad 92$

Act 3: Electronic Iconography Upon a Generic Architecture

15 Site of Speculation: The Golden Mile 99

16 Centre for Electronic Waste and Resource Recovery 106

$\begin{array}{ll}\text { Conclusion } & 121\end{array}$

$\begin{array}{lr}\text { Reference List } & 129\end{array}$ 



\section{List of Images}

\section{Act 1:}

1

Krales, Amelia. A Pile of E-Waste. 2016. The Verge.

Source: https://www.theverge.com/2016/6/26/12033226/e-waste-new-

york-city-photo-behind-the-scenes.

\section{2}

Basel Action Network. Accra, Ghana. 2009. Flickr.

Source: https://www.flickr.com/photos/basel-action-network/9263480168/

3

Noble, Ron. Ward 30 Community Environment Day Electronic Waste Collection Bin. 2017.

\section{4}

Noble, Ron. The Waste Hierarchy (re-imagined). 2017.

\section{5}

Matthews, Chris. Nadjagou Shows Off His 3D Printer Design. 2016.

Motherboard.

Source: https://3dprint.com/wp-content/uploads/2016/05/3dprintewaste1080x675.jpg

\section{6}

Noble, Ron. Circular Economy, 2017.

7

Noble, Ron. Electronic Waste Processing Diagram. 2017

\section{8}

Bill 151: An Act to enact the Resource Recovery and Circular Economy Act. 2016. 41st Leg. Assembly of Ontario.

Source: https://www.ola.org/sites/default/files/node-files/bill/document/ pdf/2016/2016-06/bill---text-41-1-en-b151ra.pdf 
City of Toronto Archives. Lake Filling at the Leslie Street Spit. 1970. OALA.

Source: https://oala.ca/wp-content/uploads/2016/10/Ground35-LeslieSpit1.jpg

10

Ports Toronto. The Development of the Leslie Street Spit, Toronto. 1975. Tommy Thompson Park. Web.

Source: https://tommythompsonpark.ca/app/uploads/2017/10/06_1975.jpg

11

TRCA. Lake filling is complete. 2013. Tommy Thompson Park. Web

Source: https://tommythompsonpark.ca/app/uploads/2017/10/10_2013_DSC07323-

1140x758.jpg

\section{2}

Herschan, Otto. Engineer Joseph Bazalgette's Thames Embankment. 1862. Getty. Web. Source: https://www.elandcables.com/media/1460337/london_sewage_system_being_ built_in_1860.jpg

13

Noble, Ron. Municipal Transfer Stations vs. Low-Income Neighbourhoods. 2017.

Base image: Google Maps \& Data: City of Toronto

14

NBC News. The Barge: Tracking the Journey of Mobro 4000. 1987. Youtube.

Source: https://www.youtube.com/watch?v=Dz86tLVXa18\&t=3s

15

Wall Street Journal. The significance of Mobro 4000's journey. 1987. Web.

Source: http://www.jconoverjr.com/images/garbagebargemagazinestoryphoto1.JPG

16

Noble, Ron. Toronto’s Electronic Waste Network. 2017. Mapping.

Base image: Google Maps

Data source: https://www.recyclemyelectronics.ca/on/

17

Google Streetview. E-Waste Recycling Facilities. 2017. Web.

Source: https://www.google.ca/maps 
Noble, Ron. Analysis and design synthesis of the industrial big box. 2017. Diagram.

19

Noble, Ron. Costco Aisle \#7. 2018.

20

Noble, Ron. "MIAGA" - Make Industrial Architecture Great Again. 2017.

21

Noble, Ron. Obsolete Electronics. 2017. Photograph

22

Philips Company. A shop window disply. 1920. Philips Company Archives.

Source: https://spectrum.ieee.org/image/MjU1MzI2Mw.jpeg

23

Noble, Ron. The Apple iPhone is a symbol of electronic obsolescence. 2018. 


\section{Act 2 (pt.1):}

1

Noble, Ron. Analogy of the Industrial Big Box and Electronics. 2018.

2

Meyer, Hannes and Le Corbusier. Diagrammatic Plan of the Palace of League of Nations. 1925. Perspecta. The MIT Press. 1963.

Source: http://www.jstor.org/stable/1566901

3

Picasso, Pablo. The Clarinet Player. 1911. Museo Nacional Thyssen-Bornemisza. Madrid

Source: https://www.museothyssen.org/en/collection/artists/picasso-pablo/man-clarinet

4

László Moholy-Nagy. A II (Construction A II). 1924. Solomon R. Guggenheim Museum. New York

Source: https://www.guggenheim.org/artwork/2979

5

Meyer, Hannes and Le Corbusier. Diagrammatic Plan of the Palace of League of Nations. 1925. Perspecta. The MIT Press. 1963.

Source: http://www.jstor.org/stable/1566901

6

Venturi, Robert and Scott Brown, Denise. The Duck Building and the Decorated Shed. 1972. Learning from Las Vegas. The MIT Press. 2017.

7

Noble, Ron. The Iconographic Transparency Square. 2018.

8

Noble, Ron. Junkspace of Signs \& Symbols at Yonge-Dundas. 2018.

9

Noble,Ron. The Conditioning of Signs \& Symbols in the Everyday. 2018.

10

Noble, Ron. Detail shot of a Gigabyte Motherboard. 2017. 
The Empress of Asia, Voisin Sports Torpedo, Delage Front Wheel Brake. 1927. Towards a New Architecture. Dover Publications. 1986.

12

Noble, Ron. Architectural Scale Figure Standing Next to a Heat Sink. 2017.

13

Noble, Ron. The Disassembly of an assortment of electronics. 2017.

14

Noble, Ron. Proposal for an Electronic Waste Recycling Facility. 2017

Base Image: Google Maps

15

Noble, Ron. Disassembly of a Dell Laptop (c.2006). 2017.

16

Noble, Ron. Yonge-Dundas Electronic Billboards at night. 2016

17

Beato, Antonio. Temple of Isis on the Island of Philae, Egypt. 1875. Library of Congress.

Source: www.loc.gov/pictures/item/2003690008/

18

Cheng, Em. Billboard along Gardiner Expressway. 2015. Log. Anyone Corporation. 2016.

19

Venturi, Robert and Scott Brown, Denise. A Bill-Ding-Board for the National Football Hall of Fame Competition. 1967. Learning from Las Vegas. The MIT Press. 2017.

\section{0}

Noble, Ron. Electronic Billboard Screen Speculation. 2018.

21

Noble, Ron. Live-Streaming Digital Dumps as a radical proposal to make the effects of e-waste felt and experienced. 2018.

22

Noble, Ron. Design research: Exploring the electronic screen of our mobile devices as hybrid between ornamental surface, billboard sign, and building. 2018 . 
23

Noble, Ron. North Elevation. 2018.

24

Noble, Ron. Image Projection\#1. 2018.

25

Noble, Ron. Image Projection\#2. 2018.

26

Noble, Ron. Image Projection \#3. 2018 


\section{Act 2 (pt.2):}

1

Griffin, David and Kolhoff Hans. City of Composite Presence.1978. Collage City. The MIT Press.

\section{2}

Charles-Edouard Jeanneret. Still Life of the Pavilion of the New Spirit. 1924. Le Corbusier Foundation. Paris.

Source: http://www.fondationlecorbusier.fr CorbuCache/900x720_2049_2103.jpg?r=0

\section{3}

Rossi, Aldo. L'Architettura Assassinata. 1976. The Bonnefanten Museum. Netherlands.

Source: https://i.pinimg.com/736x/4f/54/7d/4f547d6232be35366845bea39292c709.jpg

\section{4}

Noble, Ron. Portraits of a possible E-Waste Recycling Facility. 2017.

\section{5}

Box Cover Art of Katamari Damacy.2004. Namco. Tokyo.

Source: https://encrypted-tbn0.gstatic.com/images?q=tbn:ANd9Gc'TaeyIl-

4qoFz27XPpruKtuHtDkEGv13Yofy3g_EABLuaikwxb9

\section{6}

Cross, Brian. Madlib and J Dilla digging for records in Brazil. 2005. Stones Throw Records.

Source: https://i.pinimg.com/originals/64/5d/3c/645d3cd3a651cafbbbdd629b8fe5f553.jpg

\section{7}

Noble, Ron. A collection of found objects waiting to be sampled for architectural purposes. 2018.

\section{8}

Duchamp, Marcel. Bicycle Wheel. 1951. Museum of Modern Art.

Source: https://www.moma.org/wp/moma_learning/wp-content/uploads/2012/08/

Duchamp.-Bicycle-Wheel-395x395.jpg

\section{9}

Tom Sachs. Tungsten Reclamation Center. 2012. Instagram.

Source: https://www.instagram.com/p/BUh0KbhgoTS/?hl=en\&taken-by=tomsachs 
10

Noble, Ron. Proposal for motherboard factory plan. 2017.

11

Noble, Ron. Salvaged Electronic Components from discarded electronics ready to be sampled and remixed for architectural purposes. 2017. 


\section{Act 3:}

1

Noble, Ron. Site Context (1km Radius). 2017.

Base Map: Google Maps

\section{2}

Noble, Ron. Aerial View of Site \& Context Looking East along Eglinton at Victoria park (c. 1969).

Base Image: https://www.blogto.com/upload/2013/11/2012410-golden-mile-20-years.jpg

\section{3}

Noble, Ron. Street View Perspective (Standing on the North-West Corner of Eglinton \& Pharmacy Ave.). 2018.

\section{4}

Noble, Ron. Street View Perspective (Standing on the West side of Pharmacy Ave.). 2018.

\section{5}

Golden Mile Shopping Centre. 1956

Source: https://i.pinimg.com/originals/1c/fd/29/1cfd29ff416a515df18f2f5790d5ec0b.jpg

\section{6}

Queen Elizabeth II visits The Golden Mile's Opening. 1954.

Source: https://dynamicmedia.zuza.com/zz/m/original_/f/5/f5458a0b-9c65-487a-a9668cf02dfa0dd6/3hSC_QueenGoldenMile0407_Super_Portrait.jpg

\section{7}

Loek, Dick. General Motors' van plant in Scarborough. 1981

Source: https://static.torontopubliclibrary.ca/da/images/MC/tspa_0010073f.jpg

\section{8}

Russell, Jim. Canadian General Electric Closes this factory. 1983.

Source: https://static.torontopubliclibrary.ca/da/images/MC/tspa_0110186f.jpg

9

Noble, Ron. Site Axonometric. 2018.

10

Noble, Ron. Billboard Building (Administrative offices/Storage/Repair/Disassembly): Plan \& Section. 2018. 
Noble, Ron. Billboard Building (Administrative offices/Storage/Repair/Disassembly):

Worms Eye Axonometric. 2018.

12

Noble, Ron. Drop-off/Collection/Sorting/Disassembly: Plan \& Section. 2018.

13

Noble, Ron. Drop-off/Collection/Sorting/Disassembly: Worms Eye Axonometric. 2018.

14

Noble, Ron. Marketplace for Renewed Electronics and Components: Plans \& Section. 2018.

15

Noble, Ron. Marketplace for Renewed Electronics and Components: Worms Eye Axonometric. 2018.

16

Noble, Ron. Research Centre for Electronic Obsolescence: Plan \& Section. 2018.

17

Noble, Ron. Research Centre for Electronic Obsolescence: Worms Eye Axonometric. 2018.

18

Noble, Ron. Makerspace: Plan \& Section. 2018.

19

Noble, Ron. Makerspace: Worms Eye Axonometric. 2018.

20

Noble, Ron. Site Elevation - North. 2018.

21

Noble, Ron. Site Elevation - West. 2018.

22

Noble, Ron. Research Centre. 2018.

23

Noble, Ron. Makerspace. 2018. 
Noble, Ron. Mechanical Disassembly. 2018.

25

Noble, Ron. Tipping Floor. 2018.

26

Noble, Ron. Front Perspective. 2018.

27

Noble, Ron. Streetview Looking East Along Eglinton Ave. 2018

28

Noble, Ron. North Elevation Oblique Projection. 2018

29

Noble, Ron. Site Worms Eye Axonometric. 2018.

30

Noble, Ron. Site Perspective. 2018 

To my Grandmother Simplicia 

l. W.

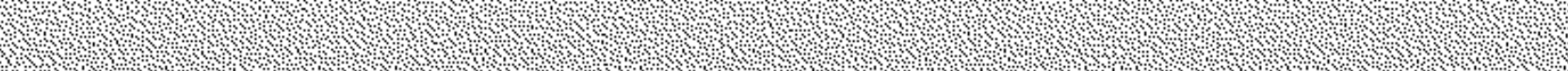

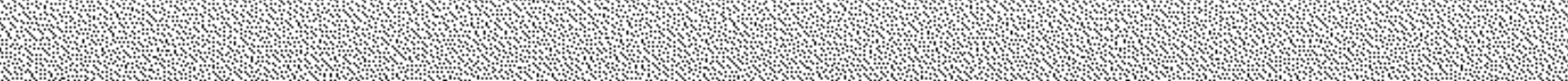


There has been an exponential rise in the volume of electronic waste in recent years due to the speed of technological innovation, consumers' insatiable desire for new things and the designed obsolescence of electronic devices. The spectacle behind the consumption of electronics masks the dark realities of extraction, production and disposal, manifesting a capitalist driven phenomenon leading to an immense accumulation of excess and waste. The subsequent effects elicit a condition of invisibility that shrouds the management of electronic waste and thus its resistance to collective contestation. The globalization of electronic waste is an important discourse relevant to the environment, the economy, and society, with implications for the contemporary architectural imaginary, yet it is one of the least examined problems of the 21 st century.

In the age of information, we often privilege our access to information over the physical object that facilitates our access. What is the worth of a computer without the Internet? Everything we do is becoming increasing dependent on access to a Wi-Fi connection. With the arrival of digital data storage and streaming platforms such as Google Drive, Dropbox, iCloud, Netflix, and Spotify, there really is no need to store any information on our electronic devices as we now have the ability to access our files from anywhere, on any device. This has lead 
to the dematerialization of our electronic devices making them objects of consumption, easily replaceable, and consequently ever more disposable.

Architecture has largely been absent from the territory of waste management as a result of specialized authorship and a compromise in its ability to radically reinvent the threshold between waste infrastructure and the public. The role of architecture concerning matters of waste has mostly been delegated to maintaining the relative invisibility of waste management facilities. However the architect as service provider should not deter our ability to be critical of the systems of waste making and managing.

A new attitude towards waste has been recently emerging in the research and design of its spaces and systems in an attempt to make the invisible visible. Projects such as Lateral Office's States of Disassembly, BIG's Amager Bakke Waste to Energy Plant, and Abalos \& Herreros' Recycling Facility, all bring waste to the attention of an architectural audience. The common thread between these projects is in raising an awareness of the consequences of waste by creating a greater visibility through public engagement. These projects demonstrate that even the most mundane quotidian aspects of life are worthy of 
consideration with equally challenging complexities that address many ethical dilemmas facing our world today.

The aim of this design research is to bring the consequences of electronic waste into greater visibility, making legible that which society fails to recognize. Key questions this thesis will attempt to address are: Can architecture mediate the engagement between waste and urbanity in order to redefine our relationship with electronic waste? Are there opportunities for electronic waste and its infrastructure to have a public value and legibility in the city? How can the consequences of electronic waste be made visible and transparent in the built environment? And can electronic waste be creatively imagined in new and unconventional ways that are not simply pragmatic?

Given the ubiquity of electronic technologies in our daily lives, the trends of population growth and rapid urbanization set to take place in the next fifty years, if waste is central in the process of capitalist urbanization can architecture improve the condition of configuring industrial form to create ecology between e-waste, culture, and the city?

The critical design project will challenge existing models of electronic waste management by focusing on creating a 
transparent architecture that opposes the linear capitalistic expansion of 'take, make, and dispose' in order to enable an alternative circular economy of zero waste and resource recovery. The site of speculation is located in the Golden Mile of Toronto with the aim of creating synergies between waste, culture, and the environment through the design of a Centre for Electronic Waste and Resource Recovery (CEWRR).

This thesis is composed into Three Acts, where each act works together to generate dialectical insight regarding electronic waste and the production of space. Act One presents facts and findings that acknowledges the existence of electronic waste and critically examines the consequences that it initiates in the spatial development of a city. Act Two builds upon this body of knowledge by analyzing the complexities and contradictions of electronic waste with the intention of not necessarily finding a definitive solution but rather to allow for a more explorative design research that speculates on a wide range of possible responses that engage the discipline and practice of architecture. Act Three will then proceed with executing a plan of action with a conviction that presents a strong polemical to electronic waste through the manifestation of a Centre for Electronic Waste and Resource Recovery. The aim is to explore the architectural potentials associated with the management of electronic waste and the implications this will have on the production of space. 
(r)

-

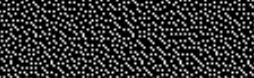

W

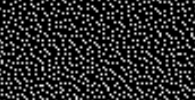

Whom

\%)

군.

1.

7.

ing

int

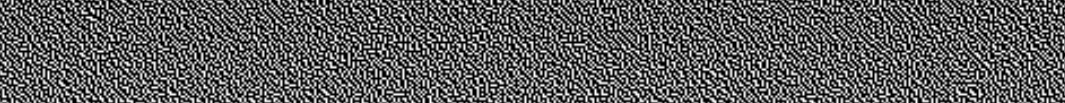

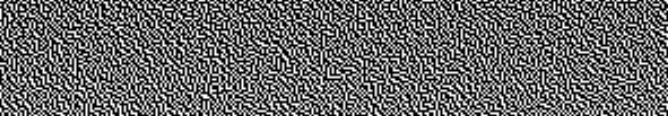

1.

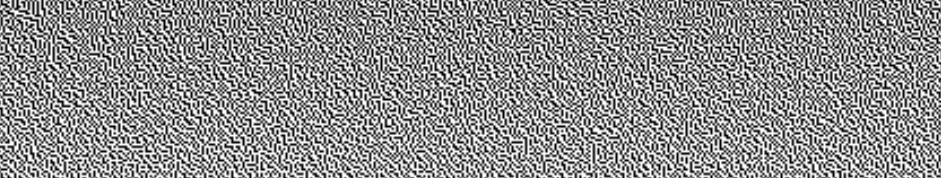

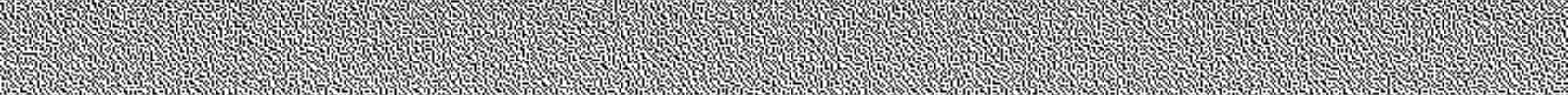

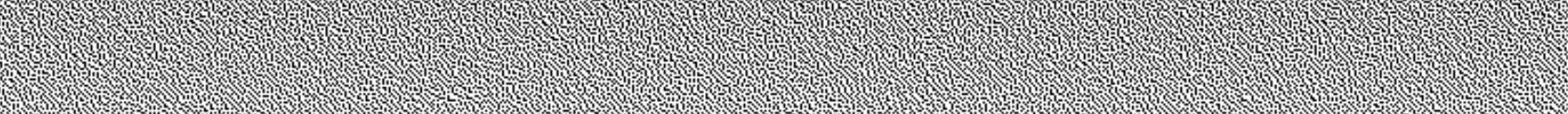

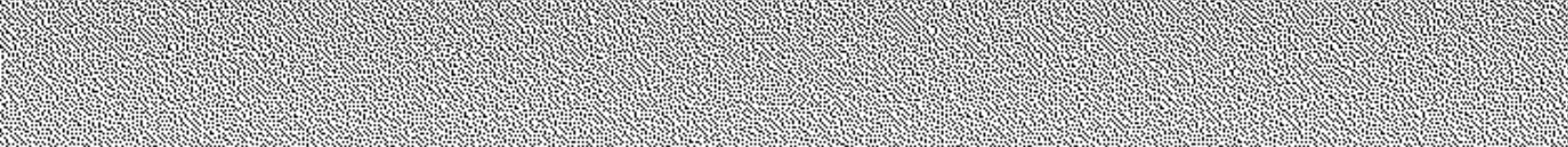

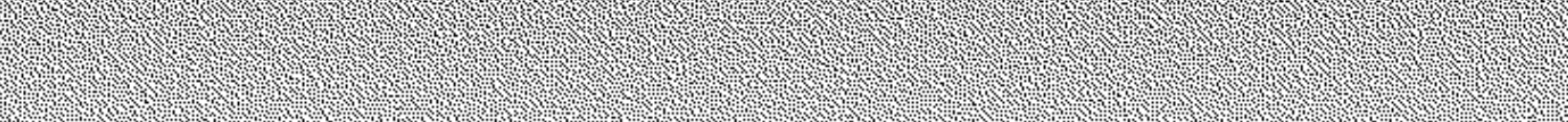
W (1. W l. l.

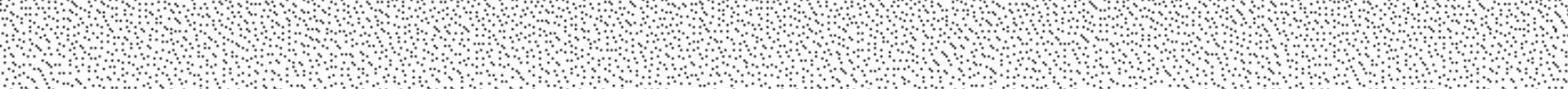




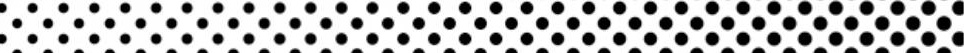
$\frac{0.0}{0}$

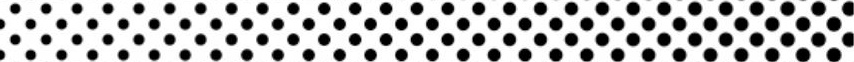

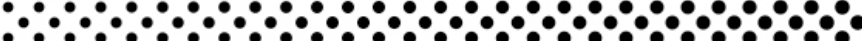

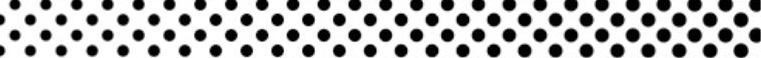
(1)

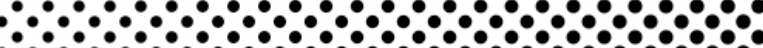
$\because \because \because \because \bullet \bullet \bullet \bullet \bullet \bullet \bullet \bullet \bullet \bullet \bullet \bullet \bullet \bullet \bullet \bullet \bullet \bullet \bullet \bullet \bullet \bullet \bullet \bullet \bullet \bullet \bullet$ $\because \because \bullet \bullet \bullet \bullet \bullet \bullet \bullet \bullet \bullet \bullet \bullet \bullet \bullet \bullet \bullet \bullet \bullet \bullet \bullet \bullet \bullet \bullet \bullet \bullet \bullet \bullet \bullet \bullet \bullet \bullet \bullet \bullet$ $\because \because \bullet \bullet \bullet \bullet \bullet \bullet \bullet \bullet \bullet \bullet \bullet \div \bullet \bullet \bullet \bullet \bullet \bullet \bullet \bullet \bullet \bullet \bullet \bullet \bullet \bullet$

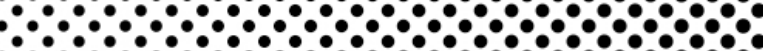
$\because \because \bullet \bullet \bullet \bullet \bullet \bullet \bullet \bullet \bullet \bullet \bullet \bullet \bullet \bullet \bullet \bullet \bullet \bullet \bullet \bullet \bullet \bullet \bullet \bullet \bullet \bullet \bullet$

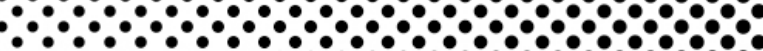

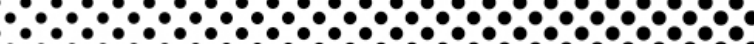

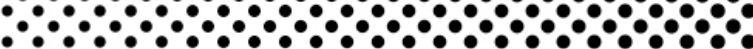

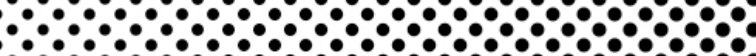

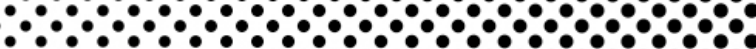

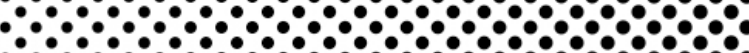

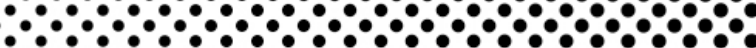

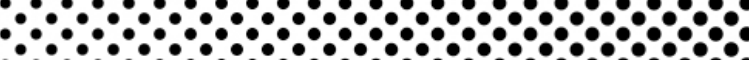

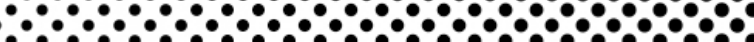
$0^{0}$ 10

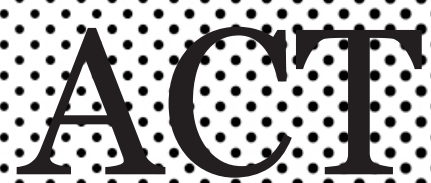

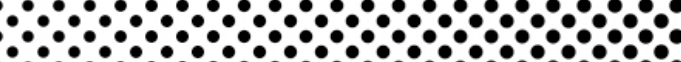

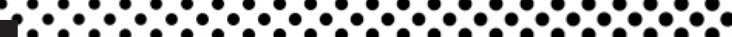
$\bullet$ $\because$

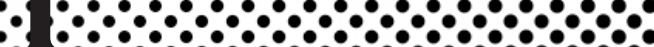

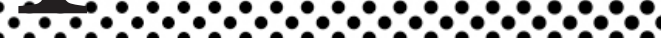
$\because \because \frac{0}{10}$ $\because \because 90$

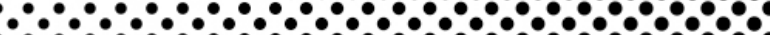
$\because \because \bullet \bullet \bullet \bullet \bullet \bullet \bullet \bullet \bullet \bullet \bullet \bullet \bullet \bullet \bullet \bullet \bullet \bullet \bullet \bullet \bullet \bullet \bullet \bullet \bullet \bullet \bullet \bullet \bullet \bullet \bullet \bullet \bullet$ $\because \because \div \div$ $\bullet \because \bullet \bullet \bullet \bullet \bullet \bullet \bullet \bullet \bullet \bullet \bullet \bullet \bullet \bullet \bullet \bullet \bullet \bullet \bullet \bullet \bullet \bullet \bullet \bullet \bullet \bullet \bullet \bullet \bullet \bullet \bullet \bullet \bullet \bullet \bullet \bullet \bullet$

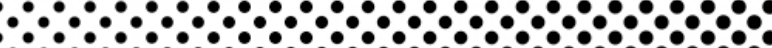
0

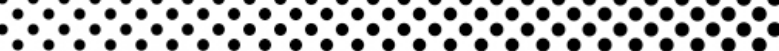

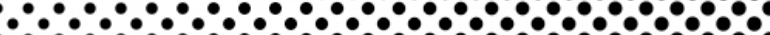

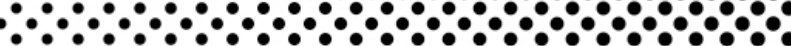

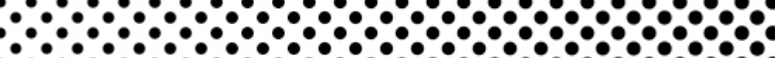

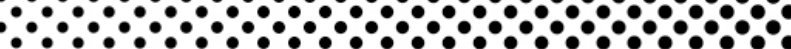
$\because \div \div \div$ $\because \because \div \div$ $\because$ $\because$

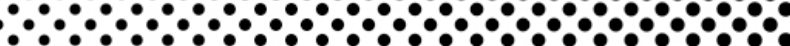
$\frac{0}{0}$

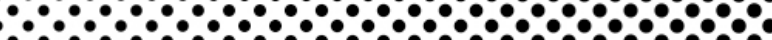

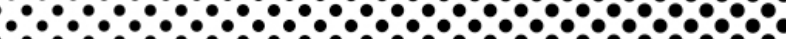

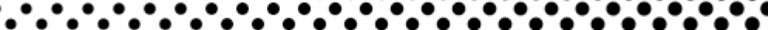

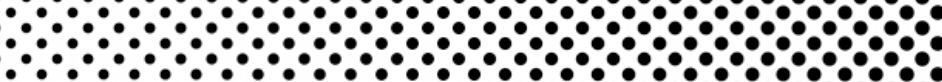

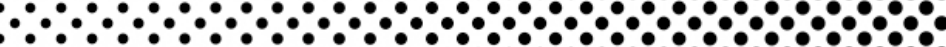
$\because \bullet \bullet \bullet \bullet \bullet \bullet \bullet \bullet \bullet \bullet \bullet \bullet \bullet \bullet \bullet \bullet \bullet \bullet \bullet \bullet \bullet \bullet \bullet \bullet \bullet \bullet \bullet \bullet \bullet \bullet$ $\therefore \circ 0_{0} 0_{0}$ 



\section{Electronic Waste}

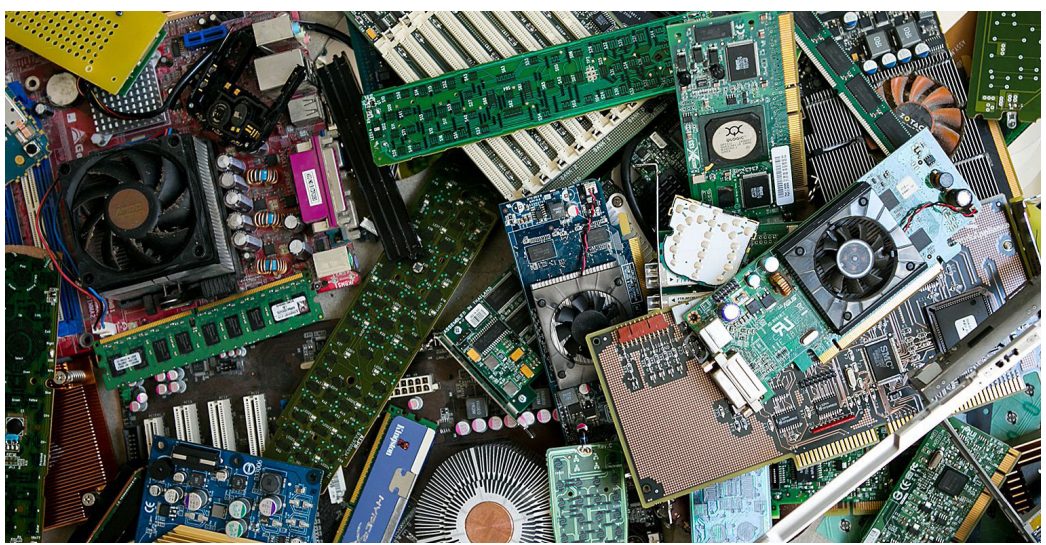

1 A Pile of E-Waste, New York, 2016, The Verge, Photograph by Amelia Krales.

There has been an exponential rise in the volume of electronic waste in recent years due to the speed of technological innovation, consumers' insatiable desire for new things and the designed obsolescence of electronic devices. As a consequence, electronic waste is a global ecological

Puckett, Jim.

Exporting Harm The High-Tech Trashing of Asia. Basel Action Network, 2002, pp.1, http://archive.ban. org/E-waste/ technotrash finalcomp.pdf. Accessed 4 Oct 2017

2

Muller, Simone

M. "Here it is

toxic, there it is

not." Youtube,

Uploaded by the

Canadian Centre

for Architecture, 22

Mar 2017, http://

www.youtube.

$\mathrm{com} /$ watch? $\mathrm{v}=$

NhWthyiHuJ phenomenon that accounts for the largest and fastest growing waste stream, with a network spanning the entirety of the planet. ${ }^{1}$ The globalization of electronic waste is an important discourse relevant to the environment, the economy, and society, with implications for the contemporary architectural imaginary, yet it is one of the least examined problems of the twenty-first century.

When our electronics become obsolete and dysfunctional we often dispose of them, expecting that they would be recycled properly. But there seems to be a common uncertainty among many people as to where our electronics go after we dispose of them. The global waste economy emerged in the later half of the 1970's and accelerated in the 80's and 90's, as a result of the pressures felt from the environmental movements that formed in the industrialized countries. ${ }^{2}$ The growing volume of waste was an outcome of an accelerated production and consumption cycle of the post-war era. It was at this moment, that people started becoming aware of the consequences 
of our waste making, and thus demanded that something be done about it. The solution by many governments resulted in the transboundary shipment of hazardous waste from rich developed countries to poor developing countries. The primary motive behind this action was governed by the notion of out of sight, out of mind. We cannot contest that which we cannot see. Fast forward to the present day, and the waste we tried to hide by casting them off to other parts of the planet are coming back to haunt us. This time we cannot ignore it. Today, the transboundary movement of hazardous waste material has switched labels from 'disposal' to 'recycling', operating no differently just under another name. The prime motivator that keeps the global waste economy running is a lack of a clear and enforceable definition for what constitutes as hazardous waste.

What differentiates electronic waste from the more traditional waste streams is its toxicity and heavy reliance on the extraction of rare earth metals from the ground. The key actors of the global e-waste economy are the very metals and minerals contained within our electronics. Extracted from the earth, these resources are converted through chemical and industrial processes to make the plastic cases of our phones, the glass screens of our

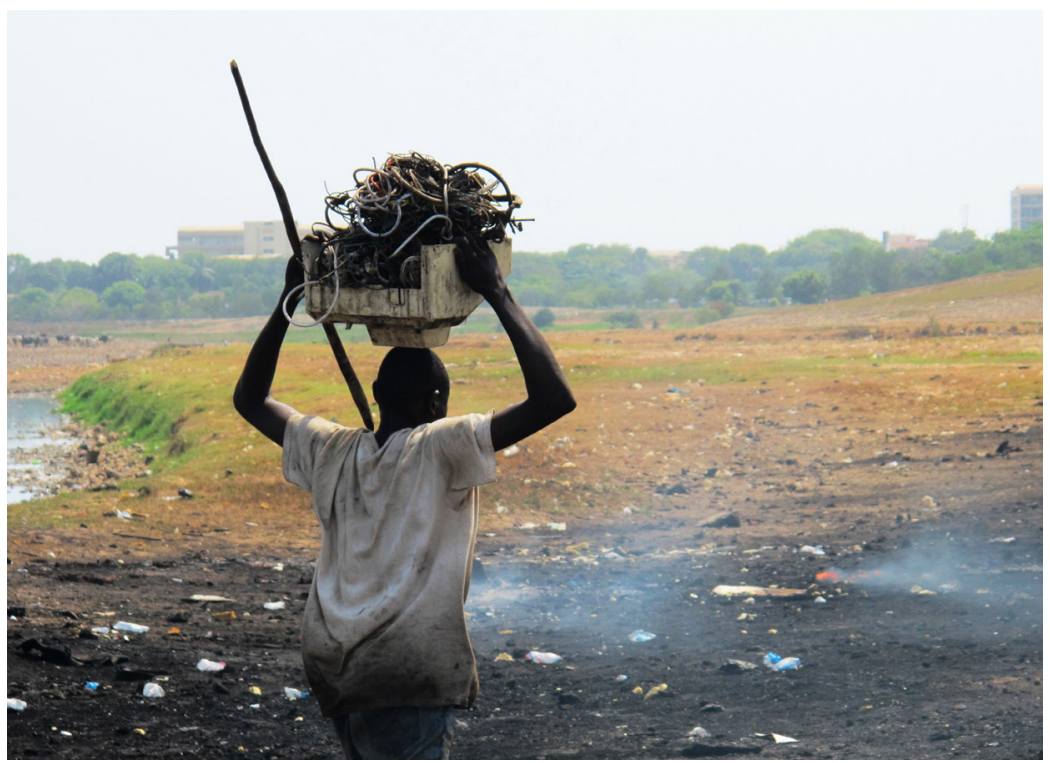

2 Accra, Ghana, 2009, Flickr. Image courtesy of Basel Action Network 
3

Magalini, Fredrico. Interview by Angela Chen. "Why Failing to recycle electronics leaves gold mines untapped." The Verge, www.theverge. com/ 2018/4/23/ 17270960 /electronicwaste urban-miningmaterials-recycling. Accessed 15 May 2018.

4

"Mason White E-Waste." YouTube, Uploaded by urbanNext, 29 Jan 2018, www.youtube $\mathrm{com} /$ watch? $\mathrm{v}=$ LcO5zKqUhtQ\&t $=35 \mathrm{~s}$. tablets, and the motherboards of our computers that contain an assortment of various metals. This results in the exploitation of land, resources, labour, and people, creating landscapes of exclusion located out of sight from spaces of consumption. The inadequate treatment and disposal of electronic waste greatly affects the environment and the people managing it. Despite, it's toxicity and being characterized as something that is no longer useful, electronics contain extremely valuable materials that should be reclaimed and recycled. One ton of discarded cellphones contains approximately $350 \mathrm{~g}$ of gold, which is eighty times the concentration of an equivalent amount of ore mined from the earth. ${ }^{3}$ Therefore, a re-imagining of the current system of electronic waste management and recovery will need to occur in order for cities to function in new ways demanded by our contemporary world.

Historically, cities have consistently produced a significant amount of waste, from urban development projects to the production and consumption of our material culture. The way we manage our electronic waste will become crucial to a city's ability to sustain itself. Given the ubiquity of electronic technologies in our daily lives, the trends of population growth and rapid urbanization set to take place in the next 50 years, the future of waste is electronics. ${ }^{4}$ 


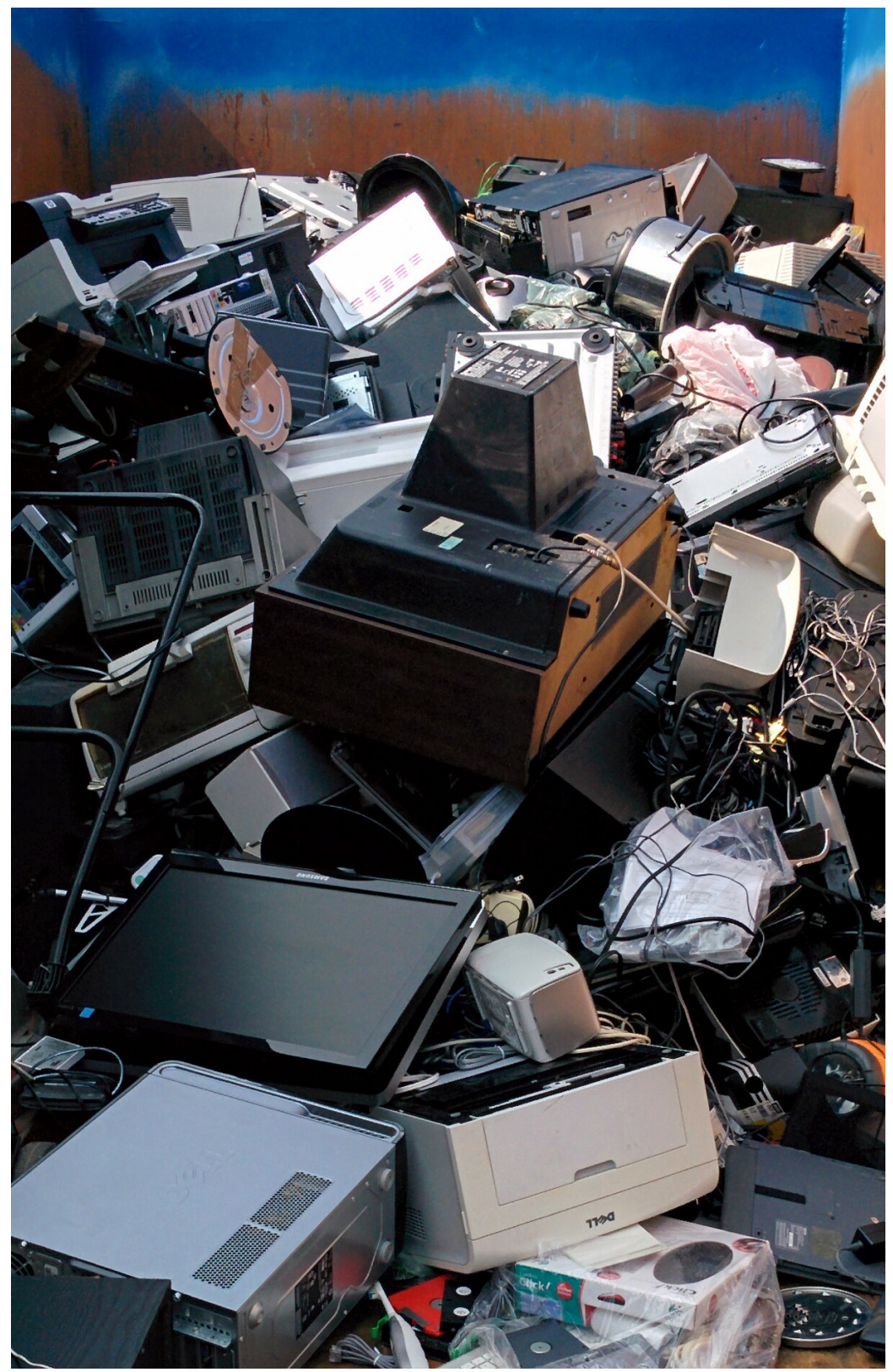

3 Ward 30 Community Environment Day Electronic Waste Collection Bin, Toronto, 2017. 


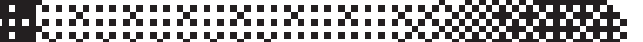

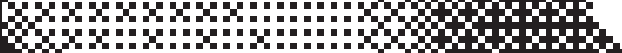

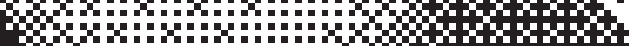

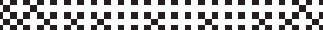
y.

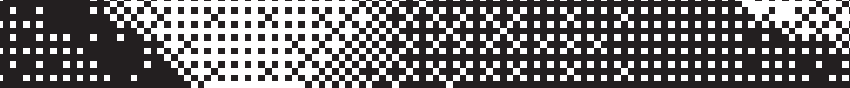

ing.

A.

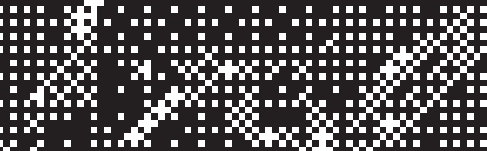

A+2:H:

AqA

APAt+2

A

A.

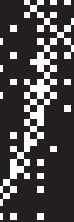

4

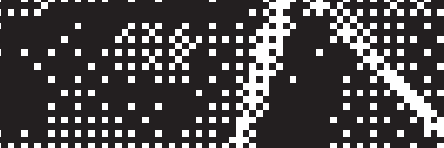

H.1.4.

$+4$

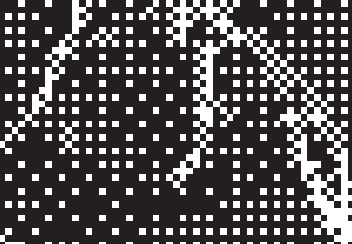

(1)

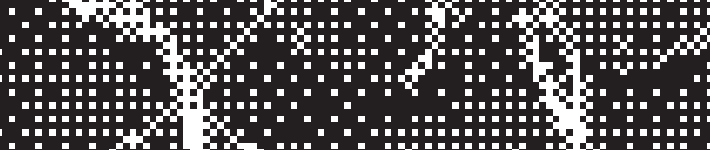

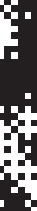

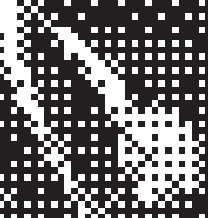

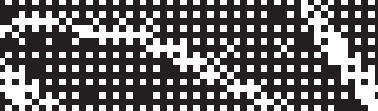

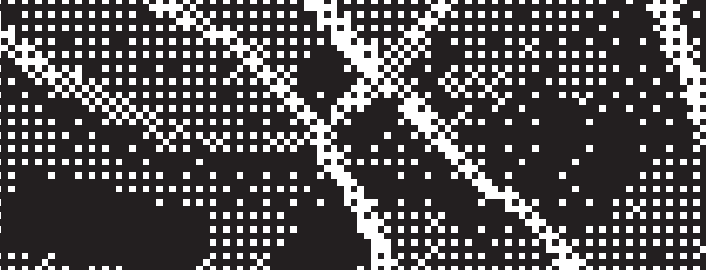
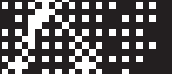

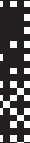

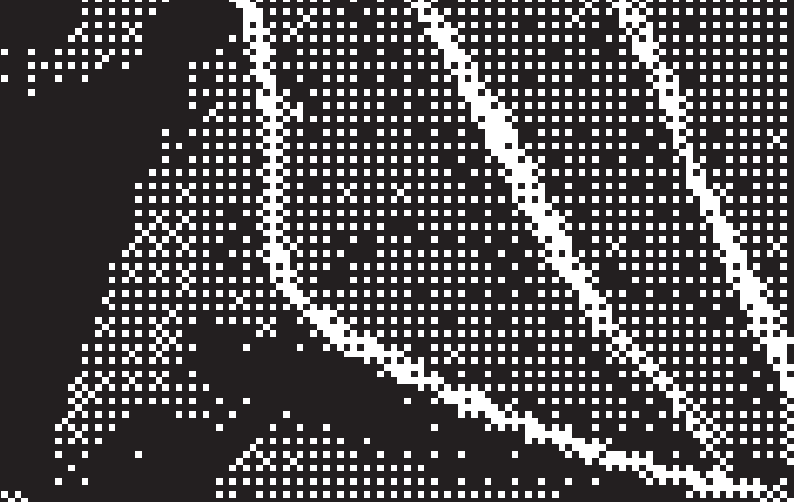




\section{Electronic Waste as Resource}

The electronic waste produced today, will be a vital stream of resources for tomorrow. The trajectory of capitalisms 'take, make, and dispose' ignores the

5

Kara, Hanif, et al

"The Missing Link:

Architecture and

Waste Management."

Harvard Design

Magazine, No. 40, 2015, pp.18-22 ecological limits of the natural environment in order to maintain the highly dysfunctional linear flows of an urban environment. In order to disrupt the linear logic of capitalistic consumption, cities must recognize electronic waste as a resource. ${ }^{5}$

The traditional hierarchy of waste management is the conventional system of Reduce, Reuse, and Recycle, with prevention and minimization being the most favoured over disposal in landfills. The difference in the three levels of this hierarchy is in the amount of energy required to recycle its materials relative to its embodied energy. Reduce and Reuse requires the least amount of energy in order to repurpose or reconfigure. Whereas the act of recycling often requires more energy than is embodied to disassemble and recover resources. This is an obstacle that is faced by many recyclers of e-waste, as the process is often complex, costly, and energy intensive. Because of this condition it is still cheaper to dispose and make new.

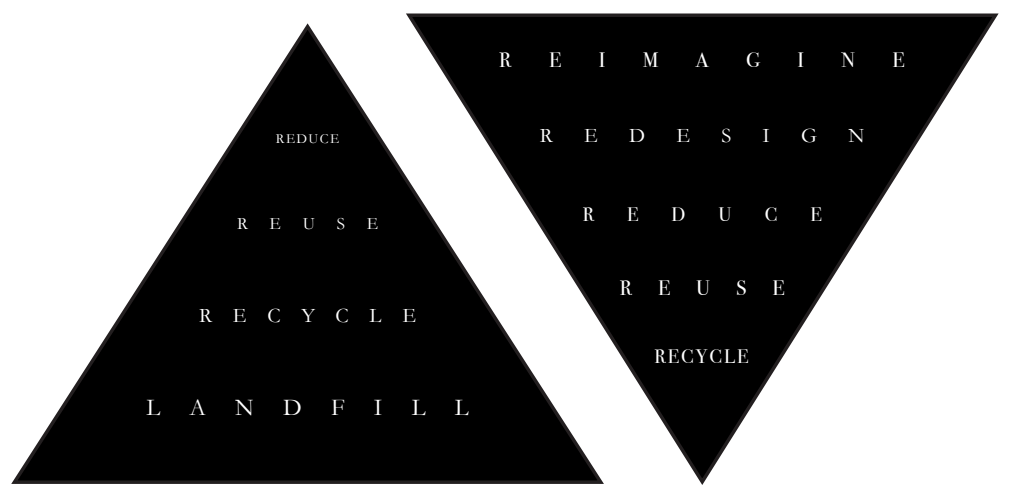




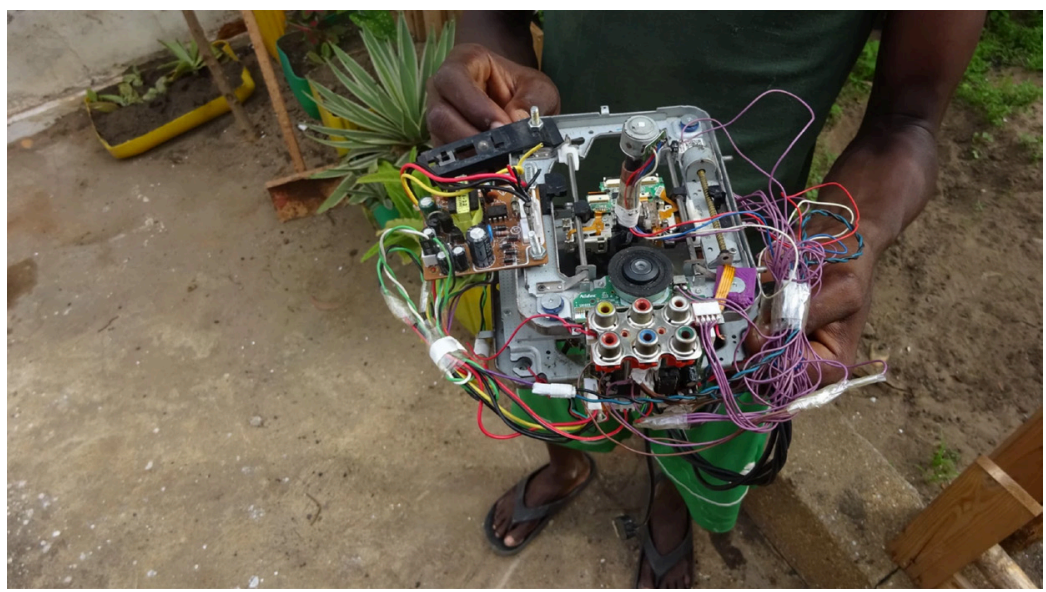

5 Nadjagou shows off his 3D printer design, Togo, 2016, Motherboard. Photograph by Chris Matthews.

In reaction to the flawed nature of the traditional hierarchy of waste, this pyramidal organization can be rearranged to include re-imagination and redesign as the first steps to diverting waste. Reuse, Repair, and refurbishment should be encouraged as the first steps prior to the recycling of materials. The re-imagining of discarded electronic waste through creativity and innovation will be fundamental in reducing the e-waste and shifting the perspective of the detritus of electronics into a potential source of value. Implicit to the notions of recycling are ideas of reconfiguring. Therefore, a new technological cycle of renewal can be facilitated through the implementation of a Makerspace in combination with an e-waste recycling center, where things can be un-made and re-made. This is already happening in places like Togo in west Africa, where people are transforming discarded electronic waste to make a $3 \mathrm{D}$ printer. ${ }^{6}$ This type of innovation facilitated by a Makerspace is the type of innovation that should be encouraged by providing a space where people can learn, share, and create new innovations for the 21 st century.

Through the process of reclaiming precious materials contained within electronic waste, urban mining becomes a form of resistance to the economics of consumption by turning electronic waste into value. ${ }^{7}$ Not only is it better for the environment, but also more efficient than traditional

6

Matthews, Chris. "This Innovative West African Lab Is Turning E-Waste into 3D Printers and Robots." Motherboard, 2 May 2014, https:// motherboard.vice. com/en_us/article/ mg7bwa/upcyclinge-waste-into-3dprinters-and-robotsat-togos-woelab.

$$
7
$$

Cossu, Raffaello and Williams, Ian "Urban Mining: Concepts, Terminology, Challenges." Waste Management, Vol.45, 2015, pp. 1-3, www. urbanmining.it/ public/documents/ simposio/ editorial-wastemanagement-2015. pdf. Accessed 25 Oct 2017 
mining, with concentrations of elements comparable to or even exceeding that of natural minerals from the ground. ${ }^{8}$ As the world's demand and reliance on the extraction of raw resources continues to grow, it is imperative that it is offset by greater efforts to recycle electronics. With proper reclamation and recycling processes in place, electronic waste can account for a large proportion of valuable resources, which can then be reintroduced back into the production stream. The encouragement of an environmentally responsible management of electronic waste will inspire a greater emphasis on a circular economy with zero waste.

Economics, capital and architecture have historically been intertwined when it comes to the production of space. At present, most urban environments have dysfunctional feedback loops that are often ignored and overridden to maintain unsustainable levels of consumption. Having recognized the ecological limits that disable the expansion and growth of capitalist development, a viable alternative could be achieved through the framework of a circular economy. This alternative economic model is more restorative and regenerative and encourages recycling through reuse, repair or resale. The circular economy has become a popular idea over the past few years as we are beginning to realize the finite supply of some of our most precious and primary raw materials. By emulating the cyclical nature of living systems, where one species waste is another's nutrients, we can build an alternative economy that privileges waste as a resource (6). This model is more restorative and re-imagines the way we perceive and treat our waste through recovery and reuse. 9 The circular economy represents a shift in thinking that fosters resilience, stimulates economic opportunities, and generates environmental and societal benefits. The waste created by electronics needs a new set of solutions apart from existing waste streams in order to transform electronic waste into value. 


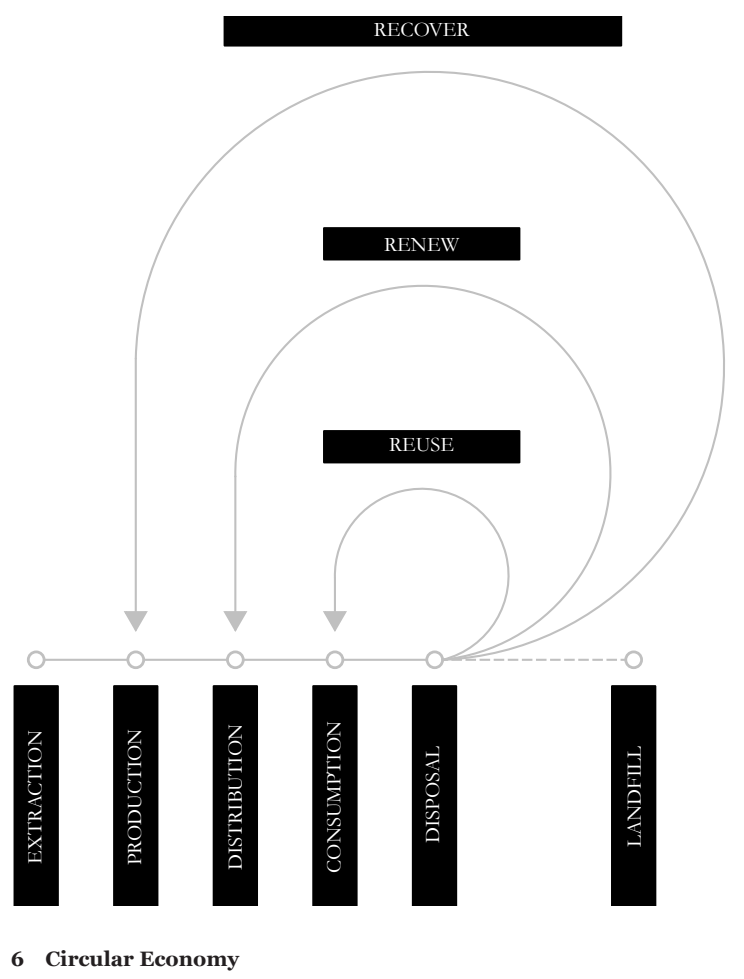


(r)

-

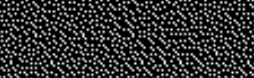

W

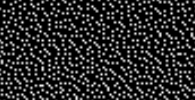

Whom

\%)

군.

1.

7.

ing

int

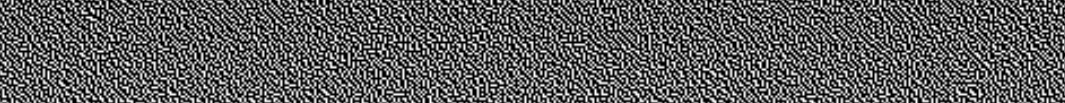

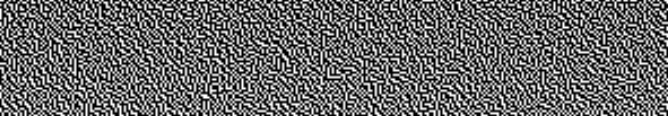

1.

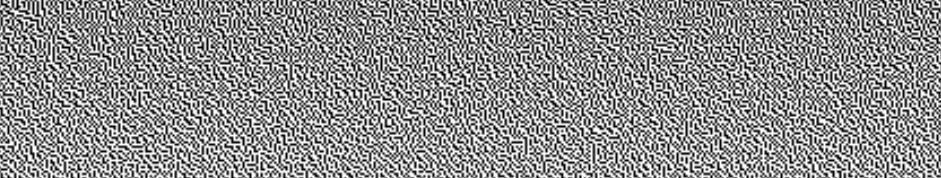

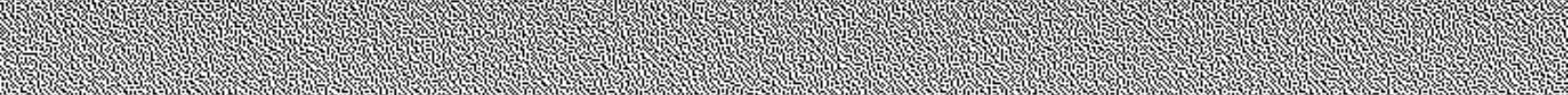

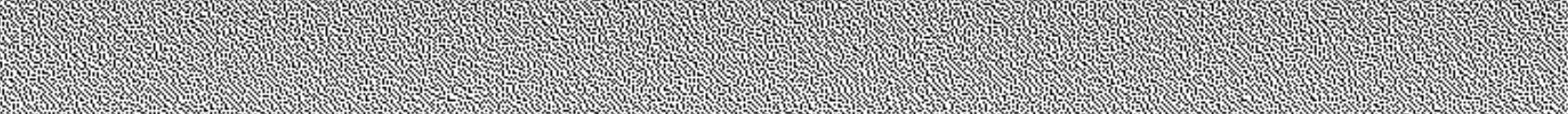

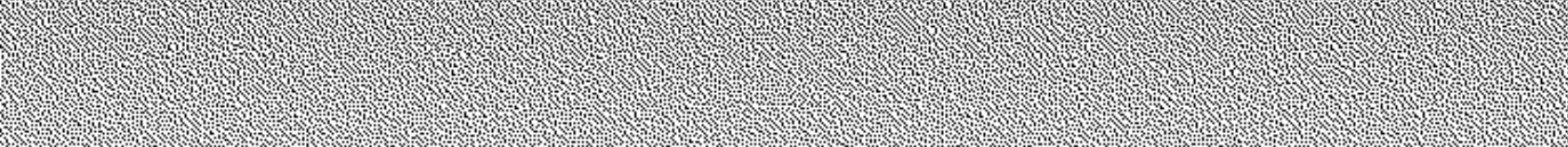

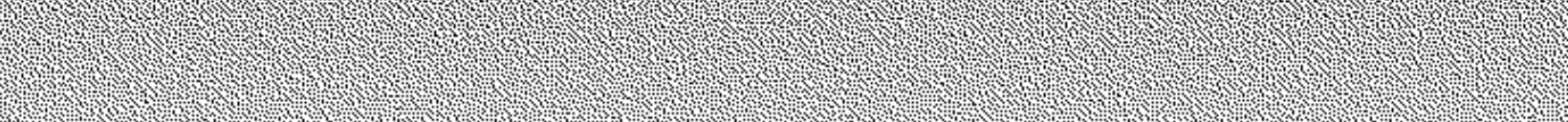
W (1. W l. l.

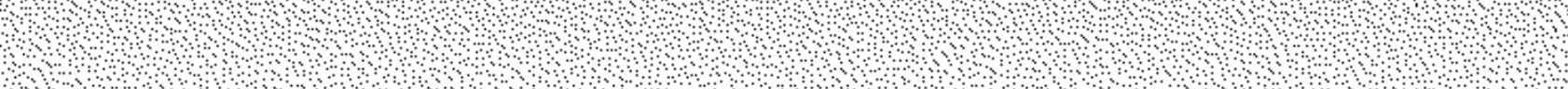




\section{Managing Electronic Waste}

The recognition of e-waste as a valuable resource in addition to the increasing market value of materials is beginning to challenge the traditional methodologies in which electronic waste is managed. However, prior to this acknowledgement, electronics were disposed of in landfills, along with the rest of municipal solid waste. Having realized the serious environmental threats to groundwater or air quality that landfill disposal presents, efforts have shifted to the recovery and reuse of electronics. The management of electronic waste is a trend unlikely to end given the ubiquity of electronics in our daily lives and the amount produced and consumed each year.

Those that know the true value of electronic waste recognize that it can be very lucrative. As a result it is often tainted by exploitation. The relaxed

10

Lepawsky, Josh. "The changing geography of global trade in electronic discards: time to rethink the e-waste problem." The Geographical Journal, vol. 181, no. 2, 2014, pp. 147-159. Wiley Online Library, doi.org/10.1111 geoj.12077. Accessed 9 Sept 2017.
11

Basel Action

Network. E-trash

Transparency

Project, 2015, www.

ban.org/trash-

transparency/.

Accessed 4 Oct 2017

12

Basel Action

Network. E-trash

Transparency

Project, 2015, www.

ban.org/trash-

transparency/.

Accessed 4 Oct 2017 enforcement of vague policies governing the global trade and management of electronic waste often leads to the illegal transboundary shipment of toxic and dysfunctional electronic discards to poor developing countries. ${ }^{10}$ This is extremely problematic given that such places often lack the resources to responsibly recycle e-waste. Informal recycling methods are generally utilized for the management and disposal of e-waste, as it is the most cost effective solution. Since economics play a big role in dictating how e-waste is managed, it intrinsically results in the exploitation of labour and the environment in the pursuit of profit.

Organizations such as the Basel Action Network (BAN) have been working diligently to expose the toxic trade of hazardous waste through their E-Trash Transparency Project. ${ }^{11}$ This initiative has raised much concern for the geo-politics and social justice of developing countries burdened by the illegal dumping and irresponsible management of toxic e-waste. Informal e-waste management practices such as open burning pits or acid baths are common methods used to extract valuable materials from discarded electronics in developing countries. ${ }^{12}$ These methods of handling e-waste 
are extremely harmful to the health of the people and their environment.

Electronic waste should not be allowed to move across borders in order to exploit loosely enforced policies for economic gain, but rather the toxicity of electronic waste should be managed where it is produced and consumed. The process of e-waste management begins with collection. This is done either formally through authorized collection centers located across the city, typically organized through local municipal services or informally across the socio-economic spectrum of scavengers, drivers, dealers, and factory owners. The recycling and processing of electronic waste collected by the city is typically contracted out to private waste management companies governed by regulated recycling programs, ensuring the safe, secure and environmentally responsible recycling of electronics. While the more informal recycling organizations operate in a decentralized self-governed

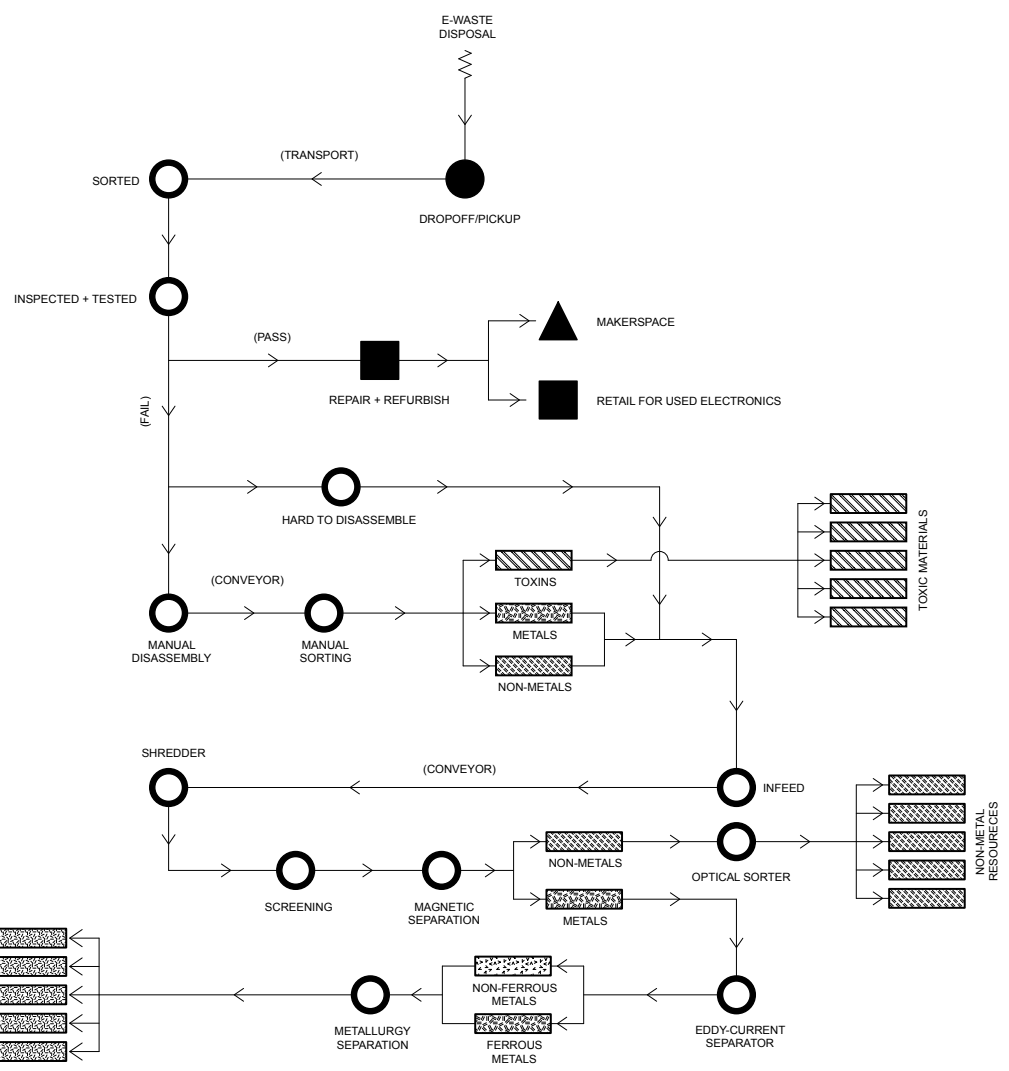


manner. From the collection points, the electronics are then transported to a sorting facility where it is sorted based on type, material, and condition.

If it can be repaired or reused, it will be renewed and resold on a secondary market at an affordable price. After the e-waste has been sorted and inspected it is disassembled, separating the various elements, extracting the valuable materials contained within electronics. Depending on the difficulty of disassembly and separation, this is accomplished mechanically through automation or manually by hand through the labour of individuals. Once the materials have been successfully reclaimed from the electronics they are then reintroduced back into the production stream. (7)

Given the current and future imperative to recycle electronics, the management of waste produced by the consumption and disposal of electronics will be critical in our ability to sustain the economic and societal demands placed on the environment. In spite of all this speculation, there are still major challenges facing the management of electronic waste. These challenges include better collection methods that separate electronics from other waste streams, more financial incentives to limit irresponsible recycling, and technological improvements that increase a greater yield of extracted materials, all of which are matters that do not directly concern the practice and discipline of architecture. However with increasing global pressures and

13 Bill 151: An Act to enact the Resource Recovery and Circular Economy Act, 1 st Sess, 41 st Leg, Ontario, 2016.

See: https://www. ola.org/sites/ default/files/nodefiles/bill/document/ pdf/2016/2016-06/ bill---text-41-1-enb151ra.pdf the implementation of policies such as the Waste-Free Ontario Act, ${ }^{13}$ which enforce ideas of waste diversion, resource recovery, and a circular economy, the need for an infrastructure to facilitate the collection and responsible management of a continually growing volume of electronic waste becomes absolutely necessary. (8) It is within this territory that I see opportunities for architecture to provide electronic waste and its accompanying infrastructure with a greater public value and legibility in the city. 


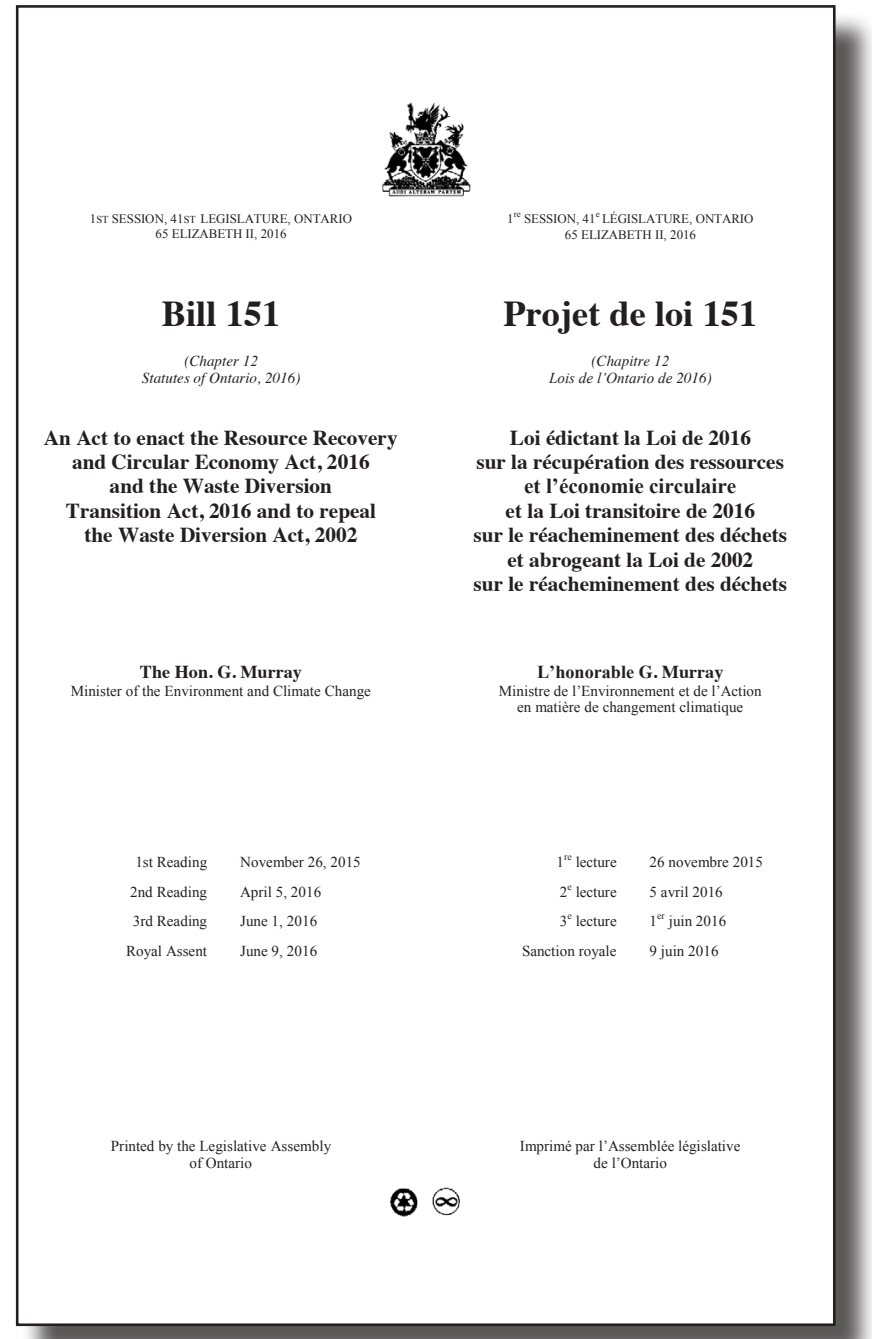

8 Bill 151: An Act to enact the Resource Recovery and Circular Economy Act, Ontario, 2016. Courtesy of the 41st Legislative Assembly of Ontario. 


\section{Waste Producing Space}

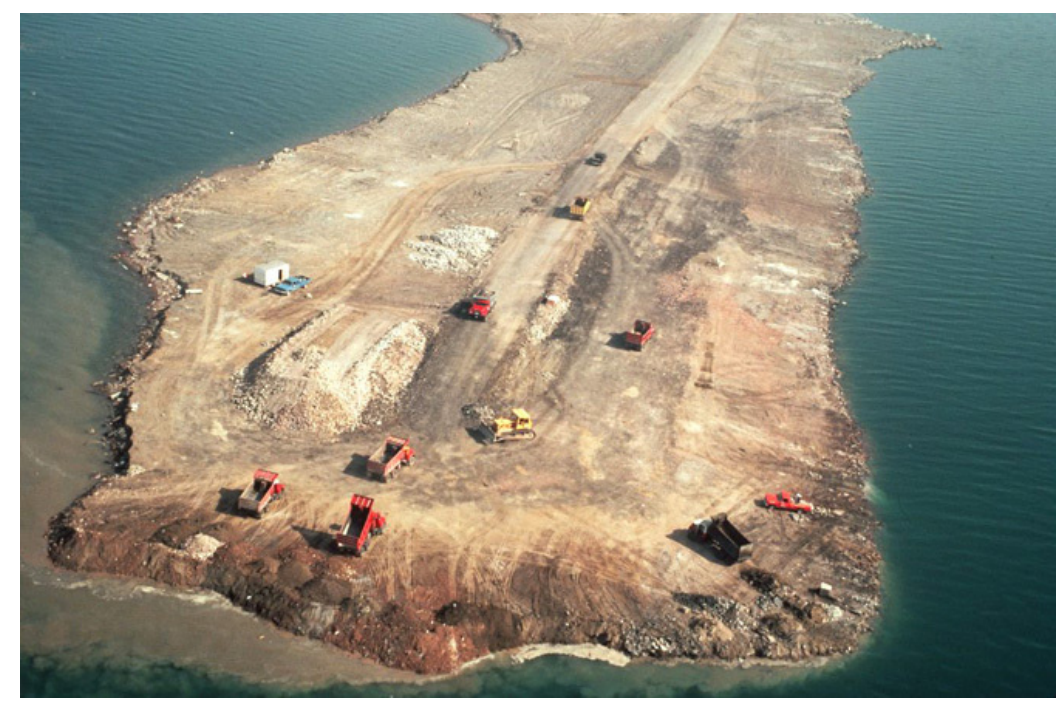

9 Lake Filling at the Leslie Street Spit, Toronto, 1970, City of Toronto Archives, Fonds 20o, Series 1465, File 148. Photograph courtesy of City of Toronto Archives.

Cities have always been substantial consumers of resources and as a consequence, extensive producers of waste. Implicit to this matter of concern is the role that waste plays in the production of space, from capitalist urban development to mass consumerism. Waste is very much a material condition, but also deals largely with issues of movement and containment, which elicits a spatial dimension. By thinking of waste in these terms, it begins to raise questions about the spatiality and location of e-waste. Central to the ways in which we organize our relationship to waste, both socially and spatially, is a public and private responsibility that is fundamental to the discipline of architecture. Therefore it becomes

Schopf, Heidy. "The Leslie Street Spit: Urban wilderness and cultural heritage landscape" Ontario Association of

Landscape Architects, 2009, oala.ca/ ground_issue/ ground-35-edges/ leslie-street-spiturban-wildernesscultural-heritagelandscapes/. Accessed 5 November 2017. important for architecture and design to acknowledge the role waste plays in the production of space.

The Leslie Street Spit in Toronto, known today as Tommy Thompson Park, is a man-made $5 \mathrm{~km}$ land form created entirely from excavated soil and construction waste from the development of Toronto's subways, office towers and other large urban renewal projects of the 1950's. ${ }^{14}$ It was 
originally conceived as a breakwater for the expansion of Toronto's outer harbour with the anticipation of increased shipping traffic on the Great Lakes. ${ }^{15} \mathrm{~A}$ literal wasteland resulting from the movement and disposal of waste has since been transformed by nature, becoming a truly unique and significant urban wilderness home to a variety of wildlife and native plants. The Leslie Street Spit is an example of an anthropogenic landscape that demonstrates a direct relationship between the making of waste and the making of space. $(9,10,11)$

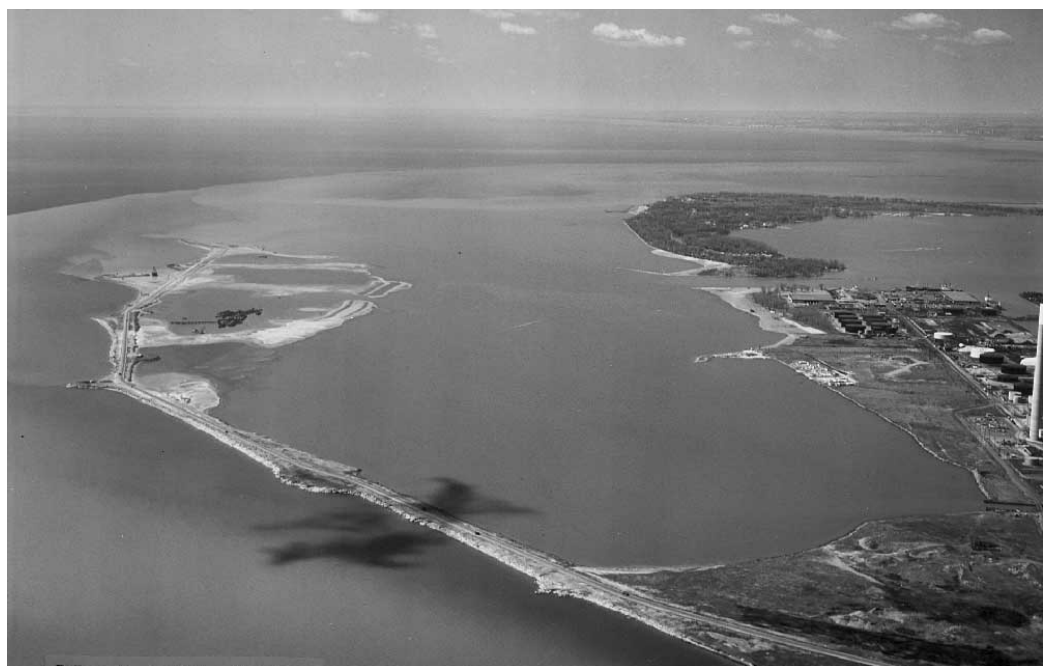

10 Development of the Leslie Street Spit, Toronto, 1975, Ports Toronto. Photograph courtesy of Tommy Thompson Park.

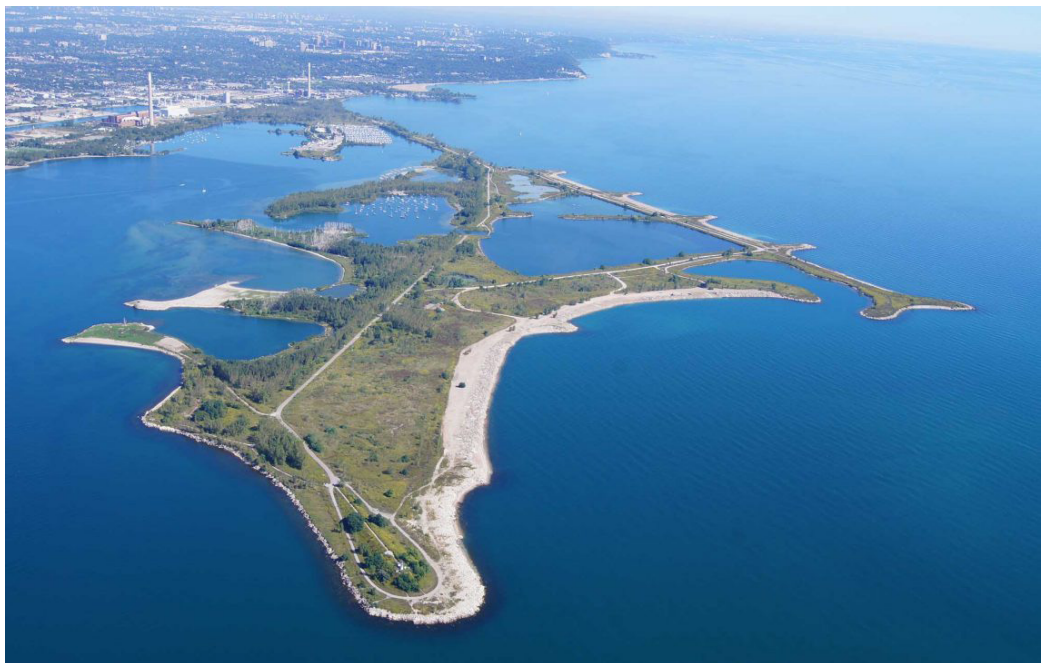

11 Lake Filling is complete, Toronto, 2013, Toronto and Region Conservation Area. Photograph courtesy of Tommy Thompson Park 
16

Halliday, Stephen

The great stink of

London: Sir Joseph

Bazalgette and the

cleansing of the

Victorian capital.

Sutton, 2001.

17

Cadbury, Deborah. Seven wonders of

the industrial world.

Fourth Estate, 2003 , pp. 194-196.
18

"Drawing on the literary theory of Gilles Deleuze and Felix Guattari, Stoner suggests that minor architectures, like minor literatures, emerge from the bottoms of power structures and within the language of those structures. Yet they too are the result of powerful and instrumental forces."

Stoner, Jill. Towards a minor arcbitecture. MIT Press, 2012.
From a historical perspective, the 'Great Stink' in London in 1858, was a moment that challenged the way we thought about waste. It raised serious questions regarding sanitation and health as well as the spatial and social transformations brought about by the production of waste. Human excrement and industrial effluent was polluting the Thames River leading to outbreaks of cholera. ${ }^{16}$ As a response to the unsanitary conditions brought about by the consequences of waste, civil engineer Joseph Bazalgette, designed an extensive sewage network of underground tunnels (12). This infrastructure would lead to the creation of new roads, parks and the eventual foundations for the underground subway. ${ }^{17}$ When we think about Bazalgette's expansion of London's sewage system, we can think of its similarities to the above ground road infrastructure that brings about spatial and social changes to the development of a city. The fact that it utilizes the space underground for above ground purposes, would define it as double operative. Hidden below ground away from public awareness giving it a minor perception, while simultaneously serving as a major piece of infrastructure that allows the city to function efficiently and effectively. ${ }^{18}$ This notion of hiding waste is a critical point that will become significant in understanding electronic waste's perceived invisibility, an idea that will be unpacked further in a later chapter.

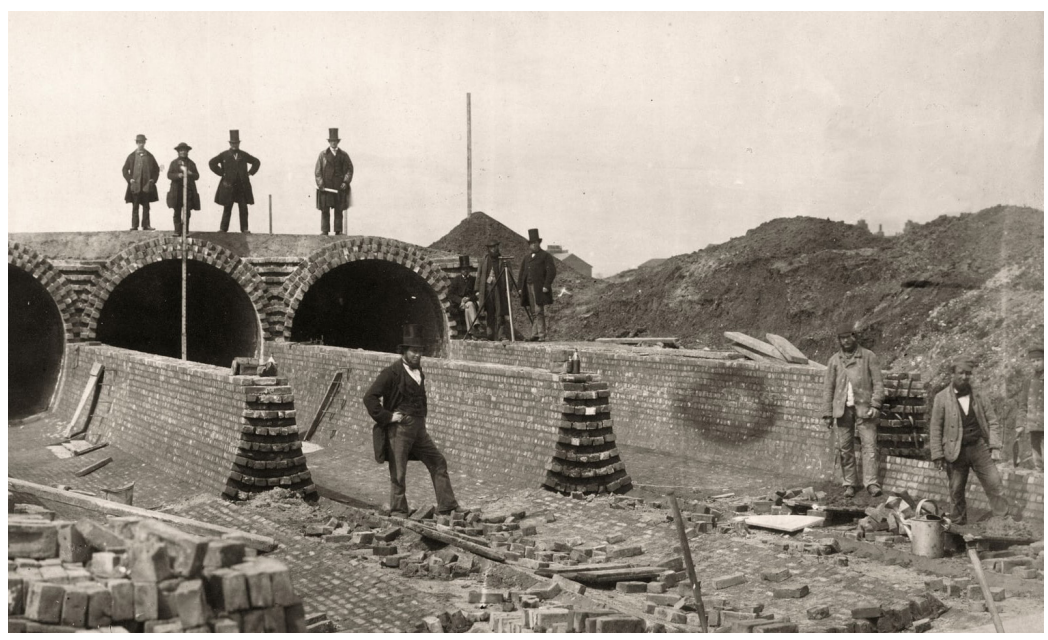

12 Engineer Joseph Bazalgette's Thames Embankment which is sewer infrastructure below and promenade above, London, 1862, Getty. Photograph by Otto Herschan. 
The way we organize our cities in relation to waste is generally an outcome of public health. Exposure to waste is undoubtedly harmful and as such we cannot live in close proximity to the waste we produce today. However, the spatial treatment of waste through land-use zoning has political and social implications. Spaces of waste are generally pushed to the periphery of the city, out of sight from the more privileged spaces of consumption. This creates landscapes of exclusion, which are a result of the socio-spatial mechanisms of zoning. By critically mapping out these forces, it becomes apparent that the spatial organization of waste is also inextricably linked to the spatial marginalization of people (13). If waste is central to the process of capitalist urbanization, can architecture improve the condition of configuring industrial form to create ecology between e-waste, culture, and the city? 


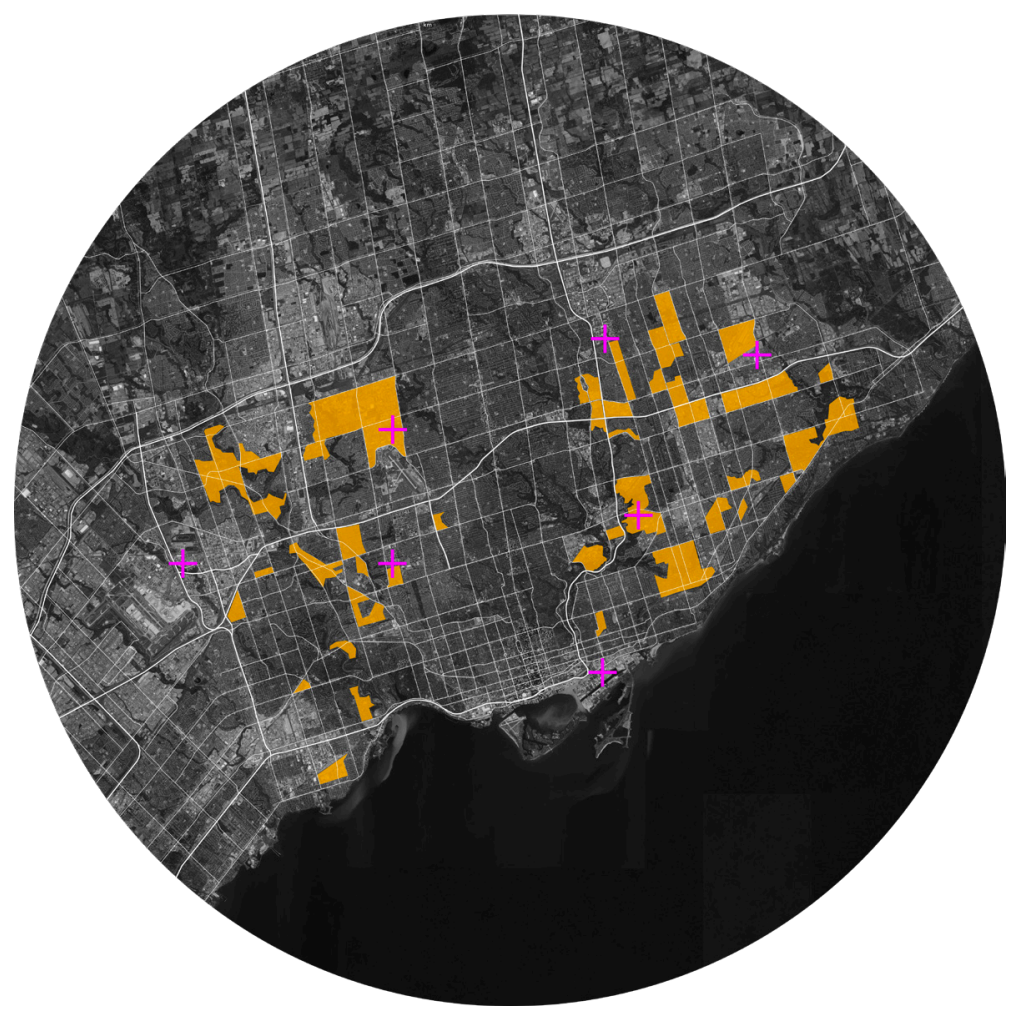

13 Municipal Transfer Stations vs. Low-Income Neighbourhoods 


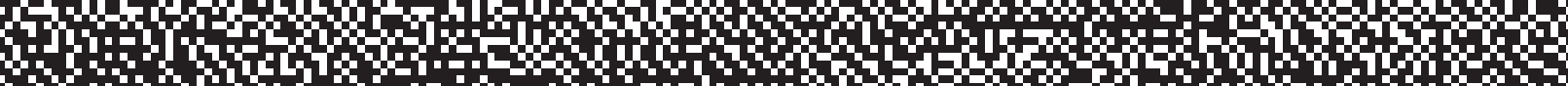

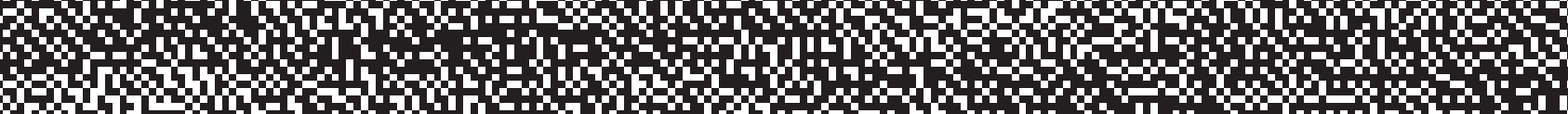
1023 佂

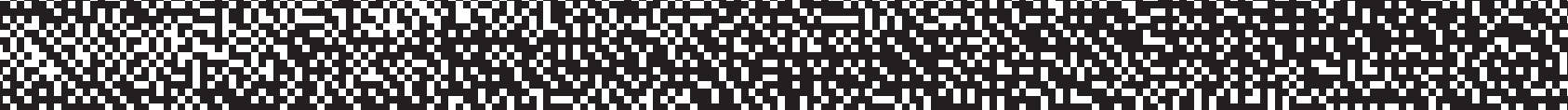

等

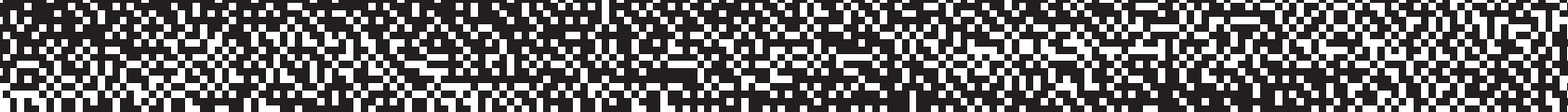

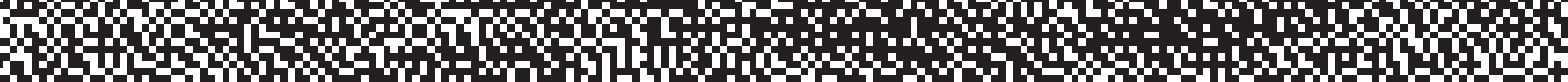

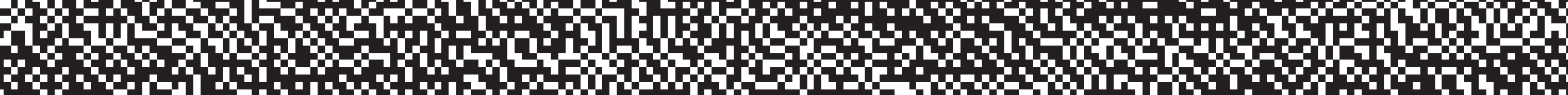
(1) 3 证 等

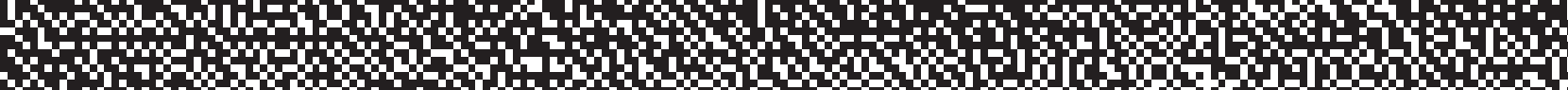
作

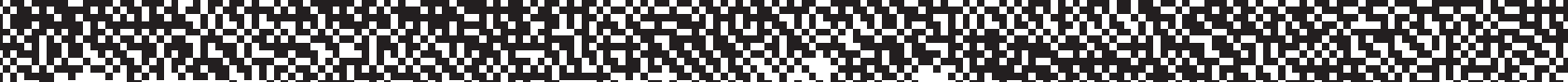

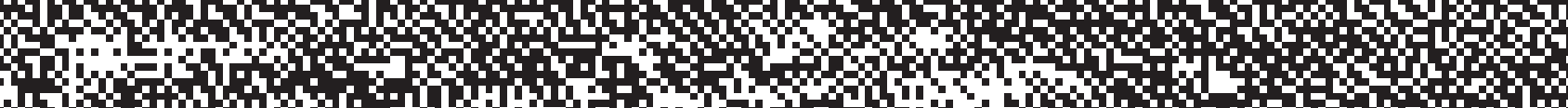

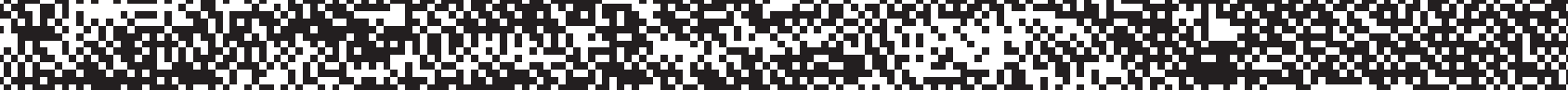

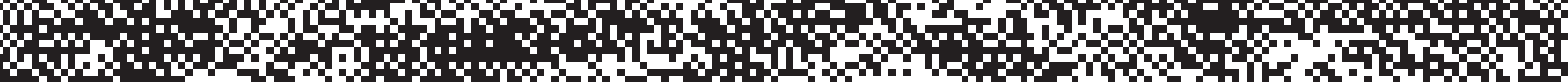

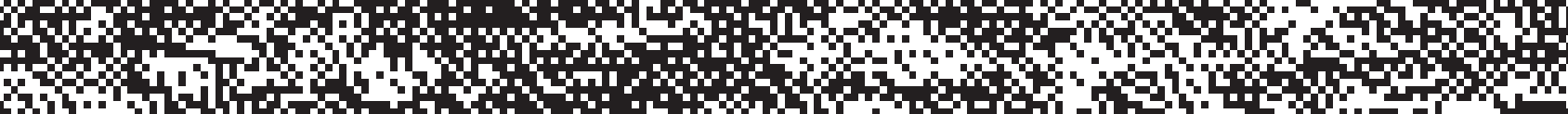

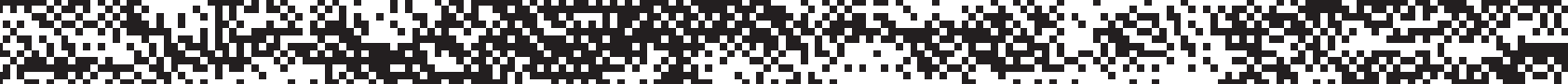

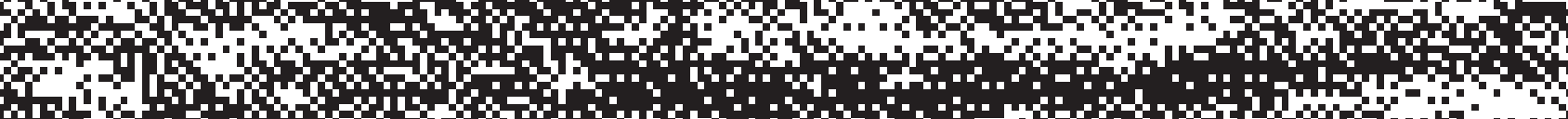

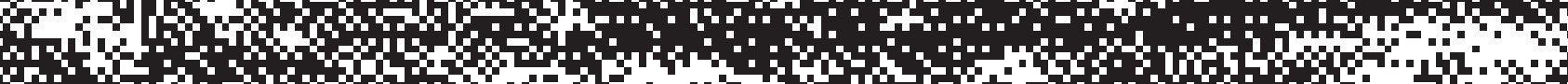

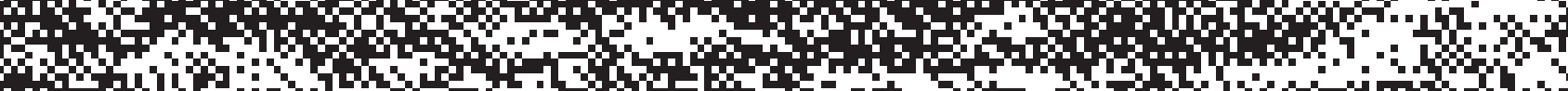

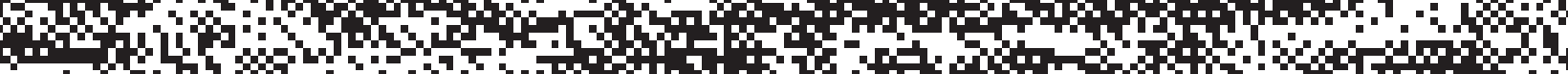

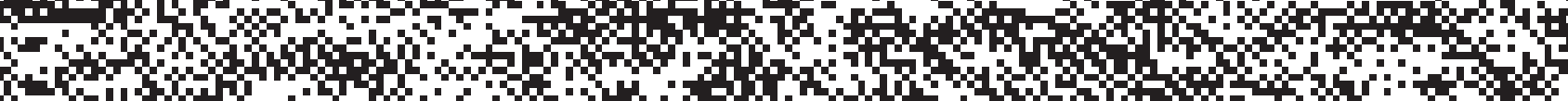

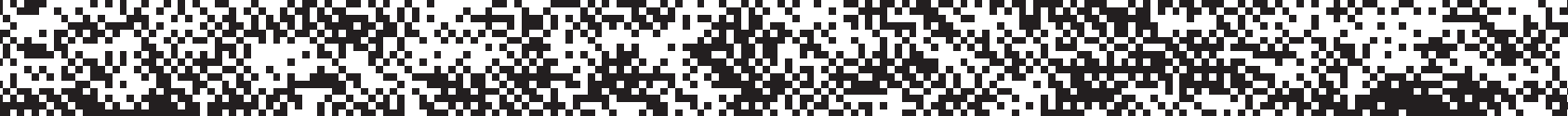

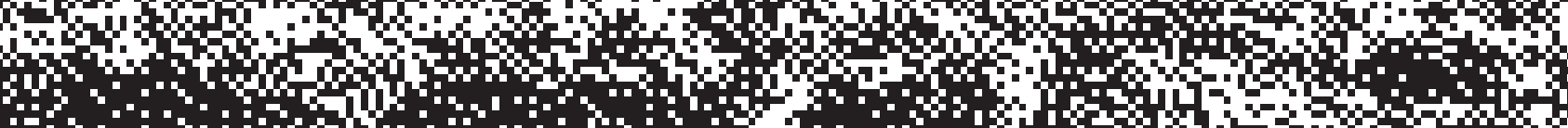

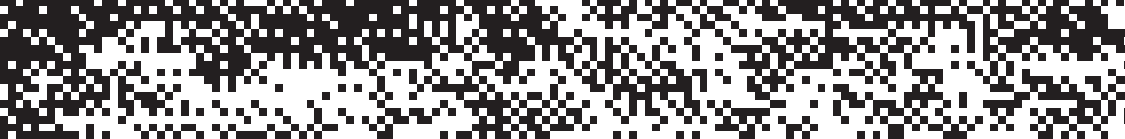

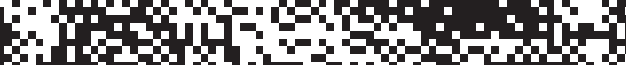

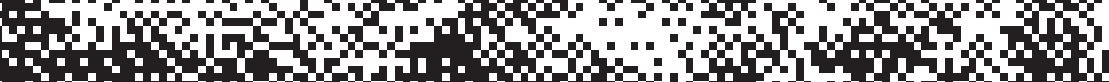

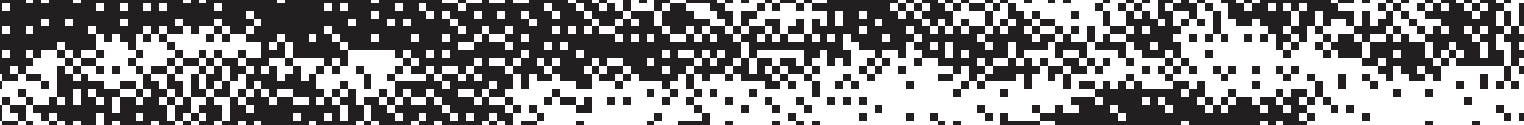

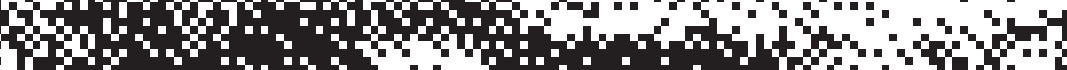
Hof

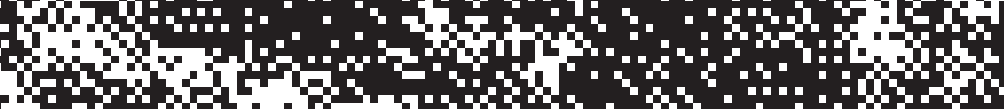

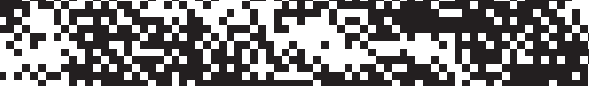
In 


\section{Invisibility of Electronic Waste}

19

Douglas, Mary. Purity and danger: an analysis of concepts of pollution and taboo. Routledge, 1966 , pp. 36
One of the provocations of waste is to question the notion of waste going away. We all know waste does not disappear and vanish from existence. It has to go somewhere. In the seminal book 'Purity and Danger', Mary Douglas, a cultural anthropologist states that, "dirt is matter out of place". ${ }^{19}$ This statement was a result of her observations made about nineteenth century urbanization as a better way of understanding waste's relationship to modern capitalist cities. So where exactly does our electronic waste get displaced to once they become obsolete?

The spatial movement of waste and its disposal is designed to be invisible so as to remove it from the possibility of collective contestation. Certain waste such as sewage should be hidden for obvious health and sanitation reasons. However, what happens when waste is made visible in a way that directly confronts its producers? The highly publicized 'Garbage barge of 1987', an event that publicly tracked the voyage of a barge Mobro 4000, from New

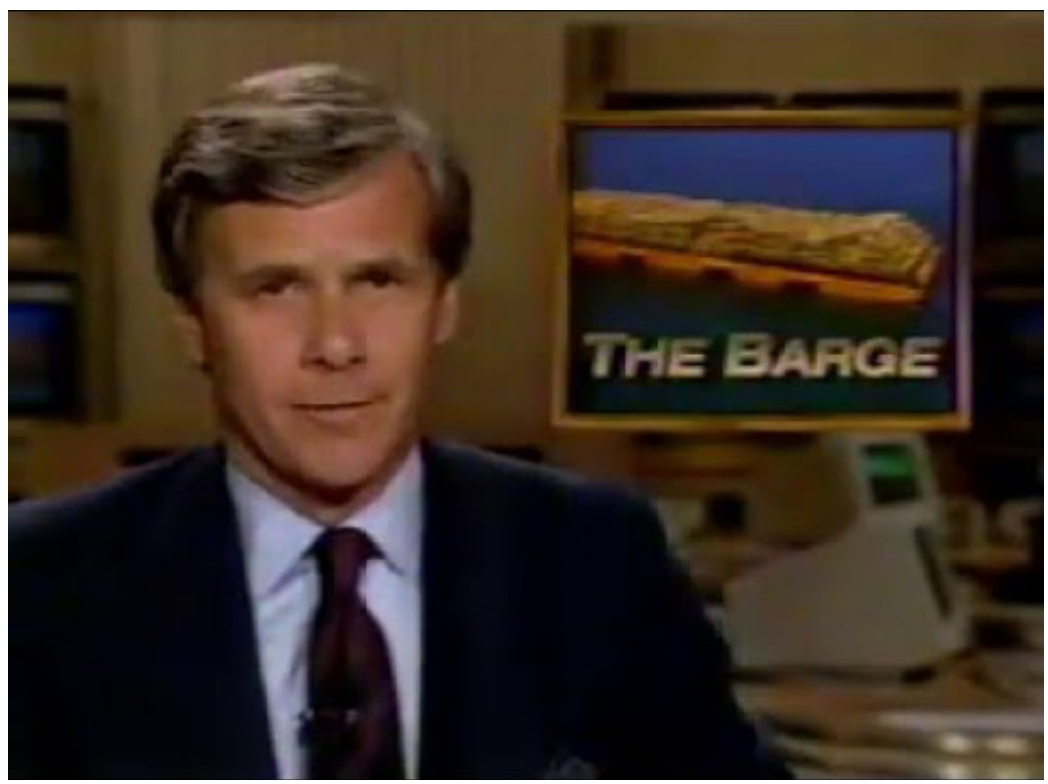

14 The Barge: Tracking the Journey of Mobro 400o, Florida, NBC News, 1987. Video still courtesy of Youtube. 


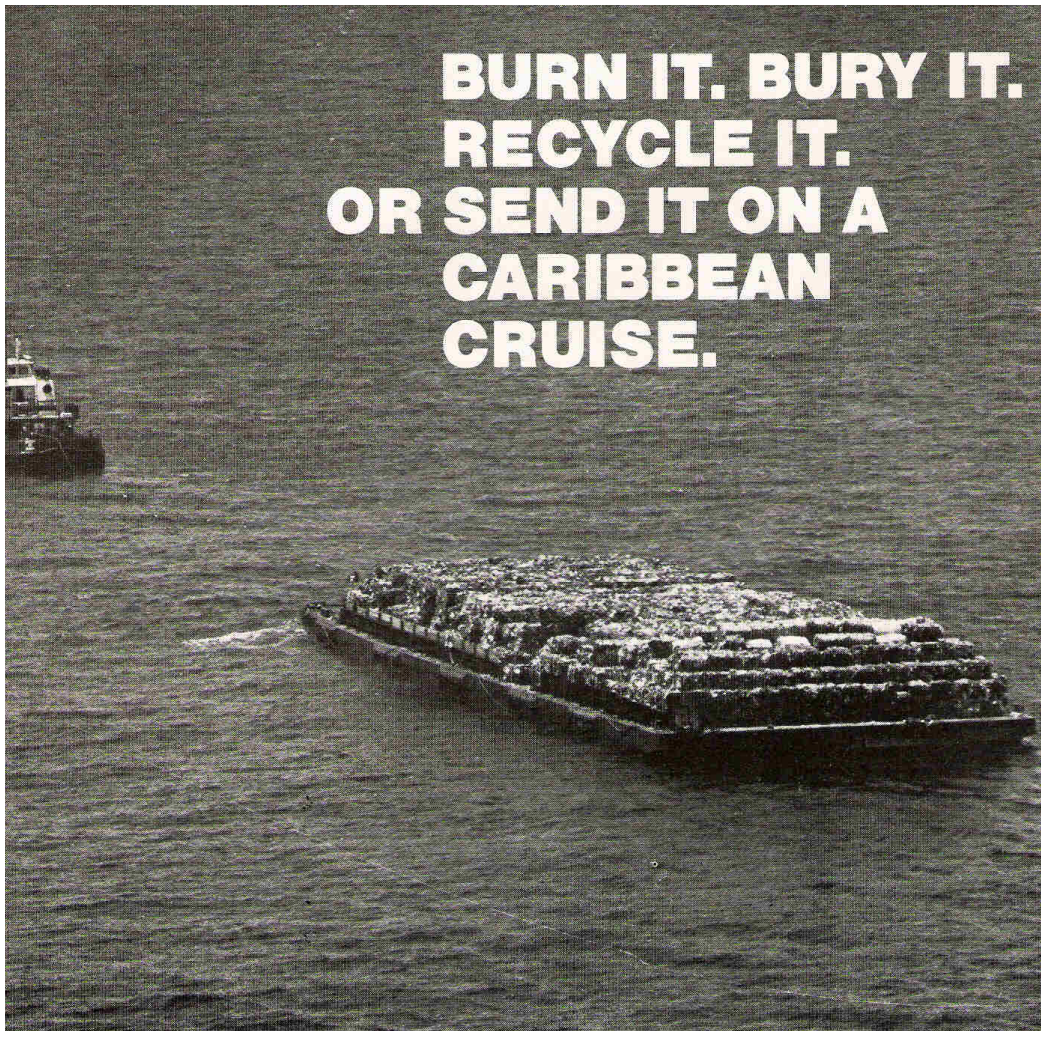

15 The significance of Mobro 40oo's journey, New York, Wall Street Journal, 1987. Advertisement courtesy of Wall Street Journal.

York City to Belize and back, was just that. A barge carrying 3,000 tons of New York City's trash was initially headed to Morehead City, North Carolina, to be disposed of due to a lack of available landfills in New York. ${ }^{20}$ When news broke, Mobro 4000 was denied entry to North Carolina and was forced to move on. The barge proceeded along the eastern coast making it as far south as Belize until it was forced to return to where it came from. Ironically, when it arrived back in New York, it was met with a temporary restraining order preventing it from docking. ${ }^{21}$ The Barge of 1987 illustrated the movement of waste demonstrating that waste does not disappear it just gets displaced. The legacy of the Mobro 4000 represents how the visible management of waste can spawn public discourse and raise awareness that can lead to greater willingness to recycle.
20

Rathje, William. Rubbish! The archaeology of garbage. HarperCollins, 1992.

21

Rathje, William and Murphy, Cullen. "Poor, misunderstood garbage." New York Times, 1992, pp. 21. Proquest, http://ezproxy. lib.ryerson.ca/ login?url=https:/ / search-proquestcom.ezproxy.lib. ryerson.ca/ docview/ 108845812 ? accountid $=13631$. Accessed

7 June 2018.

Gambetta, Curt. "Inside infrastructure." ARPA Journal, 2016, www.arpajournal. net/inside-infrastruc ture/\#note $492 \mathrm{~b} 258$ $020323292242 \mathrm{ba} 73 \mathrm{c}$ cd5e3b6d. Accessed 28 Dec 2017 
The management of electronic waste and its disposal is deliberately hidden for social and political reasons. But as demonstrated by Mobro 4000, our electronic waste should not be hidden, but rather it should be exposed and made constituent of urban space in order to engage the public. In general, electronic waste and its workers remain undervalued and invisible to the majority of society. Electronic waste is located at the peripheries of the city in urban blind spots, far from public awareness. Questions are often raised regarding where our electronic waste is dumped, as it often exploits marginalized communities in Toronto and abroad. These wastelands are supported by the understanding of displacing waste out of sight and ultimately out of mind from the consumers and producers, disguising the effects of electronic waste from the public gaze.

The invisibility of electronic waste is a bit of a contradiction in the sense that it is still spatially present in the urban fabric despite efforts to hide it. Through the act of mapping Toronto's e-waste network, the processes of collecting, transporting, recycling, and repairing, are spatially revealed and made visible (16). So how can this condition of invisibility be made transparent and constituent of urban space? Is it possible that the e-waste network goes largely unnoticed due to a lack of aesthetic identity? The conditions that lead to the invisibility of electronic waste are an assemblage of factors at different scales ranging from the ways in which it is managed to the spaces that it is contained, right down to the objects and technologies that eventually become waste. 


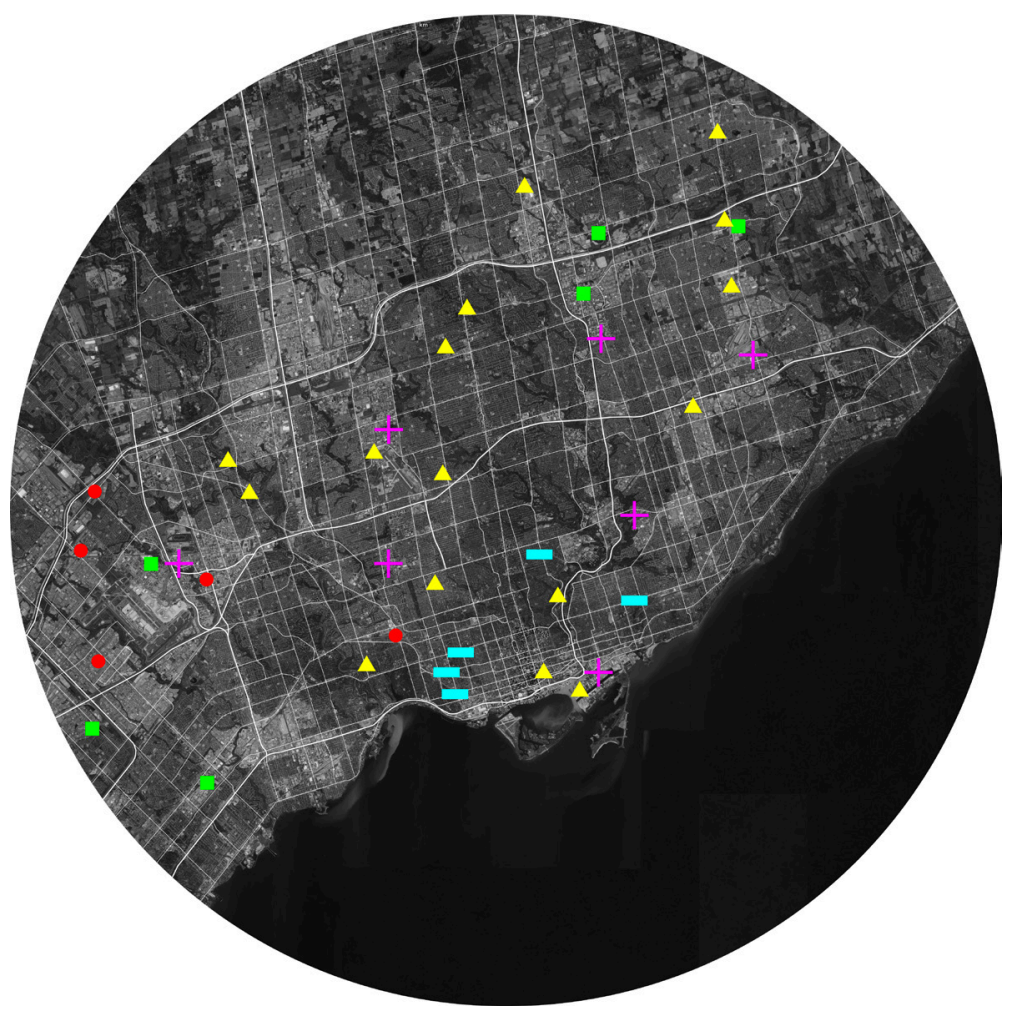

16 Toronto's Electronic Waste Network 

l. W.

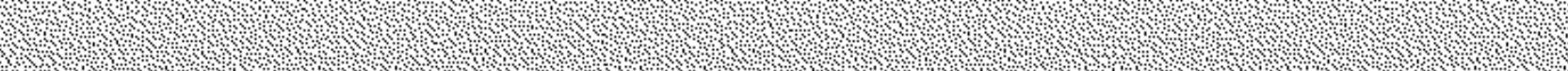

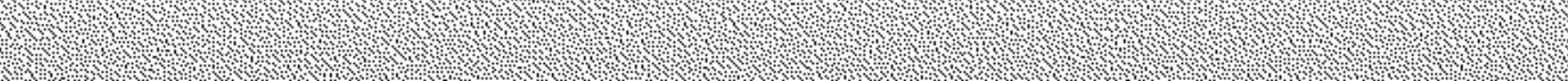





\section{A Generic Architecture: The Industrial Big-Box}

Upon a closer examination of the places and spaces that electronic waste occupies, the map of Toronto's E-Waste Network shows that it exists mainly in the industrial zones of the city contained within the big box. Looking critically at the industrial big box as the predominant building type responsible for processing Toronto's electronic waste, it becomes evident that the management of e-waste exists isolated from public awareness, conveniently out of sight from spaces of consumption. These buildings are hard to access, difficult to observe, offer no alternative purpose beyond its function, no opportunities for communities to engage, and are disconnected from their surroundings (18). All of which are ideal conditions that give reason for the big box as an optimal container for supporting and managing electronic waste's disappearance from the built environment.

The big box is the rational outcome of efficiency and flexibility capable of equally expressing geometry and economy. It is a pure form that has been utilized throughout the history of architecture from time immemorial. The big box remains specific yet generic. Reiner de Graaf, architect, theorist,
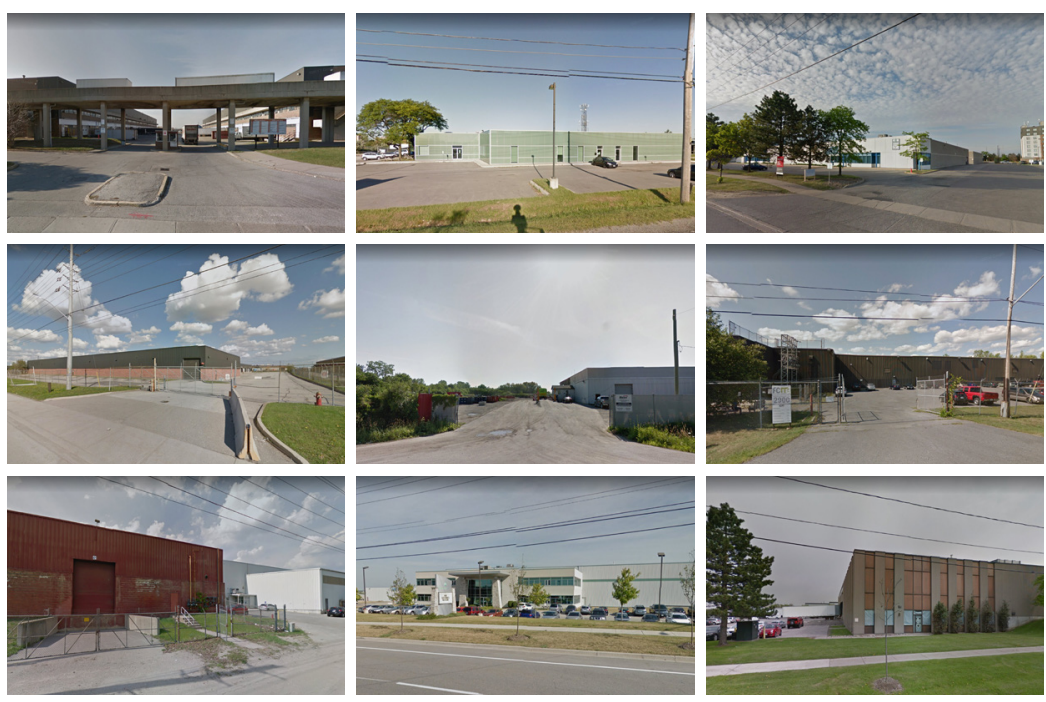

17 E-Waste Recycling Facilities (Top Left to Bottom Right): ADL Process Inc., Artex, COM2 Recycling, E-Cycle, Evolu-TIC, FCM, GEEP, Greentec, Shift, Google, Ontario, 2012-2016. Images courtesy of Google Streetview. 
and writer describes the big box as, “architecture's main achievement as well as its main trauma - both the result of an extreme effort and of no effort whatsoever." ${ }^{23}$ It has become a dominant and quintessential North American building type responsible for defining the suburban landscape.

These containers help to further enforce the invisibility of e-waste and the management of its disappearance from the built environment despite being materially and spatially present. (18)

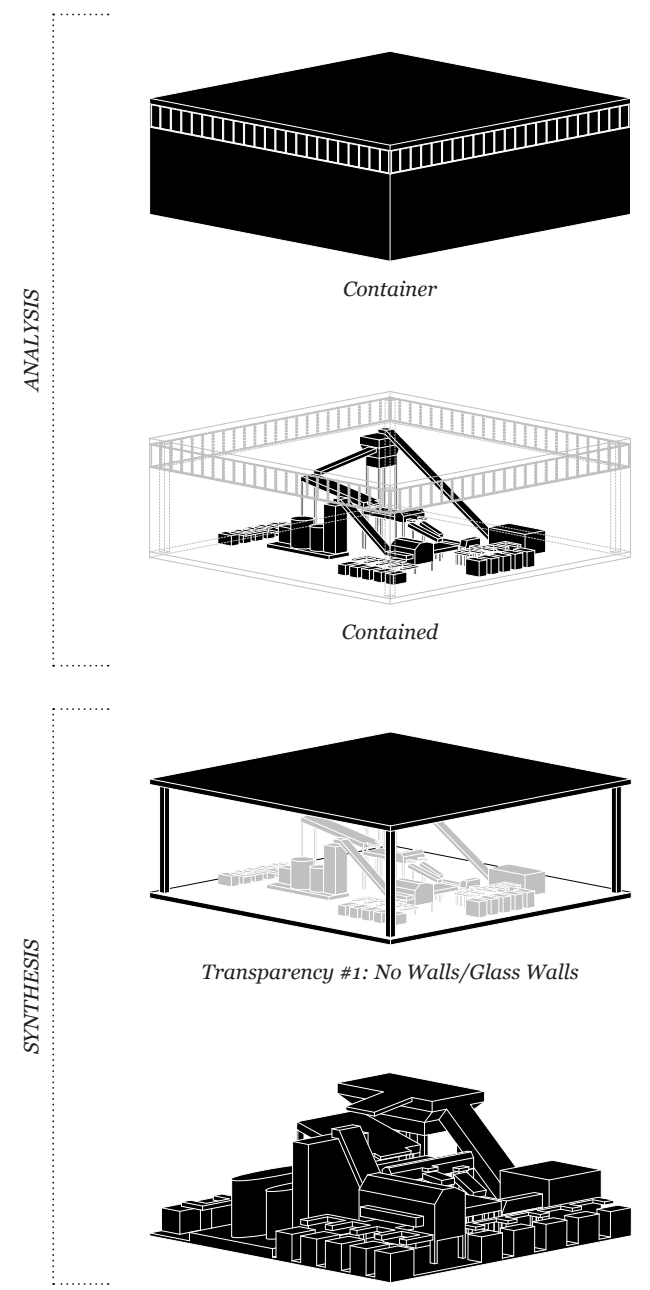

Transparency \#2: The machines become the architecture 
24

Clapham,

Christopher and

Nicholson, James.

The concise oxford

dictionary of

mathematics, 4th ed.

Oxford university

press, 2009.

25

De Graaf, Reinier.

"The inevitable box: architecture's main

achievement and

its main trauma."

The arcbitectural

review, 2017, www.

architectural-review

com/essays/

campaigns/notopia/

the-inevitable-

box-architectures-

main-achievement-

and-its-main-

trauma/10024071.

article. Accessed 14

Feb 2018
While most commonly referred to as a box, this designation creates a

semantic shift in the way that it is thought of as a building. To be precise, the mathematical definition of the box is a rectangular prism: a six faced volume with each face set at 90-degree angles to the adjoining surfaces. ${ }^{24}$ Where the rectangular prism denotes both volume and mass, the box has a tendency to separate the two. As a result, the box remains incomplete and empty, a container in need of content. Thus, giving reason to privilege the content over the architecture as observed in contemporary uses of the big box (19). However, in architectural terms, the industrial big box can be re-imagined not as form following function but rather of form preceding function. ${ }^{25}$

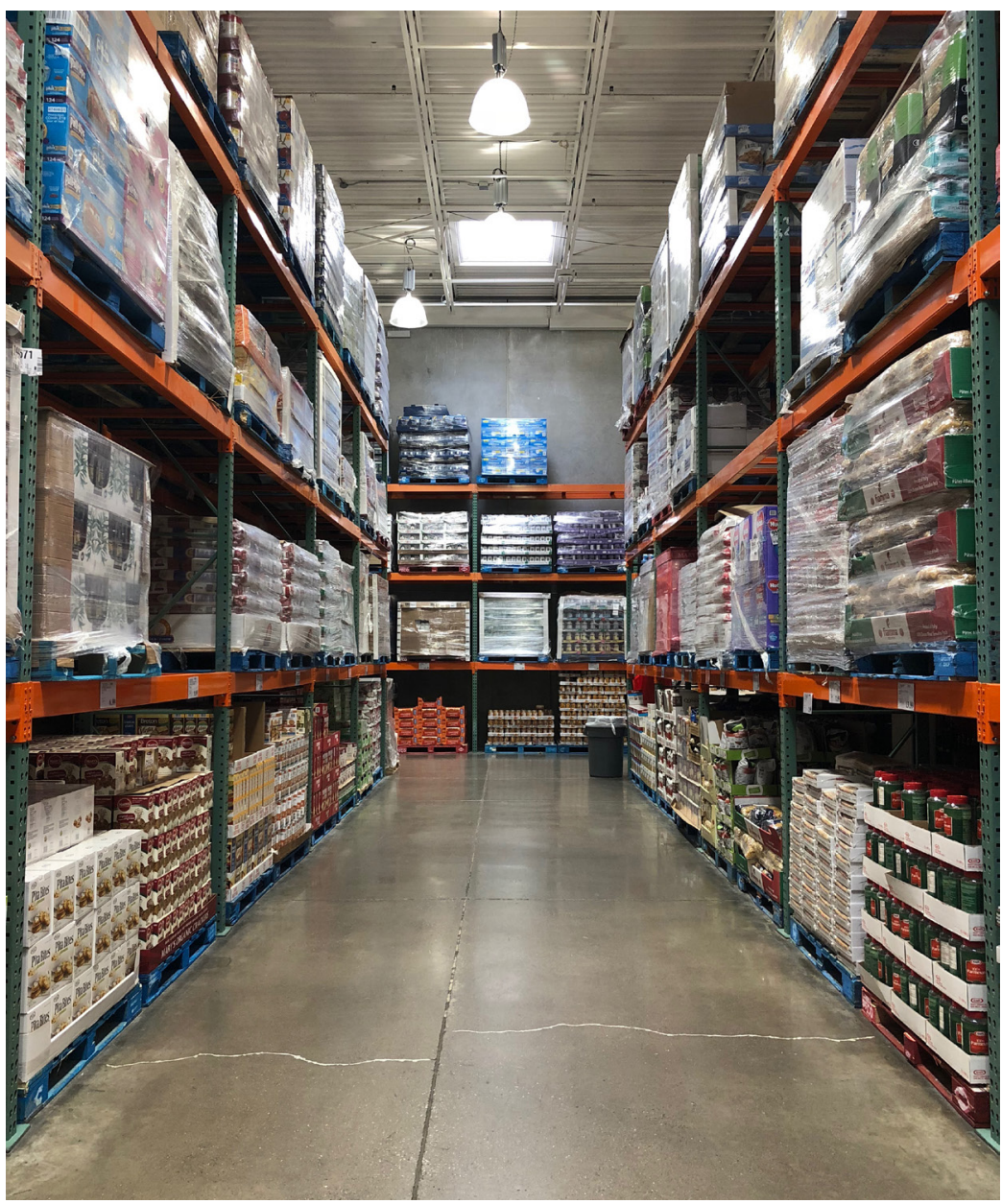

19 Costco Aisle \#7, Toronto, 2018 
So in the case of a building outlasting its function, there will still remain an architecture that is flexible and worthy of being repurposed. This is evident in the conversion of nineteenth century industrial brick and mortar buildings from factories to trendy loft spaces and chic offices. Although these factories were an outcome of form following function, they were by nature flexible spaces having to accommodate for large industrial processes, and are, therefore, today valued not only for their flexibility but also for their architectural design qualities and formal motifs reflecting the machine aesthetic of the industrial age.

Reviving the ideas of Venturi and Scott Brown's 'Complexity and Contradiction', we are able to derive of an architecture that is divorced from its function, which is a key idea when re-imagining the industrial big box. Architecture without content uses the function as an alibi for its own reason for being. The function of a building is the impetus but I argue that it should not be its essence. As observed in today's contemporary big boxes, there is a disconnect between the container and the contained. An architecture created as a container for the pragmatic purpose of being a large open space that can house a variety of content and functions. The discipline of architecture often criticizes the big box as being 'not architecture', however upon a closer examination I would contend that the big box finds its roots in the classical architecture of temples, palaces, and villas as proto-big boxes prior to the orthodox of functionalism, which is an ideology that still dominates architectural thought today.

In essence the highly regarded factory buildings that precede today's generic industrial shed can be characterized as architecture without content. Given modern architecture's celebrated ties to industrialization and the timeless architecture that it has produced, we should make industrial architecture great again. (20) 


\section{MAKE INDUSTRIAL ARCHITECTURE GREAT AGAIN}

20 "MIAGA" slogan campaigning for the revival of industrial architecture. An obvious variant and parody of Trump's Presidential Campaign. 



\section{Electronic Obsolescence}

The planned obsolescence of electronics is a major cause in the production of electronic waste. Consumer electronics have always produced waste by virtue of the toxic materials contained within them. However, their denomination as objects of consumption signifies a temporal quality, which suggests that they are intentionally made to be expendable and disposable. Thus dematerializing the object leading to its invisibility. The designed obsolescence of electronics encourages replacement over repair leading to the rapid increase in the volume of electronic waste in recent years.

Obsolescence comes from the Latin word 'obsolescere,' which means to grow old. The term was first used in sixteenth century England to describe old adages growing old and out of use, then in the nineteenth century to describe the loss of function in organisms, before its commonly known
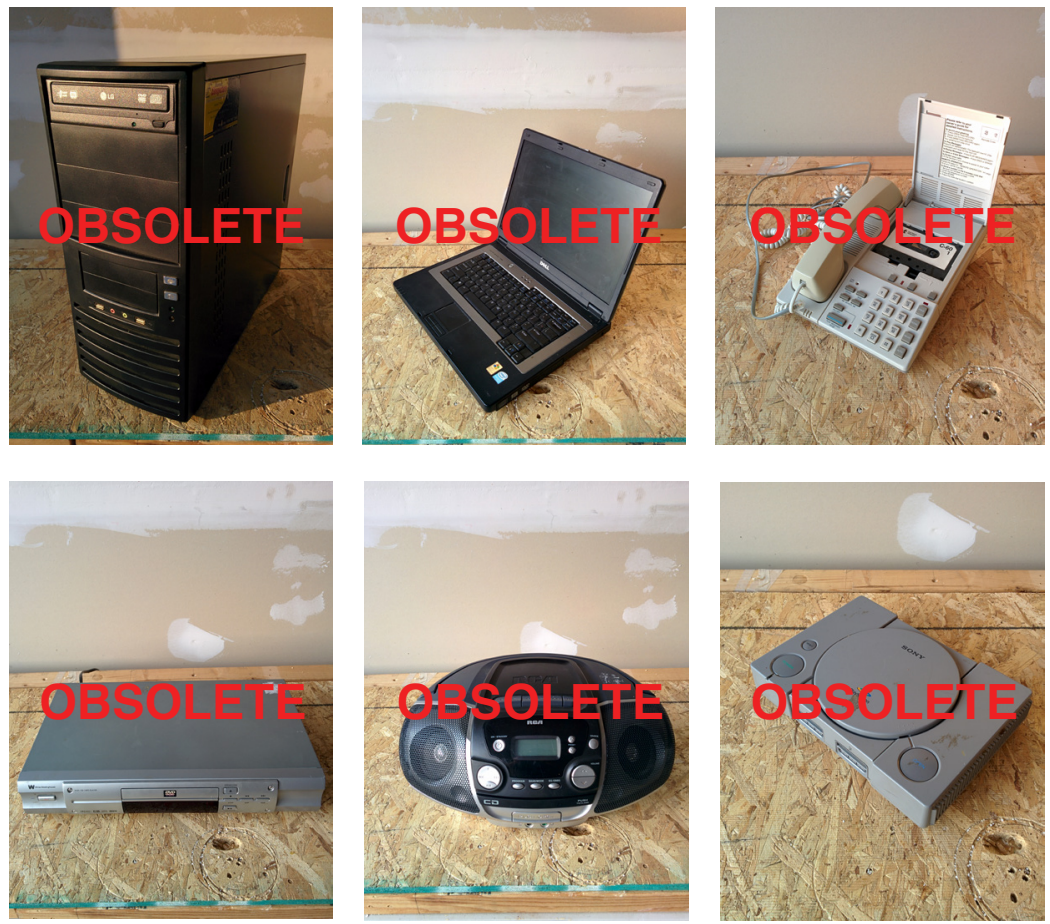

21 A collection of obsolete electronics: Desktop PC Tower, Dell Laptop c.20o9, Land-line Telephone with Voice Message Cassette Recorder, Magnavox DVD Player, RCA Stereo with Cassette and CD, Sony Playstation all of which have been replaced by newer technologies. 


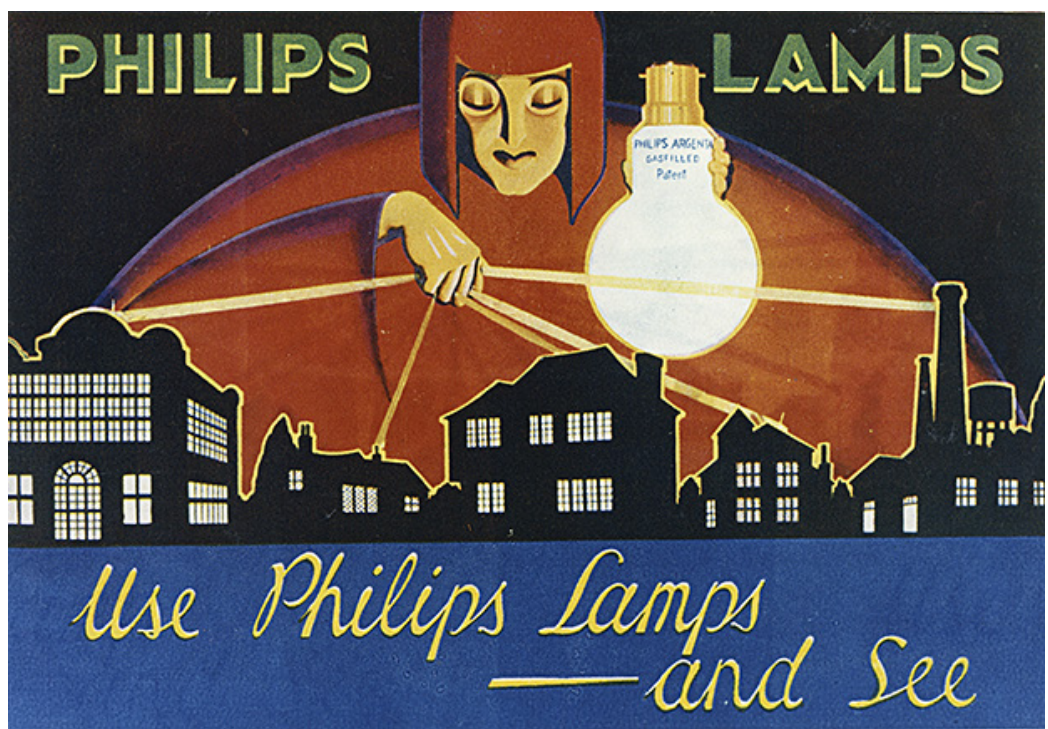

22 A shop window display for Philips speaks to the spread of electrification and artificial illumination the early 2oth century, Eindhoven, Philips Company, 1920. Image courtesy of Philips Company Archives.

association to a machinery's loss of utility. ${ }^{26}$ Obsolescence is a natural occurrence associated with degradation over time, but was accelerated by the industrial revolution inspiring the scope of creative destruction that induces

26 Abramson, Daniel. Obsolescence - an arcbitectural bistory. University of Chicago press, 2016. innovation and competition. The light bulb was the poster child that gave birth to planned obsolescence. (22) When light bulbs were first introduced to consumers, electrical companies were responsible for installing and maintaining entire systems that supported electrical lighting in homes, and as a result of this, light bulbs were initially made to last as long as possible.

When the electric light bulbs became wide spread to serve a mass market, responsibility shifted to the consumers. It is at this very moment that the business model changed upon the realization that greater sums of money could be reaped by making light bulbs disposable. ${ }^{27}$

The built in obsolescence made famous by the light bulb has since been extended to electronics, with the smartphone serving as the contemporary model. According to the Consumer Electronics Association, smartphones have an average life cycle of 4.7 years. ${ }^{28}$ Very rarely is there any device now that lasts for more than a couple of years in the hands of the original owner. Manufacturers have made it increasingly difficult to repair our electronics

27

Hadhazy, Adam. "Here's the truth about the 'planned obsolescence' of tech." BBC, 2016, www.bbc. $\mathrm{com} /$ future/ story/20160612heres-the-truthabout-the-plannedobsolescence-of-tech. Accessed $5 \mathrm{Nov}$ 2017 2017, pp.20 
for reasons that include the lack of availability of replaceable parts and the information regarding the repair of our devices. The right to repair has been stripped away from the consumers by design, disconnecting us from an understanding of how they work. This type of relationship we have with electronics is rather odd, especially considering we rely heavily on them for the daily rituals of contemporary life. As a consequence of designed obsolescence, we have a tendency to dispose of electronics at the slightest inconvenience when they become dysfunctional.

On the flipside, there are those that would argue that obsolescence isn't necessarily a negative thing, especially when it comes to technology. ${ }^{29}$ If electronics were built to last, then it would impede any technological advancement that is necessary to its own evolution. Although true, this still does not negate the fact that electronics should be designed for disassembly in order to improve the ease of repair and the efficiency of recovering valuable materials. If planned obsolescence is intentionally designing products to expire, which ultimately lead to waste, we should instead make products that intentionally could be unmade so that they could be made again and again, empowering the reuse and recovery of electronic waste.

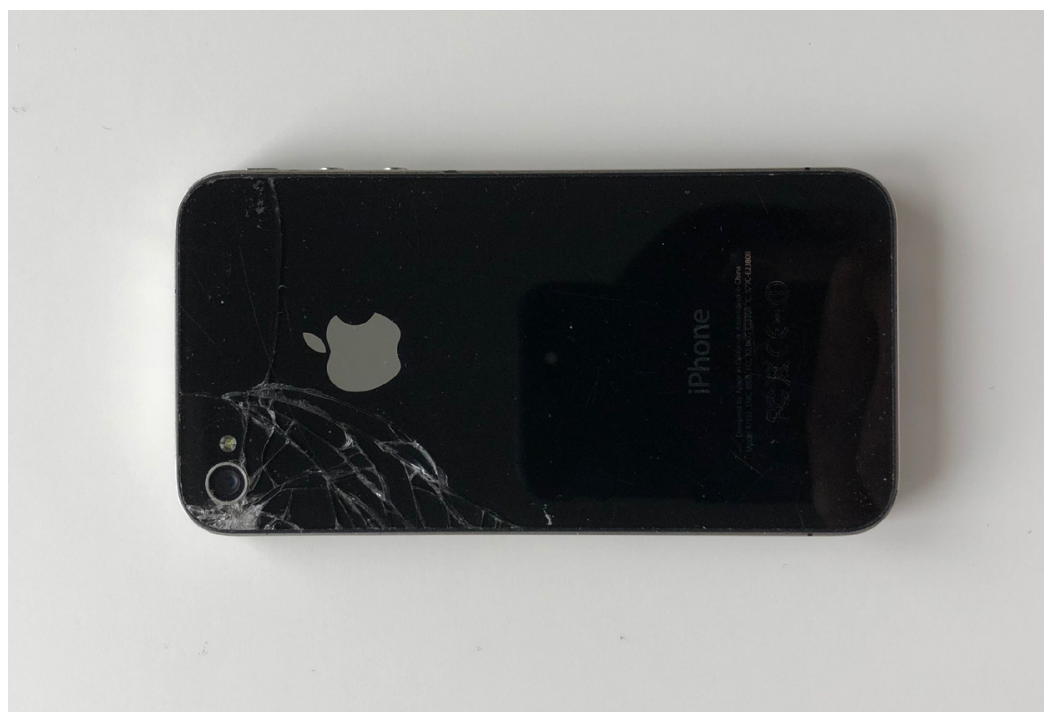

23 The Apple iPhone is a symbol of electronic obsolescence 
This model is more regenerative and beneficial for not only the environment but the economy as well. Disassembly and reassembly will be a key idea in the design of the critical project.

The factors contributing to the conditions of invisibility are complicit to perpetuating electronic waste's mystery and subsequent resistance to public inquiry. Obsolescence dematerializes electronic devices further enforcing its invisibility through the normalization of its consumption. The architecture of waste management simultaneously helps to maintain the invisibility of e-waste and its workers through the industrial big box by means of its opaque containment.

The consequences of electronic waste and its invisibility have political and social implications that affect the spatial transformations of the environment and city. If resistance towards e-waste will only happen when the effects are felt and experienced, then the big question lies in the how. How can architecture address the notion of transparency to make electronic waste constituent of urban space? Furthermore, if waste is central in the process of capitalist urbanization, can architecture improve the condition of configuring industrial form to create ecology between e-waste, culture and urbanity? 

8 


\section{The Need For Transparency}

1

Gambetta,

Curt. "Inside

Infrastructure."

ARPA Journal,

2016, http://www.

arpajournal.net/

inside-infrastructure

/\#note492b258020

$323292242 \mathrm{ba} 73 \mathrm{ccd} 5$

e3b6d. Accessed 28

Jan 2018.
The reality of electronic waste is one in which its processes are shrouded in secrecy in order to resist opposition and to encourage a consumptive lifestyle of excess.

The current attitude of design research concerning electronic waste is united by a common ethos of bringing its consequences into greater visibility, making legible that which society refuses to acknowledge. ${ }^{1}$ The invisibility syndrome of electronic waste is evident throughout many facets of its life cycle, from the way that it is managed to the big boxes in which it is contained and processed, down to the de-materialization of electronics as objects of desire meant to be consumed and wasted. The interiority complex that is expressed by the industrial big box and our electronic devices both act in similar ways when it comes to hiding the consequences of e-waste. The industrial big box is a container that hides the machines responsible for processing e-waste, while the cases of our electronic devices hide the contents and valuable materials embedded within, alienating us from any understanding of their inner workings (1). This assertion thereby positions transparency as the ultimate agent in disrupting the logic of electronic waste's invisibility, in favour of a more transparent architecture that creates an engagement between waste, culture and the city.
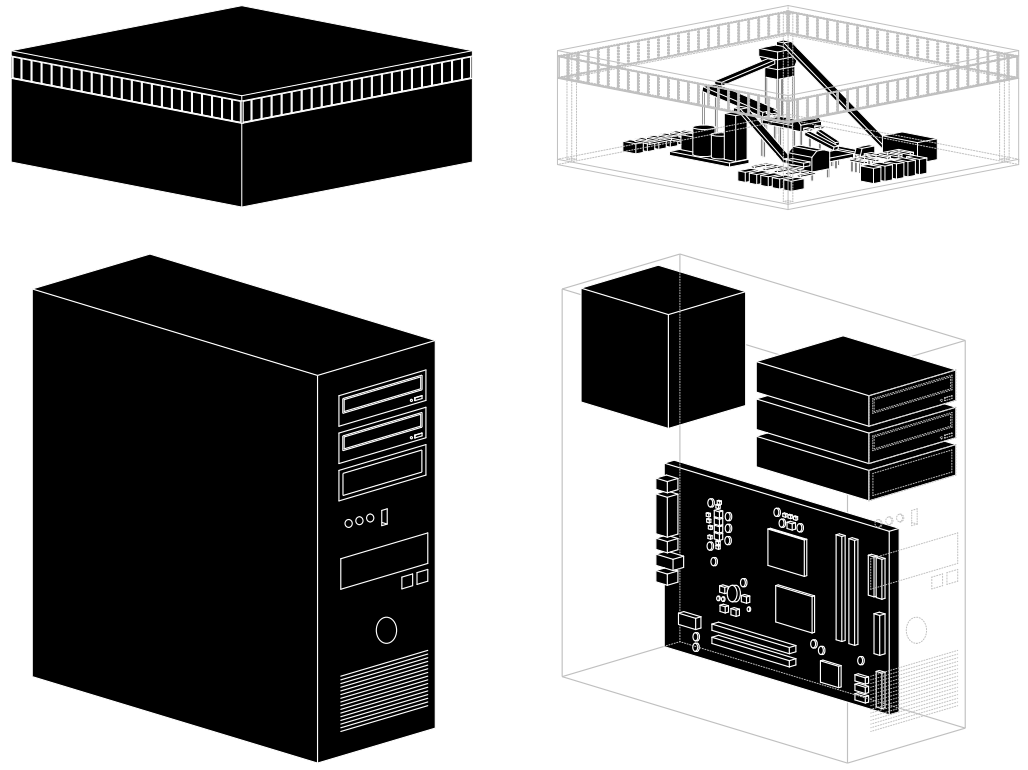

1 Analogy of the Industrial Big Box and Electronics being containers for the contained. Parallels can be drawn between the invisibility of the e-waste process down to the components that are made from valuable materials and rare earth metals. 
Transparency has become a commonly used catchphrase for governments,

corporations, and institutions, giving it a familiarity that has seemingly lost its significance. According to the dictionary, transparency is defined as a material and intellectual condition, the former being pervious to light and the latter being easily detected and free from pretense or deceit. ${ }^{2}$ In architecture, transparency is understood mainly as the dematerialization of a building façade and therefore generally translated through the use of glass as a primary building material. There

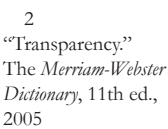

is a tendency however in architecture to speak about transparency in its material sense more than its symbolic and theoretical understanding. The one-dimensional applications of transparency lead Colin Rowe and Robert Slutsky to argue for a more critical understanding of the term in architecture.

In their seminal essay on a literal and phenomenal transparency, Rowe and Slutsky contend that transparency is predominantly treated literally through materiality often neglecting the more perceptual or intellectual understanding of the term. ${ }^{3}$ They were very critical in the normalized attitude of a literal transparency. And so by applying Gestalt theory to the experience of architecture, they were able to derive a new awareness of transparency, which they termed phenomenal, from their Rowe, Colin and Slutsky, Robert. "Transparency: Literal and Phenomenal."

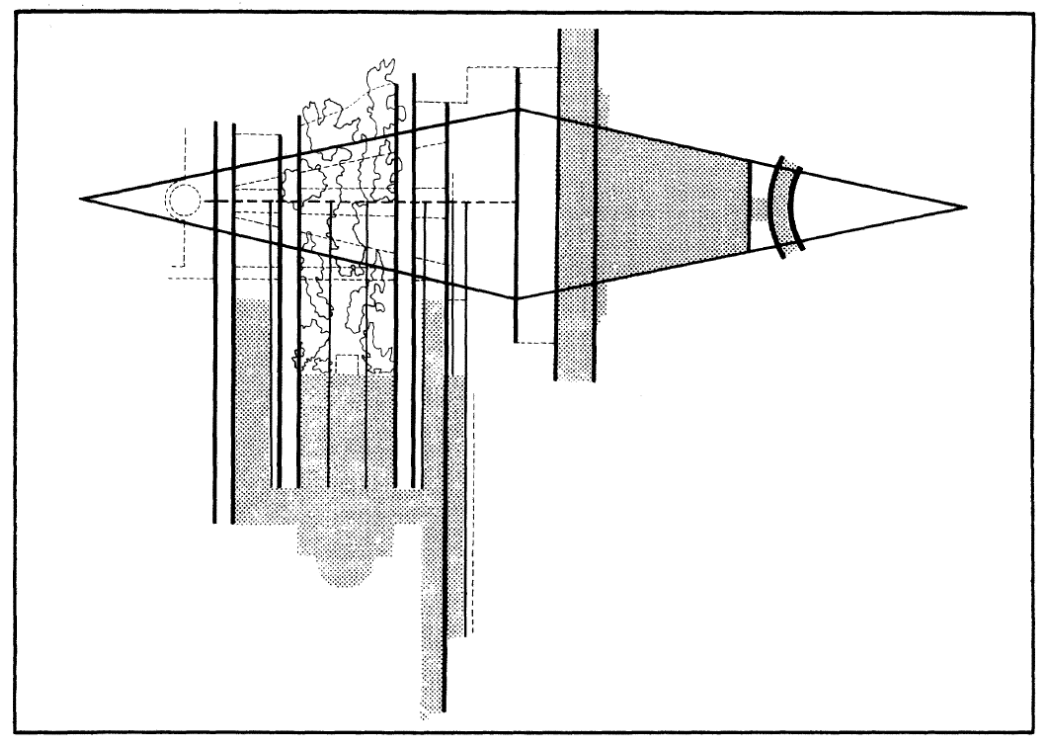

2 Diagrammatic Plan of the Palace of League of Nations: An alternative proposal demonstrating a stratification of planes, a transparency devices by means of which spaces becomes constructed, Geneva, Switzerland, 1925. Diagram courtesy of Hannes Meyer and Le Corbusier. 


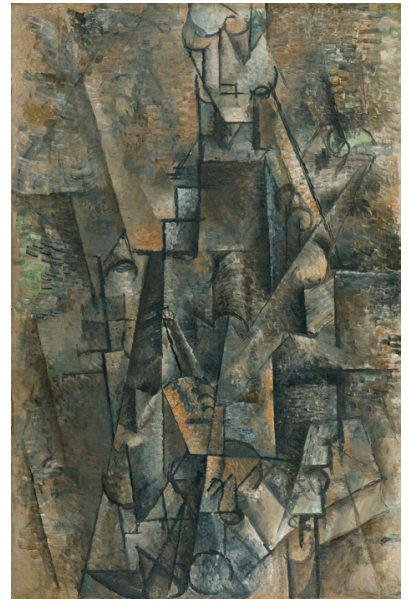

3 The Clarinet Player, Pablo Picasso, Madrid, 1911. Image courtesy of Museo Nacional

\section{Thyssen-Bornemisza.}

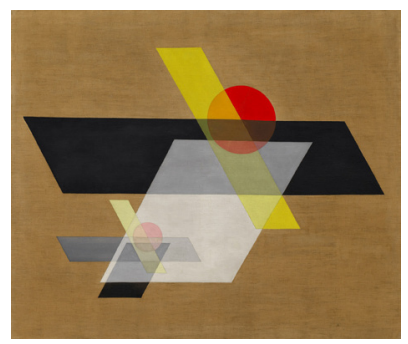

4 A II (Construction A II), László Moholy-Nagy, New York, 1924. Image courtesy of Solomon $R$.

Guggenheim Museum.
Borrowing ideas from Gyorgy Kepes in his "Language of Vision", when two or more figures overlap one another then a new optical quality is required in order to understand the contradiction of this spatial condition. ${ }^{4}$ Based on this definition, this ambiguity would require a cerebral acuteness rather than a mere physical and explicit transparency, allowing the proverbial 'light' of the mind to penetrate the obscurity of overlapping figures, revealing what is hidden beyond the foreground of the picture plane, making it phenomenal. Furthermore, when thinking of Moholy-Nagy's referral to superimpositions of form, Nagy argues for a space-time fixation that transposes insignificant singularities into meaningful complexities through the process of distortion, re-composition and double entendre. ${ }^{5}$ While considering both Kepes' and Nagy's explanation of transparency when analyzing cubist and suprematist paintings, it becomes clear that organization and composition are an inherent quality of a phenomenal transparency. Within this tradition, transparency can also be understood as a stratification by means of which space becomes constructed, substantial, and articulate. ${ }^{6}$ Although this pictorial analysis of transparency through the medium of painting can only suggest a spatiality of the third dimension, how can this be achieved in architecture, a medium that is inescapably bounded to the production of space? More importantly how can this articulation of transparency be applied to making the consequences of electronic waste visible and more

Kepes, Gyrgy Language of Vision. Dover Publications, 1995 5 László Moholy-Nagy Vision in Motion, Theobald, 1947; pp 210

6

Rowe, Colin and Slutsky, Robert. "Transparency: Literal and Phenomenal." Perspecta, vol. 8, The MIT Press, 1963, pp. 53 perceptible to the public?

Whether understood as a quality of organization or material, the confluence of form and meaning by way of symbolism would imply, what I claim to be an alternative understanding and application of transparency, suggesting an extension of Rowe and Slutsky's theory. And so by borrowing the ideas of sign and symbol, articulated by Robert Venturi and Denise Scott Brown, 
and applying them to a critical understanding of transparency, I argue that the ability for architecture to communicate meaning through symbolic form has the potential to also communicate a dual transparency that is both literal and phenomenal. The provocation that transparency can be expressed through an iconography makes it natural to wonder, can architecture as symbol communicate the consequences of e-waste to engage the public and convey a visibility that gives it value and legibility in the city?

For architecture to be read as legible, it needs to articulate one of its richest dimensions, which is its ability to communicate meaning. One of the necessary qualities that make a building architecture is meaning. Meaning that is delineated through the symbolism of form. The creation of symbolic form in architecture is rooted in past experience as well as cultural and historical memory. ${ }^{7}$ However, with the tendency for architectural form to be seemingly esoteric, how does one begin to interpret the symbolism and meaning behind a building's formal appearance without any prior knowledge or understanding? The contradiction between that which appears and that which signifies, between form and meaning, structures a complexity that requires a physiognomy or in other words, an intellectual interpretation of its formal characteristics. This interpretive reading can lead to an understanding that I contend illustrates the presence of a phenomenal transparency, ultimately making visible the invisible.

So in essence, the ambiguity of symbolic form creates a tension between object and subject, allowing for a multiplicity of readings and meanings that offer a curiosity leading to clarity, and thus a greater transparency that is legible. It is through this theoretical hybrid of connecting the ideas of Rowe and Slutsky with that of Venturi and Scott Brown, which I contend that what is hidden, can be made transparent through an articulation of an iconography of sign and symbol. This propositional mode of thinking is diagramed in 'the iconographic transparncy square,' (7) which I termed in reference to A. J. Greimas's square, explaining the theoretical framework that attempts to illustrate a correlation between transparency and iconography. Within this framework, offers the exploration of alternative possibilities, which 
5

Diagrammatic Plan of the

Palace of

League of

Nations,

Geneva,

Switzerland,

1925. Diagram

courtesy

of Hannes

Meyer and Le

Corbusier.
6 The Duck

building \&

The Decorated

Shed, Las

Vegas, 1972,

MIT Press.

Image courtesy

of Robert

Venturi \&

Denise Scott

Brown. begin to respond to the invisibility of electronic waste by providing a complex and contradictory model that allows us to see the intricate problems of our day with new perceptions.
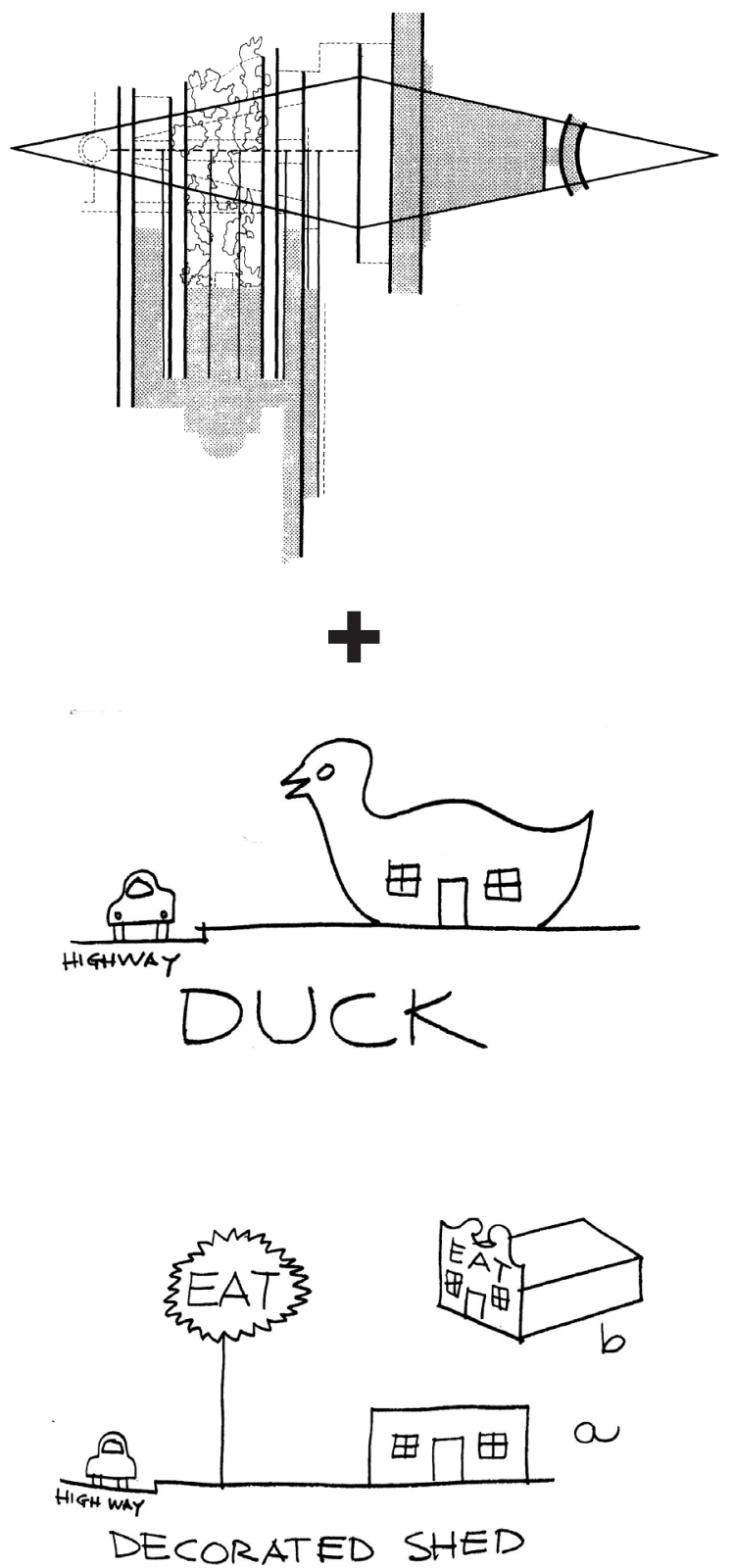


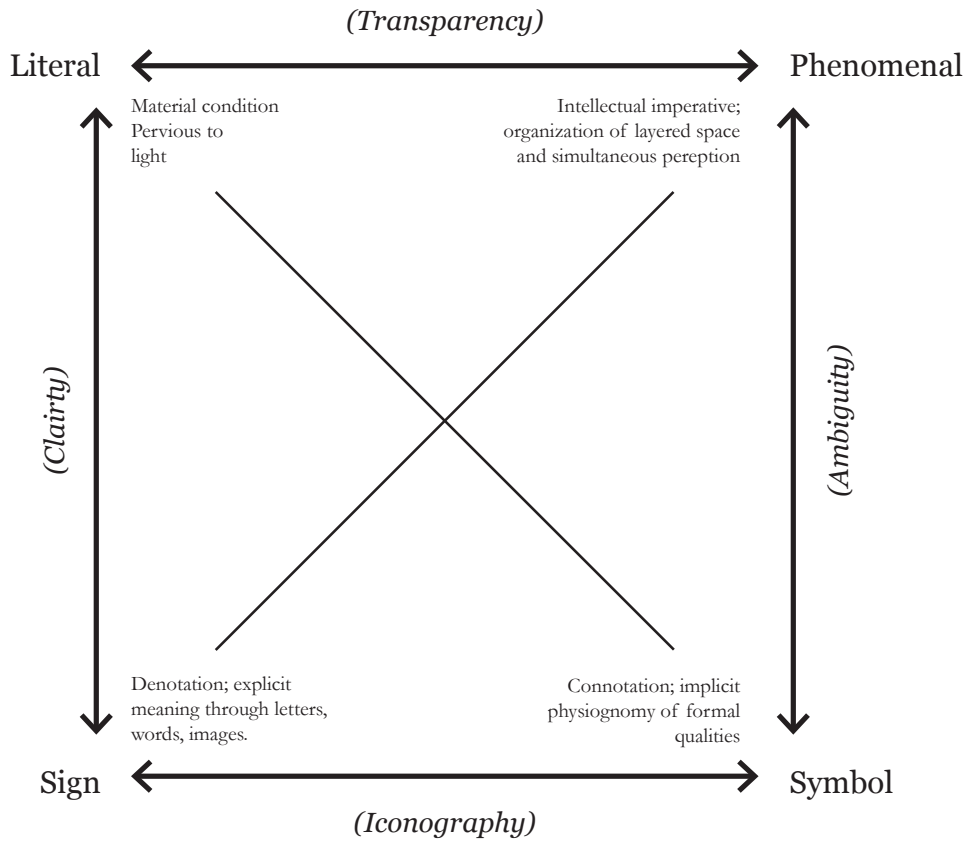

7 The Iconographic Transparency Square 


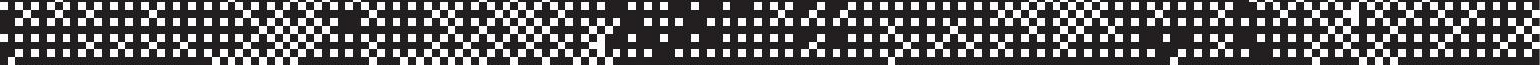

Pad

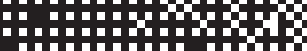

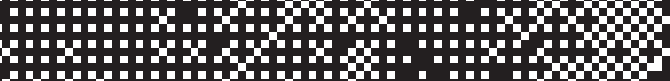

".

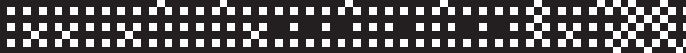

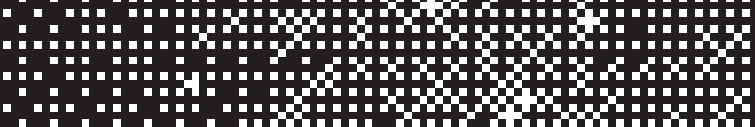







+N+21

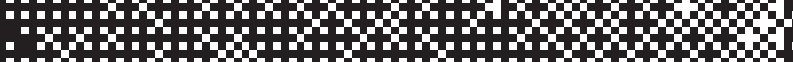

Py:

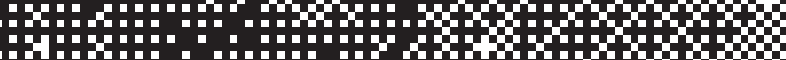

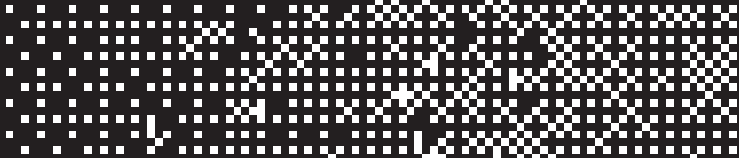

-

Xis.

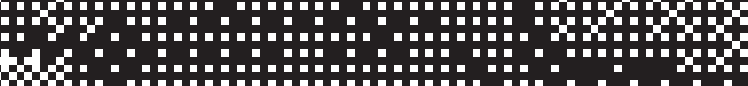

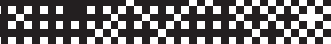

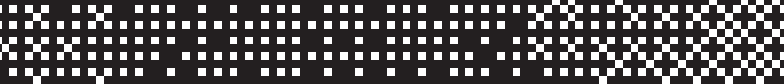

A

a.

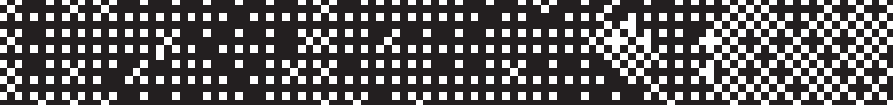

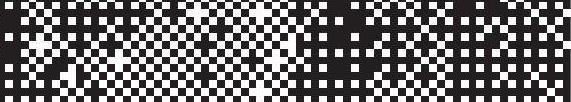

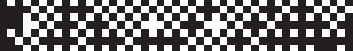

2020

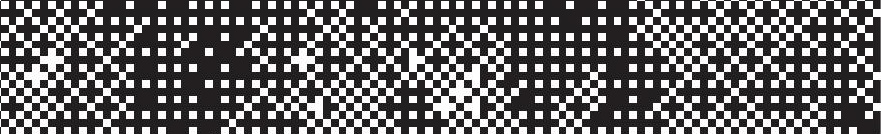





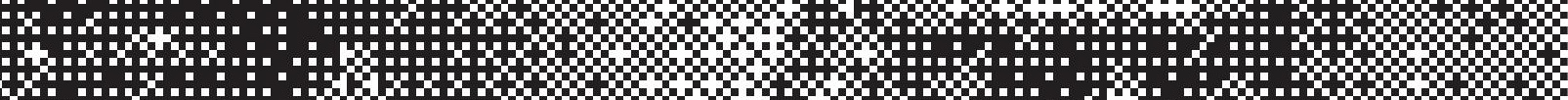
2
2 


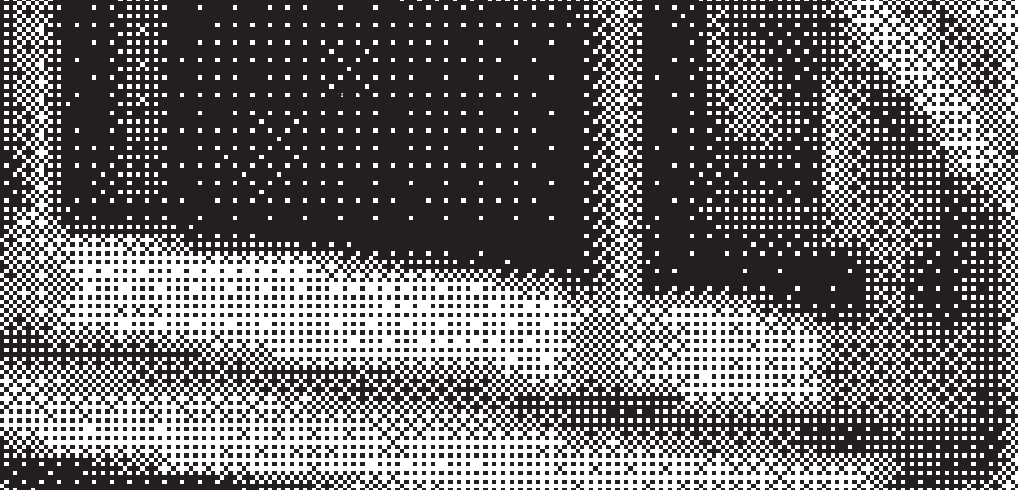

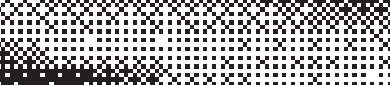
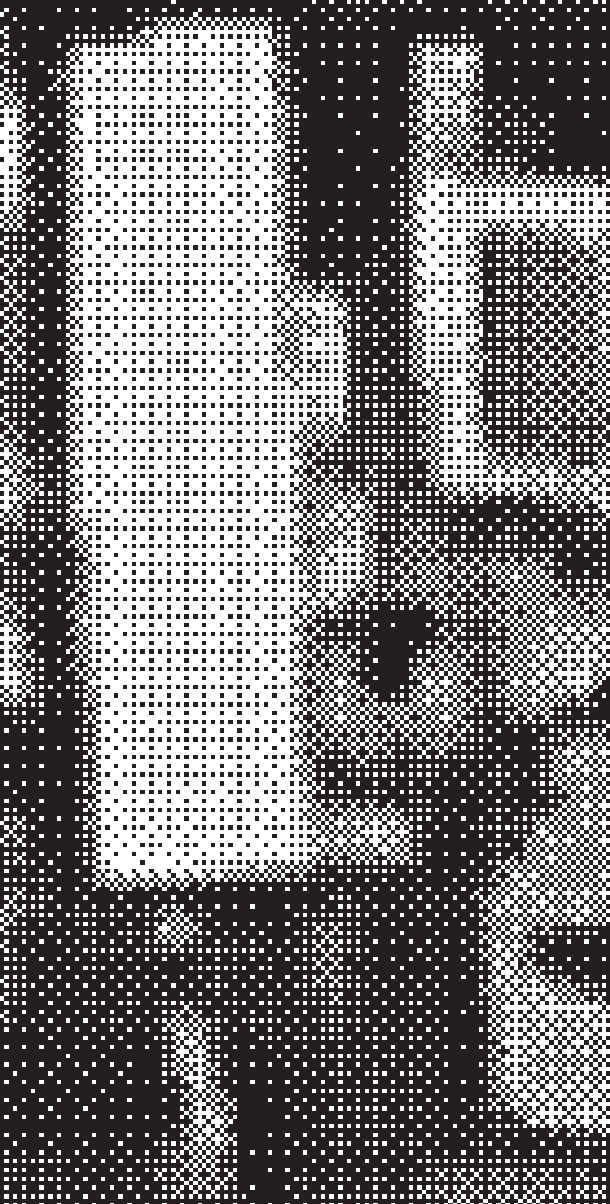

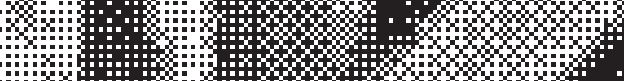

认

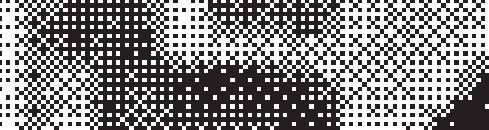
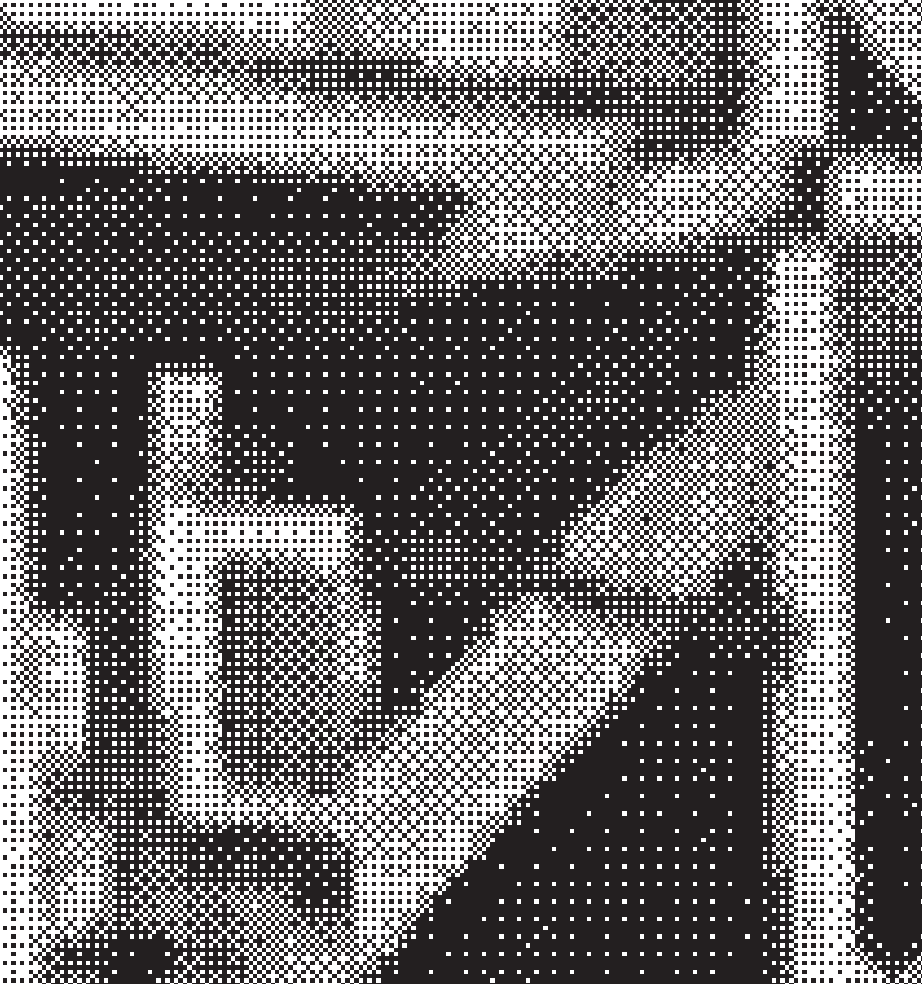

$+2+\frac{1+10}{+1+10}$
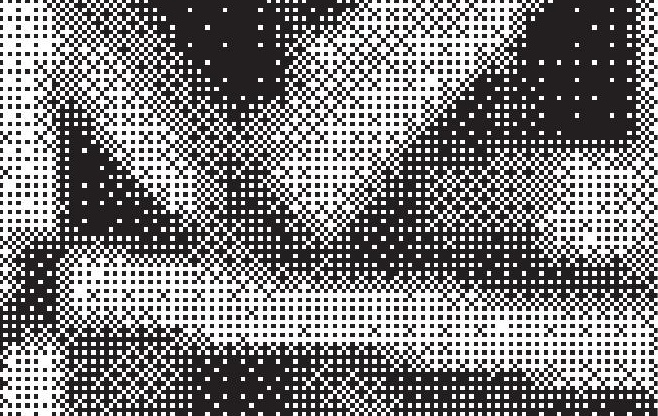

+

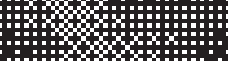

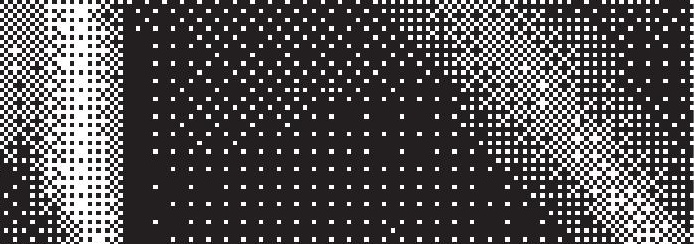

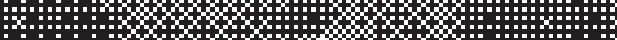

事冓

央

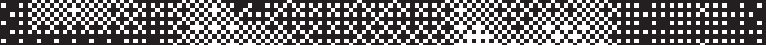

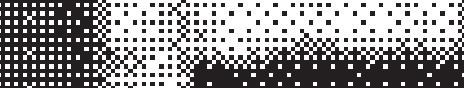

$+\ldots$

3 对

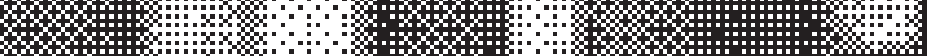

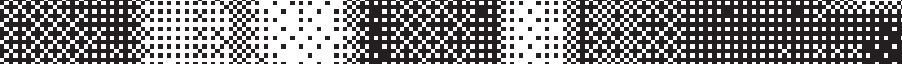

$+1+20$

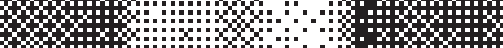

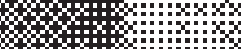

$\because \because 8+4+4+4+4$

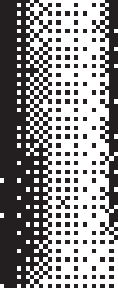
 ' (

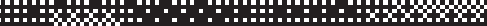

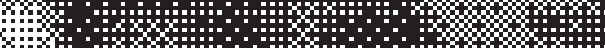
接

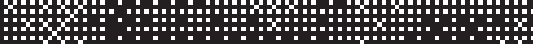

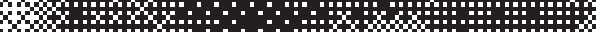
イ

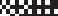

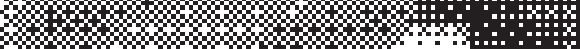

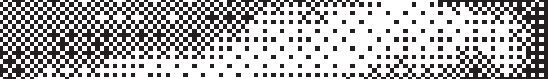
$34200+\cdots$ A

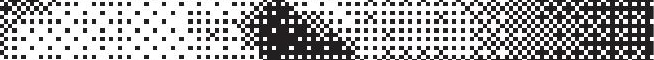

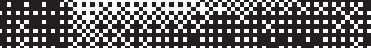
\# (2) 1.:...

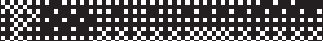

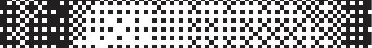

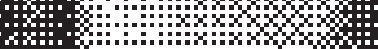
弗. 


\section{A Transparent Architecture of Sign and Symbol}

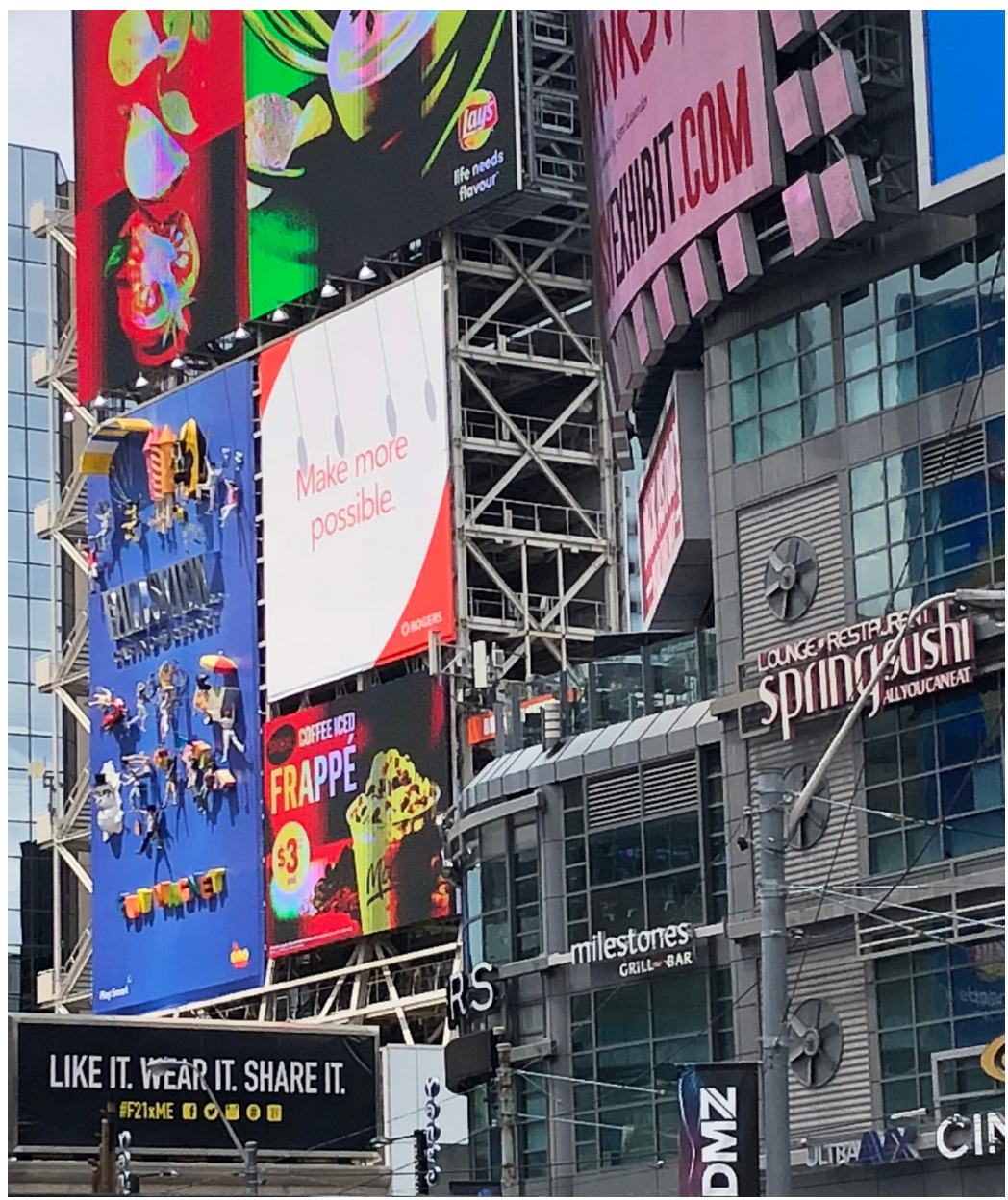

8 Junkspace of Signs \& Symbols at Yonge-Dundas

The complex and contradictory programmatic alchemy of buildings today, have made us dependent on signs and symbols to navigate the mess of a non-straightforward urban environment. From transit stations to shopping malls, billboards to emojis, signs and symbols communicate information that

Munari, Bruno. "A Language of Signs and Symbols." Design as Art, Penguin, 2008, pp. 73. conditions many of our activities today. ${ }^{8}$ And so by taking a semiotic stance to transparency it becomes important to re-evaluate the role of sign, symbol and meaning, not just in architecture, but also in the context of our current contemporary culture. If you take a stroll down any busy commercial street, you will notice a messy aggregation of signs and symbols layered in space, 
competing with one another to be the biggest, brightest, and most attractive sign on the street. The urban environment of today can be characterized as 'a seamless patchwork of the permanently disjointed,' as observed through the critical eye of Rem Koolhaas, in his essay Junkspace9 (8). Despite the seemingly chaotic nature of this urban condition, the mash up of symbolic forms in space generates a rich complexity of meaning that has an attractive pull on people, proving the relevance of signs as being a part of an architectural and urban vocabulary within the built environment. Therefore, the utilization of signs and symbols to convey a transparency becomes significant to making the effects of electronic waste felt and experienced.

Charles Jencks was one of the first to apply a linguistic approach to the understanding of architecture. His assumption was that architecture could be read as a language of semiotic forms. The principal behind this approach is an understanding that any form or sign in language is motivated, or capable of being motivated. ${ }^{10}$ Jencks goes on to state that, 'the minute a new form

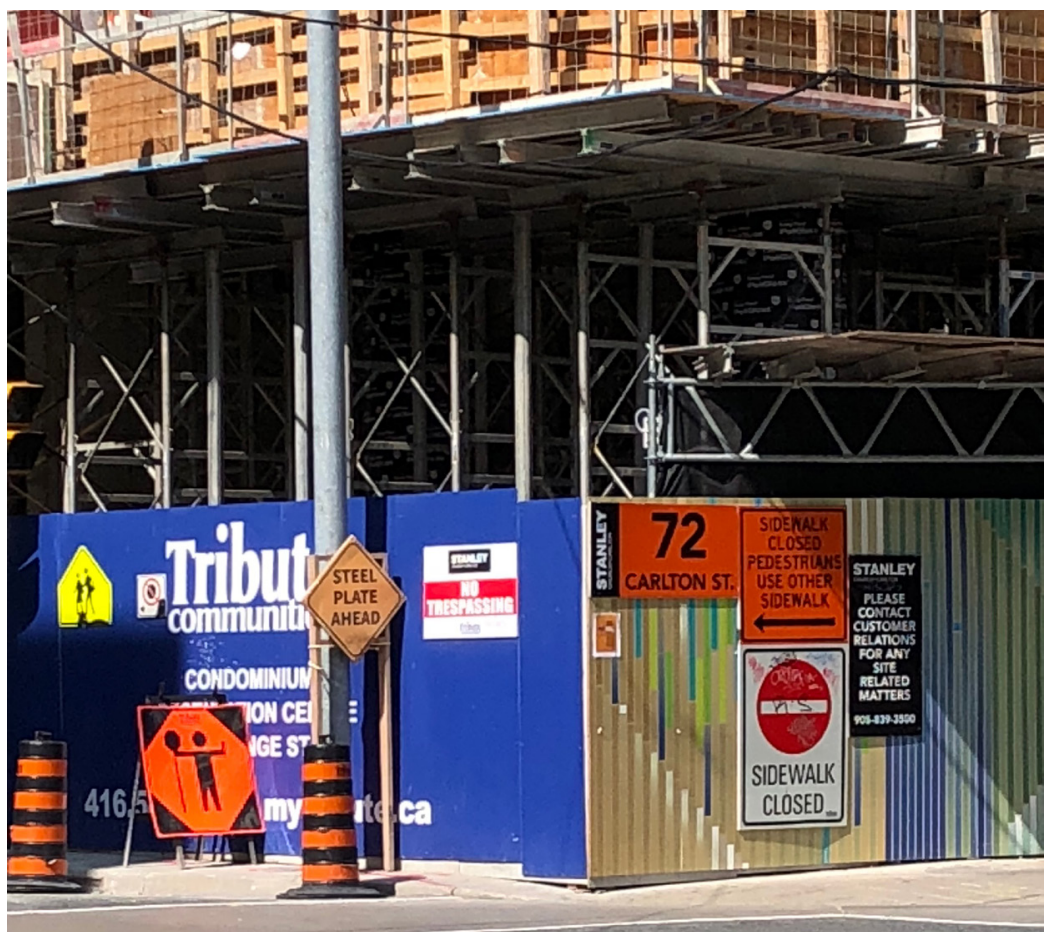

9 The conditioning of signs \& symbols to help us navigate a non-straightforward urban environment
9

Koolhaas, Rem.

"Junkspace." October, vol. 100 , The MIT Press, 2002, pp 175-190.

10 Jencks, Charles and Baird, George. Meaning in architecture. G. Braziller, 1970, pp.11. 
12

Jencks, Charles and Baird, George.

Meaning in

architecture. G.

Braziller, 1970, pp.11.

13

Venturi, Robert and

Scott Brown, Denise

Complexity and

Contradiction. The

Museum of Modern

Art, 1966, pp.23

14 is invented it will acquire, inevitably, a meaning. ${ }^{11}$ And so to contradict the famous design motto of 'form following function', things can't just be functional they will always be condemned to meaning. ${ }^{12}$ Similarly, these ideas paralleled those of Venturi and Scott Brown who have strong convictions about the function of communication in architecture. Together they argued for a 'complex and contradictory' architecture that promotes a 'richness of meaning.' ${ }^{13}$ Their theories regarding the duck and the decorated shed, which was learned from Las Vegas, become significant in re-evaluating symbolism in architecture and its role in communicating meaning, bringing architecture back to its primitive roots of sign, symbol, and shelter. ${ }^{14}$ 


\section{Electronic Iconography}

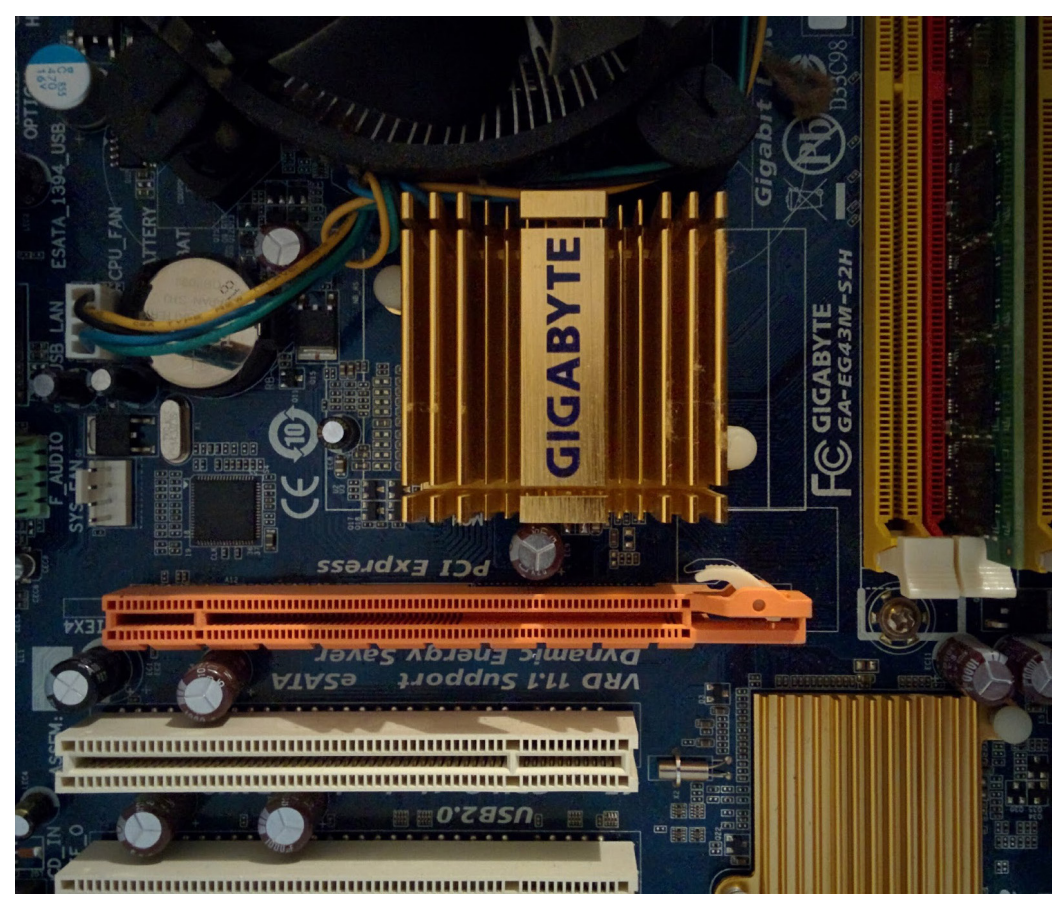

10 Detail shot of a Gigabyte Motherboard

Central to the proposition of making visible the invisible effects of

electronic waste is the assumption that iconography, via signs and symbols, has the capacity to convey a sense of transparency through the confluence of form and meaning. Because of this proposition it therefore becomes a question of deriving an electronic iconography. An iconography whose architecture of form incorporates references to an electronic order that is responsible for facilitating the digital age of information and our connectivity to the World Wide Web. Looking back at the many periods within the history of architecture, it becomes apparent that the tradition has always been to reference an ideal past. If you think of Renaissance architecture, it incorporates references to a classical order, where as Modernism referenced an industrial order, and Post Modernism promoted an eclectic historicist tradition, and so on and so forth. Given that the medium of our time is electronic, do we look back at the electric age as an ideal past that makes reference to the origins of our current digital age of 
information? What is interesting is how we still romanticize about industrial stylistic associations. We have buildings that have been created using digital technologies, but I would argue that the smooth shiny blob-like objects are still very much industrial in character. So where does an electronic aesthetic and iconography fit within this spectrum? Upon this realization, I believe that it only makes sense to look at the physical artifacts of our soon-to-be obsolete electronic technologies, which are integral to the functioning of our current digital world, as inspiration for a possible electronic iconography.

The fascination with the formal qualities of electronic components is comparable to that of the early modernists' attraction to the industrial vernacular of the machine (11). The formal vocabulary of the modern movement was dictated by the axiom of 'form following function,' and as a result, architects explicitly appropriated the engineered forms of automobiles, ocean liners and airplanes, as a means of symbolically representing a brave new world of science and technology, known as the industrial age. ${ }^{15}$ And so carrying on with this tradition, which precedes modernism, as discussed previously, is the appropriation and adaptation of the forms found in everyday electronic objects such as the computer, tablet, and cellphone, as a way of deriving an iconography that is symbolic of the origins of the digital age. These components will be converted into signs of themselves and adapted into architecture with the intention of communicating a transparency that exposes the consequences of electronic waste.
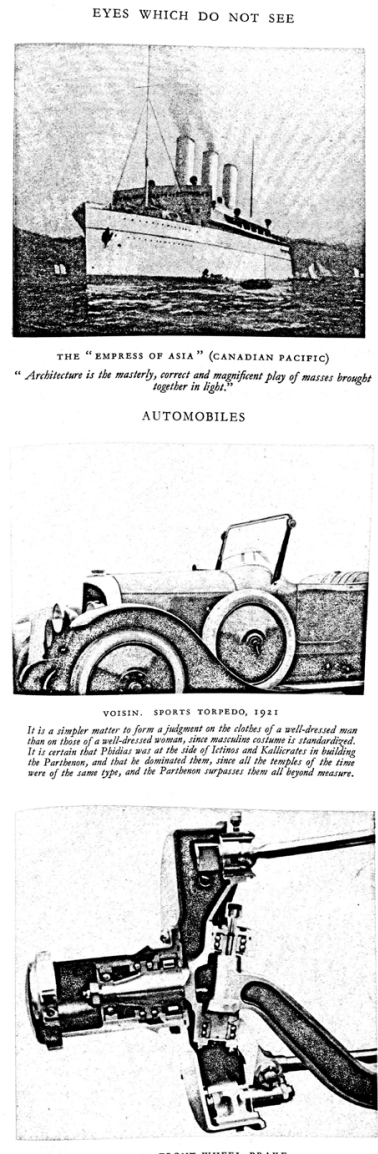
DELAGE. FRONT-WHEEL BRAKB

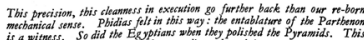

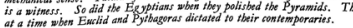

11 Ocean Liner, Automobile, Front-Wheel Brake, 1927. Image courtesy of Towards a new architecture.

\footnotetext{
15

Le Corbusier. Towards

a new architecture.

Dover Publications,

1986.
} 
This train of thought was explored further through the disassembly of old discarded electronics to see which electronic components were worthy of being transformed into a symbolic architecture of electronics. However, before any disassembling could occur I needed to gather a collection of dysfunctional electronics. I was able to source a majority of my electronics from family and friends who had a treasure trove of old vintage electronics just sitting in their basements and storage closets. This habit is common, as many people are unaware of how to properly dispose of their old electronics. When it came time to disassemble the electronics, I was very careful not to break anything, but some of the cases made it inevitable to not take a hammer to it, cracking it open to expose the inner workings. As the parts became smaller and more intricate, the more difficult disassembly became. The experience of this exploration, which initially started out as a iconographic form finding exercise, became very insightful in understanding the difficulties associated with the disassembly of electronic waste. It was clear that electronics were not designed for disassembly, making it difficult to recycle and recover valuable embedded materials, confirming the claims made early on about electronic obsolescence.

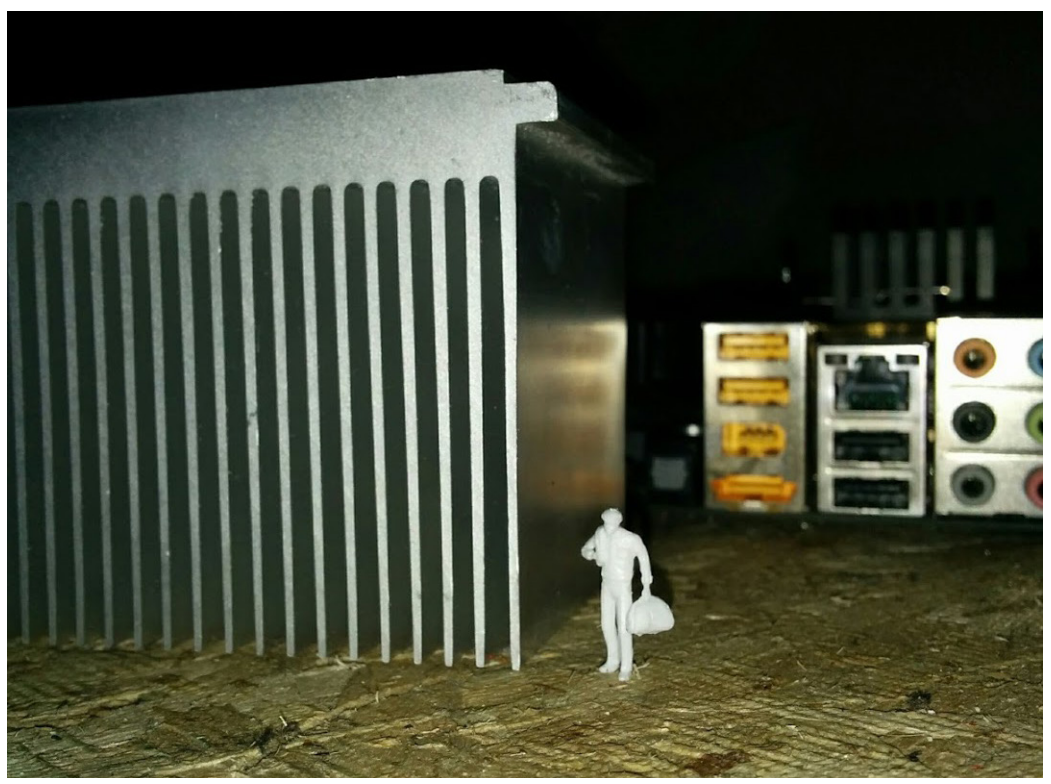

12 Architectural scale figure standing next to a heat sink 


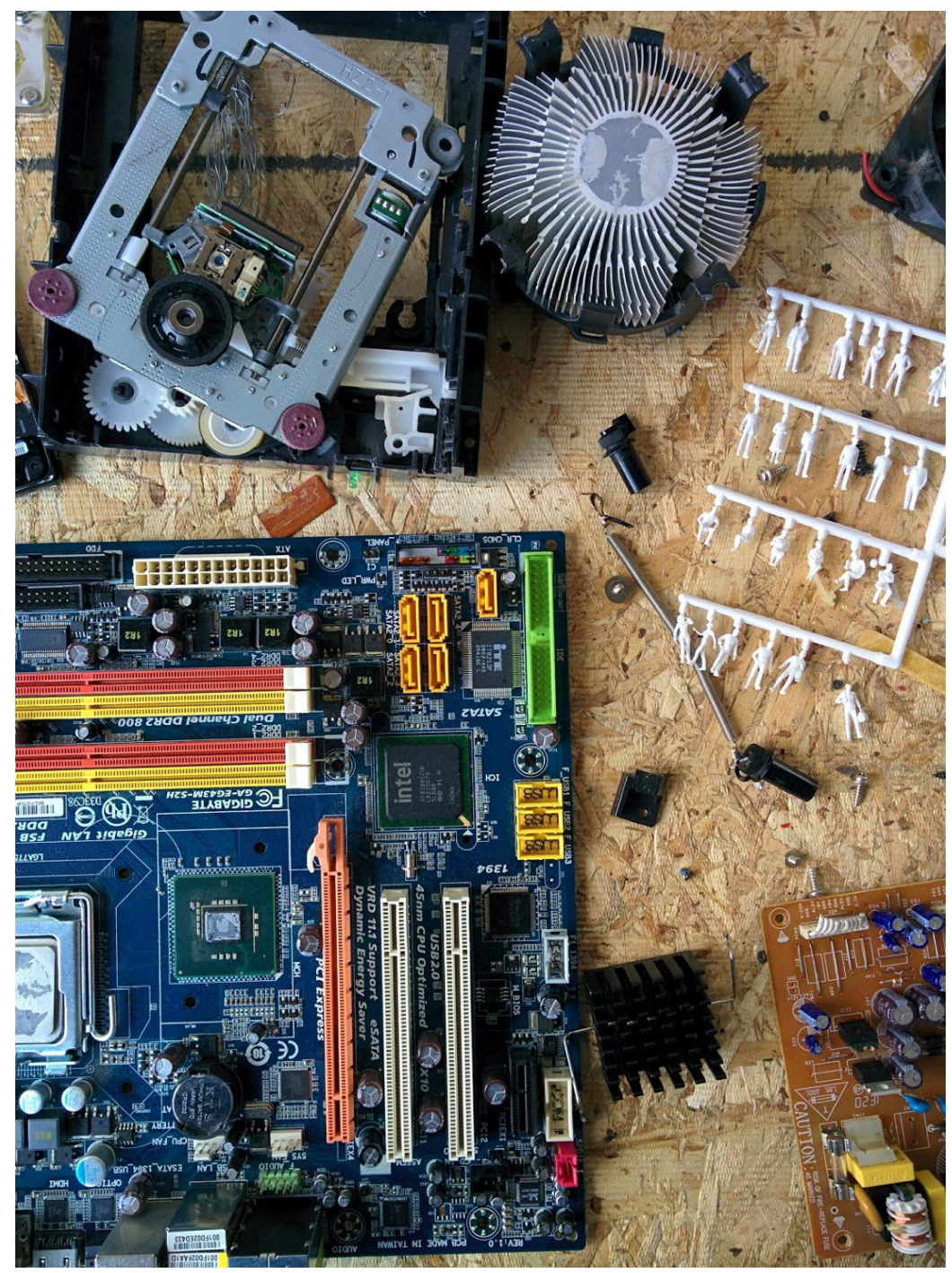

13 The disassembly of an assortment of electronics 
Once the disassembly process was complete, I was then able to step back and see what I was able to extract from these discarded electronics. Seeing an assortment of electronic parts and components in their deconstructed state elicited a desire to reconstruct them into something entirely new. The forms of these electronic components captivated me for they possessed an architectural quality to them that instantly ignited the imagination. The most interesting forms were the heat sinks, as they naturally lent themselves to be easily scaled up and re-imagined as a building. I was also captivated by the circuit boards and motherboards for their functional layout and organization. The reality, however, is that these components are mostly hidden and rarely seen, bringing up an earlier analogy I made between electronic devices and the industrial big box, as being containers that hide their true inner essence. Therefore, the proposition of using the discards of electronic waste as the literal and symbolic form for an e-waste facility, in many ways, exposes and makes transparent that which is hidden, in an attempt to create a public value and legibility for e-waste in the city.

Furthermore, the photomontage of a computer motherboard as a proposal for an electronic waste recycling facility is a provocation that deserves a closer examination (14). For one, the motherboard is a type of organization that may very well be obsolete one day. But also, the motherboard is an organization that is arguably responsible for organizing our current society and the ways in which we live our lives. As I've said before, the physical artifacts that facilitate our digital world are responsible for organizing society without us even being aware of it. The motherboard is designed for the sole purpose of the efficient movement of electrons. But is it coincidence that the layout of a motherboard is analogous to the layout of cities? Regardless, the method of approaching electronic waste as a found object to be used for architectural purposes allowed for the use of the motherboard as a organizing framework to structure the site of an electronic waste recycling facility. 


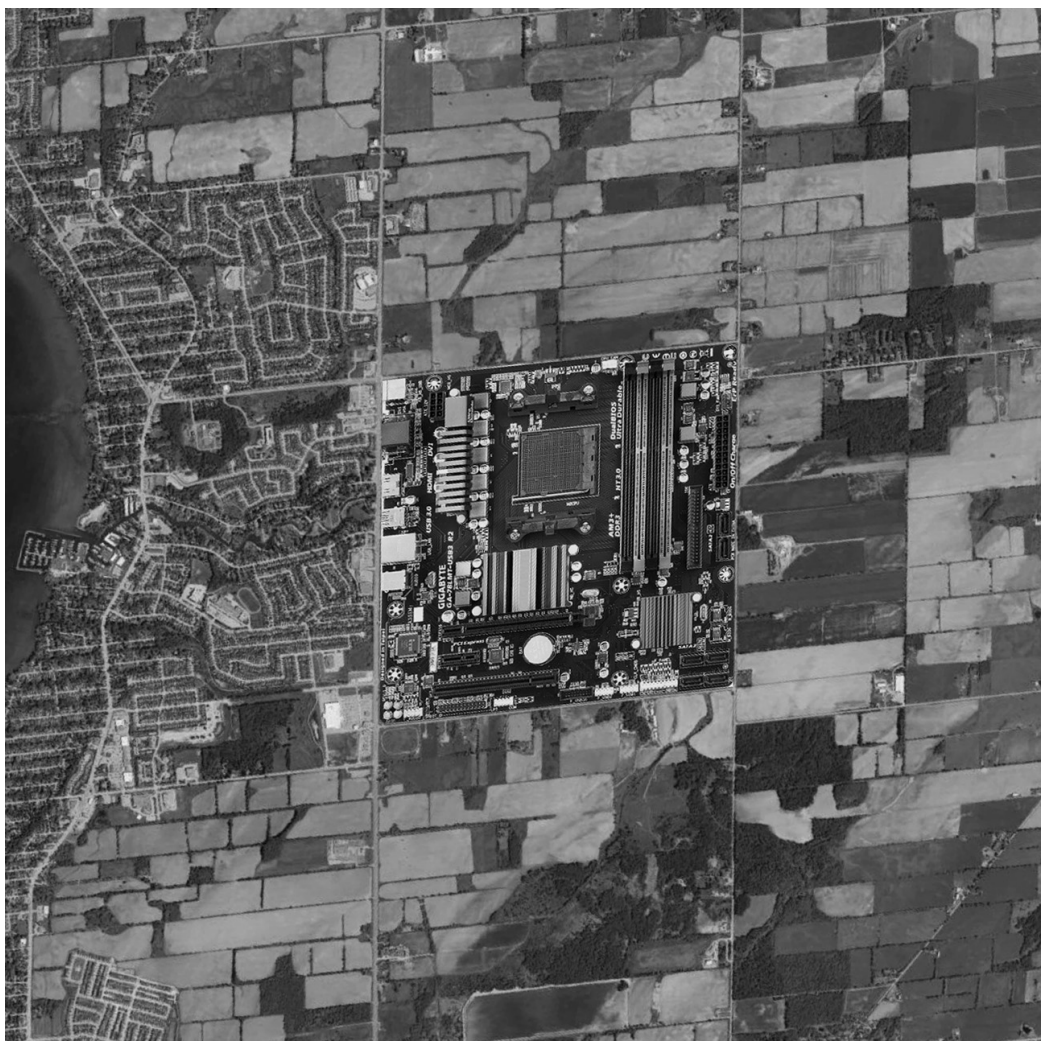

14 Proposal for an Electronic Waste Recycling Facility

The re-imagining of these discarded electronic components as an

iconography of electronics upon a generic architecture, engages electronic waste in new and unconventional ways that are not simply pragmatic.

This approach addresses many issues on different levels, such as defining an aesthetic for e-waste that gives it legibility, as well as issues concerning invisibility and the need for transparency by exposing these unfamiliar forms. Making the forms of e-waste the signs and symbols that are able to communicate a transparency by making them the buildings we inhabit on a day-to-day basis. In this case, to borrow an idea from Marshall McCluhan, the medium is the message. ${ }^{16}$

16

McCluhan, Marshall. "The medium is the message." Understanding media: the extensions of man, McGrawHill, 1964. 

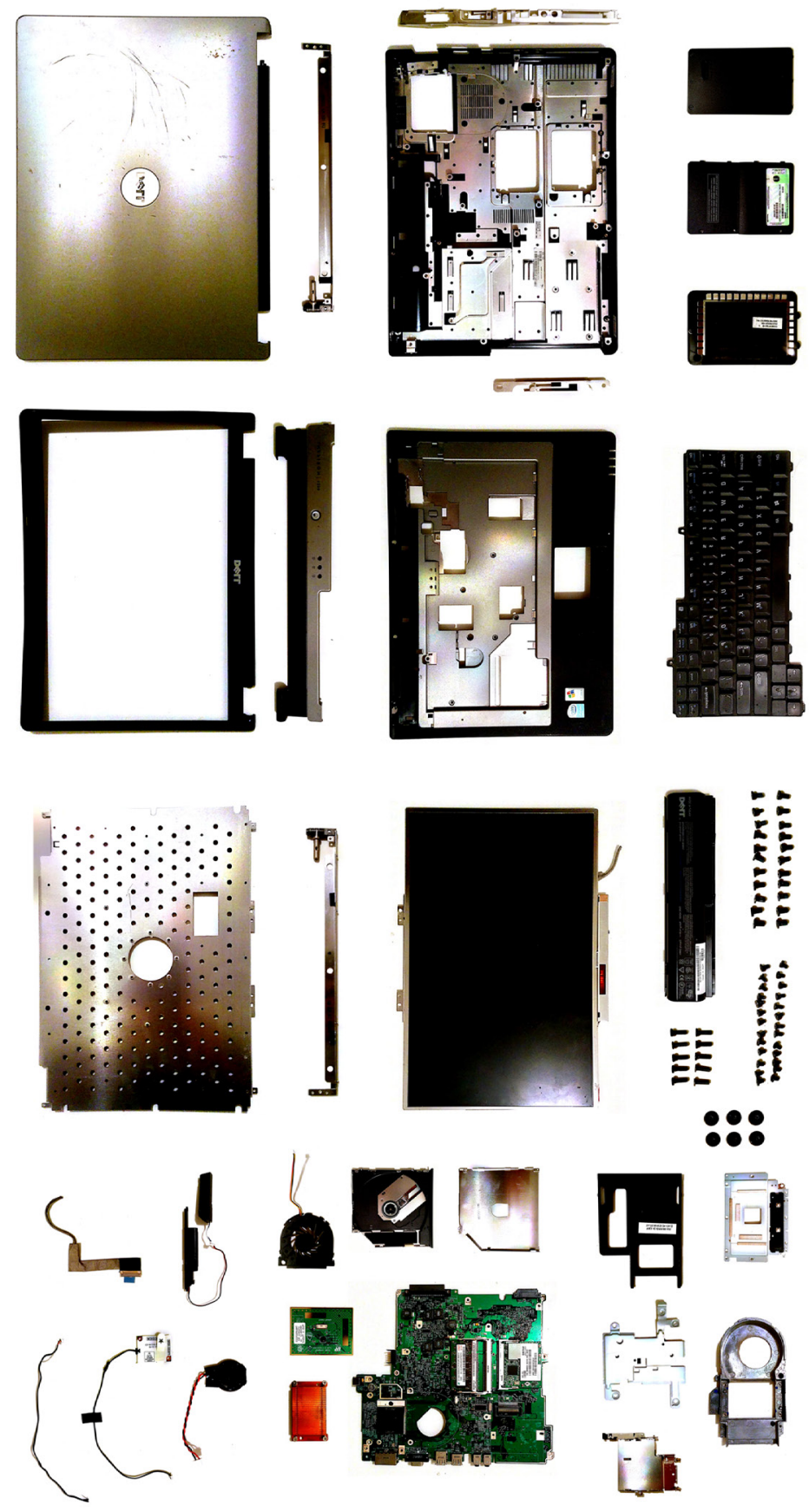


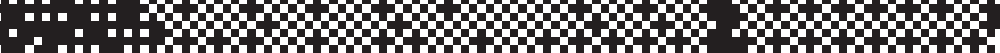

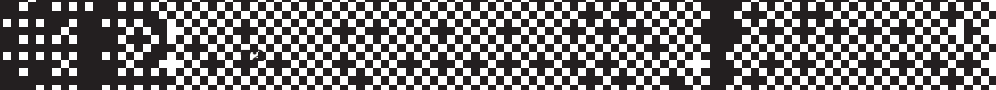

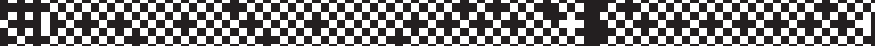
r c ×

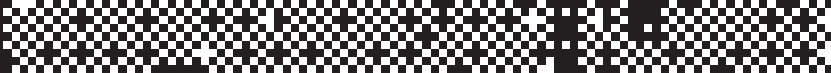
2012010

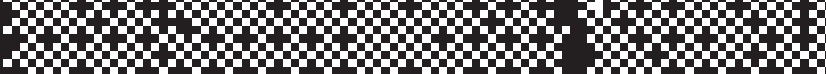

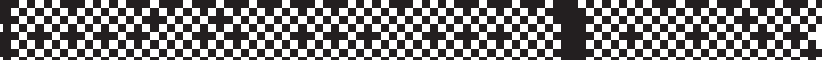

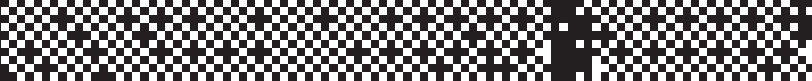

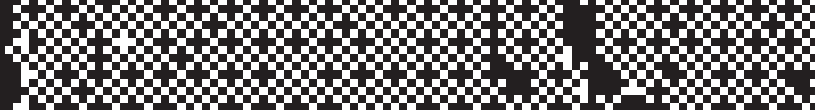

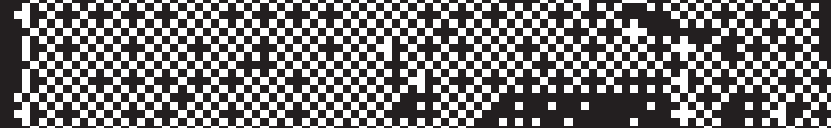
201020102010

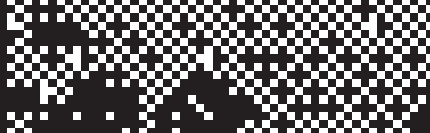

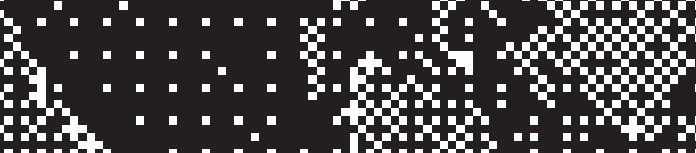

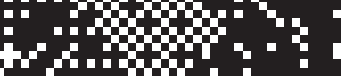

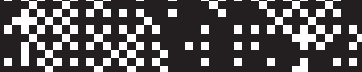

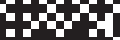

굴.

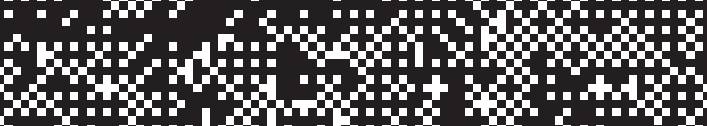

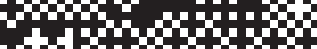

IS

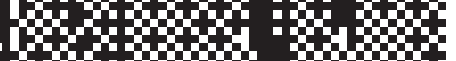

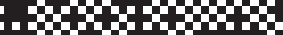

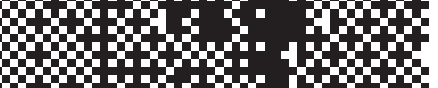

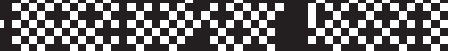
202010 2014

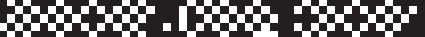
20102 200120 120 $2021+2002$ 2019 20120 12012

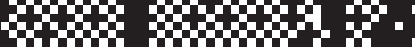
2012 2012 201019.

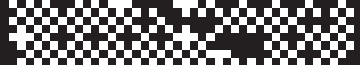

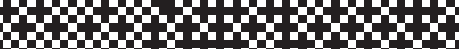

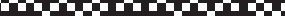

2001 -

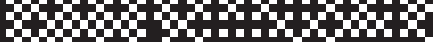

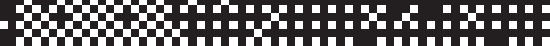

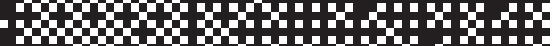
2020

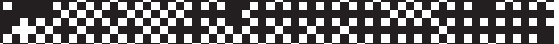

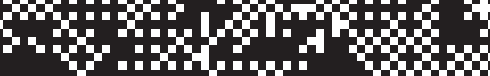
: ram

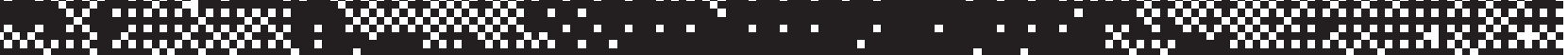

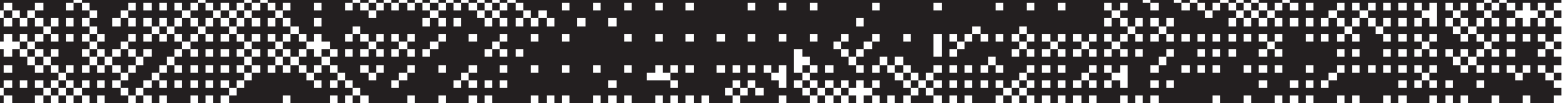

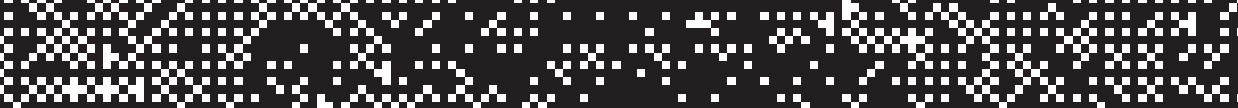

$$
32
$$

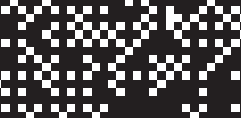

$20201+19$

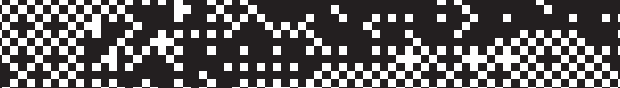

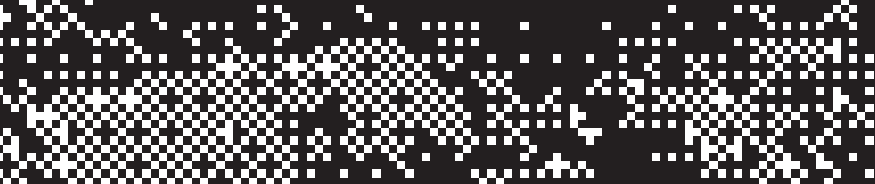

\section{$20+1+2$}

$\$ 2$

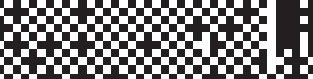

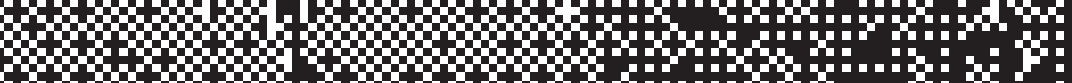

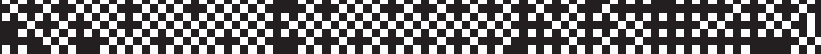
2in

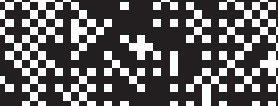
"

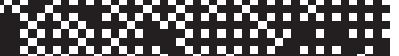




\section{Electronic Billboards Are All Right}

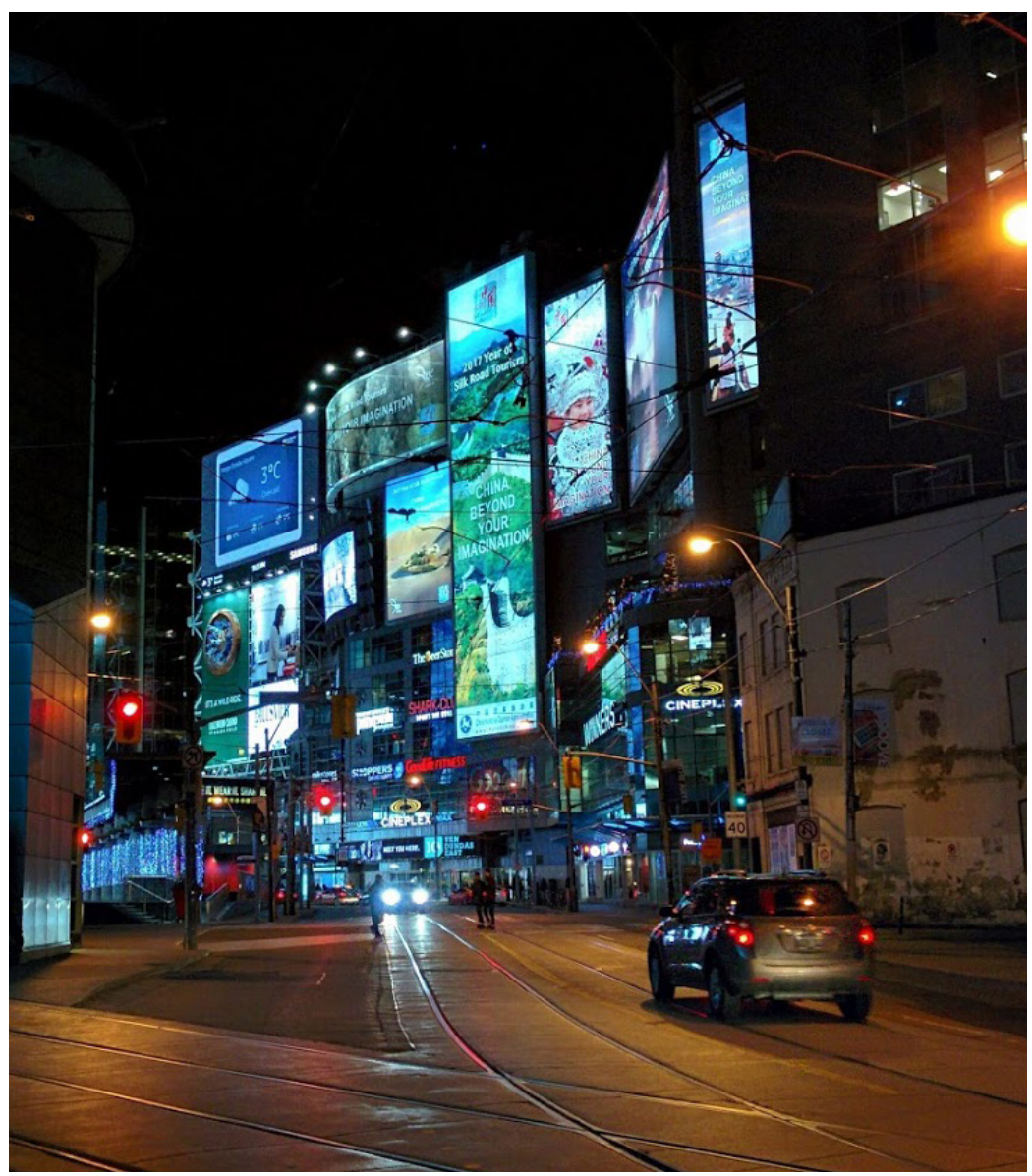

16 Yonge-Dundas Electronic Billboards at night

With the speculation of transparency and iconography being focused mainly on a sculptural form that is a symbol (duck), It's also important to acknowledge the application of symbol onto a surface or generic shelter (decorated shed), as yet another means in which to communicate transparency. If capitalistic consumption is arguably one of the main proponents that motivate the exponential rise of electronic waste, then it would be worthwhile to take a closer look at the mechanisms behind an architecture of commercial persuasion, for the sake of subverting the billboard in an attempt to confront the invisible presence of electronic waste in our built environment. 
Observing the effectiveness of the electronic billboard screen in capitalist cities is quite fascinating from an architectural point of view. What is explicitly clear, in contemporary environments such as Yonge-Dundas Square, in Toronto, is the overwhelming amount of electronic signs, screens and billboards, that act in a similar fashion to the screens of our phones, laptops, and tablets. Displaying colorful moving images at one hundred times the size of our own personal devices. These larger than life billboards engage the curious gaze of those in the space. They are able to engage its viewers in a way that is relevant to how we relate to the world around us, which is behind the screens of our electronic devices. And so if the problems associated with electronic waste will only be strongly contested if the effects are felt and experienced, then the electronic billboard screen becomes the appropriate medium for this message.

To many, Yonge-Dundas Square is a violation to the very public-ness of public space. The aggressive assault of advertisements turn the square into a privately owned public space unworthy of being called architecture. ${ }^{17}$ But if we were to look at it purely from an architectural point of view, an argument can be made for the billboard as architecture.

If form follows function, and communication is a function of architecture, then the billboard can be characterized as a legitimate architectural element. The billboard draws many parallels that link it to a historical tradition within architecture. From Egyptian temple exteriors with hieroglyphs etched in stone to the beautiful interior murals and mosaics of Roman basilicas. (16) Love it or hate it, what you observe at Yonge-Dundas Square is part of a long architectural tradition of projecting ornamental signs and

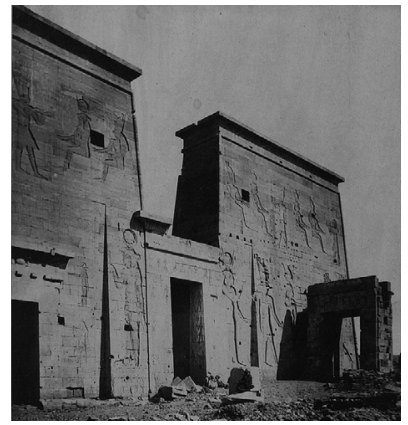

17 Temple of Isis on the Island of Philae, Egypt, 1875, Photograph by Antonio Beato. Image courtesy of Library of Congress. (www.loc.gov/ pictures/item/2003690008/)

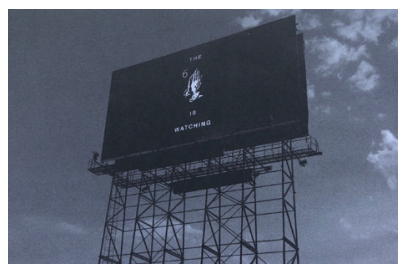

18 Billboard along Gardiner Expressway, Toronto, $\log , \mathbf{2 0 1 5}$, Photograph by Em Cheng.

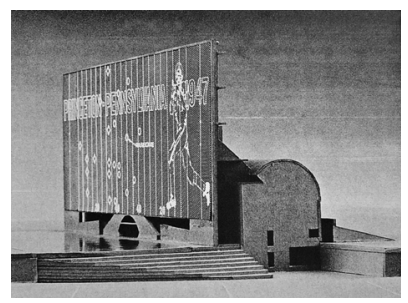

19 A Bill-Ding-Board for the National Football Hall of Fame Competition, New Brunswick, MIT Press, 1967. Image courtesy of Venturi Scott Brown Associates.

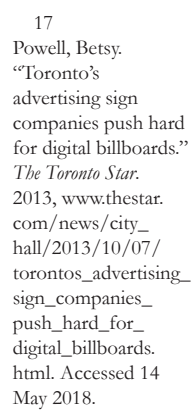


18

Venturi, Robert. Iconography and Electronics Upon a Generic Architecture. The MIT Press, 1996, pp.4.

19

Loos, Adolf.

"Ornament and Crime." Crime and Ornament: The art and popular culture in the shadow of

Adolf Loos, edited by Bernie Miller and Melony Ward, YYZ Books, 2002, pp.29-36.

20

Venturi, Robert and Scott Brown, Denise. Learning From Las Vegas. The MIT Press, 1972, pp. 9.

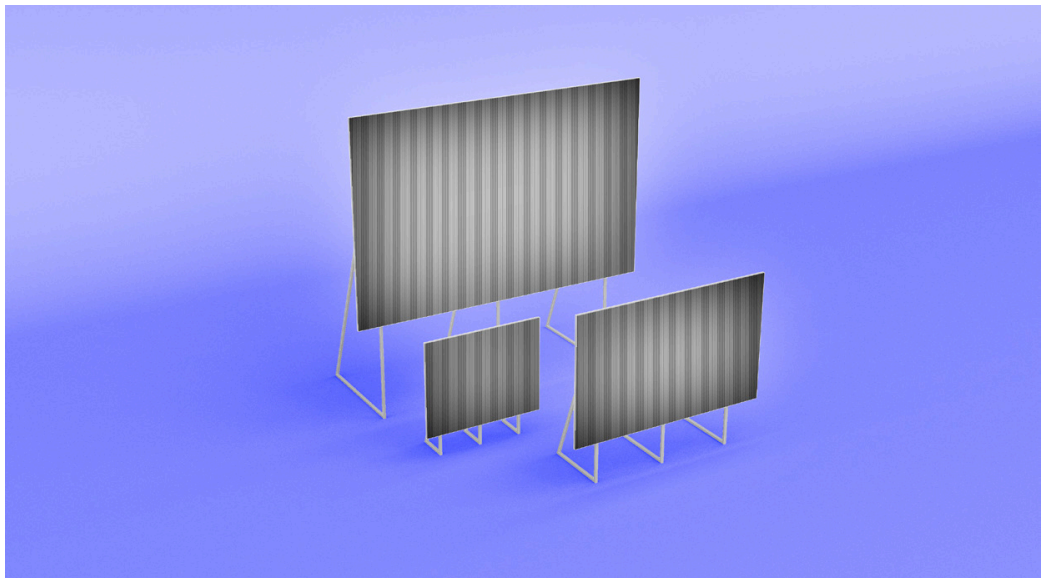

20 Electronic Billboard Screen Speculation

symbols onto generic surfaces to communicate meaning. The difference however between ornamentation via static decoration and ornamentation via electronic screen, is the ability for the electronic screen to continuously change its information, image, and thus its meaning over time. ${ }^{18}$ With this newfound possibility never witnessed in the history of architecture, and to contradict the views expressed by Adolf Loos, I would like to think that the electronic screen as an information surface decriminalizes ornament from being a crime. ${ }^{19}$ In this contemporary environment, it is not form that defines space, but rather it is the sign and symbol in space that dominates the urban context of today. ${ }^{20}$

All things considered, within the context of this thesis, there is value in investigating the application of electronic screens as ornament or information surface in the form of a large billboard (19). Furthermore, projects such as Venturi and Scott Brown's unbuilt proposal for the National Football Hall of Fame competition, serve as a precedent for the combination of billboard and building (18). It is neither but both simultaneously. The hybrid of sign and building helps to enrich meaning and communication in architecture and presents itself as an appropriate response to making the effects of electronic waste felt and experienced, in a way that appeals to society's sensory overload through bold stimuli of flashing lights and moving images. 


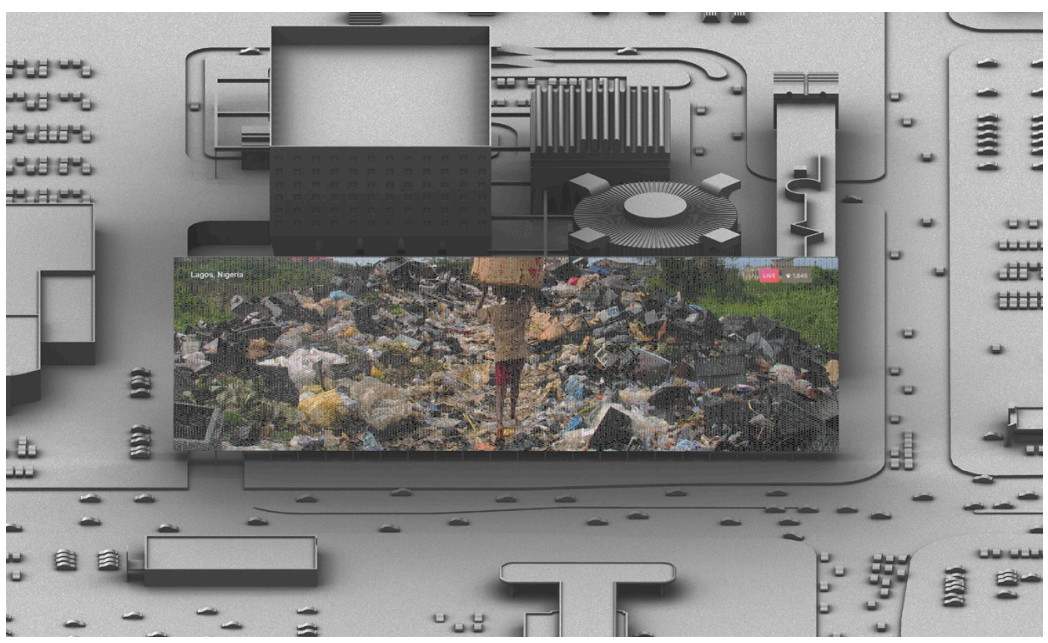

21 Live-Streaming Digital Dumps as a radical proposal to make the effects of e-waste felt and experienced

Like a Roman triumphal arch, the billboard exemplifies a deliberate formula for viral appeal and becomes a site-specific message that engages the act of witnessing or monitoring, as noted by architect Em Cheng, on her observations of Drake's billboard ${ }^{21}(17)$. The ability for a billboard to communicate a complexity of meaning, across space and time, becomes significant when considering the spatial separation between places of waste and places of consumption. As a result of being out of sight from one another the billboard creates a space of contestation and discourse for e-waste. And so as a radical proposal, I thought of the possibility of live streaming the digital dumps of the world on a large billboard as a way to collapse the space between waste and consumption in order to directly confront the producers of e-waste, making the effects felt and experienced. It may sound like an extreme proposition that would cause a lot of controversy, but I do see value in expanding the use of billboards in architecture as communication, ornamentation, and inhabitable space. Speculating on the fusion of architecture and media technology forming new hybrid possibilities, the electronic billboard screen offers yet another critical response that allows us to rethink the role of ornamentation and surface facades. ${ }^{22}$ When symbol applied to architecture is combined with symbol as architecture, the aim is that it would lead to a greater transparency and thus forming an ecology between e-waste, culture, and the city.

Cheng, Em.

"Observations on Log, no. 38, Anyone Corporation, 2016 pp. 150 


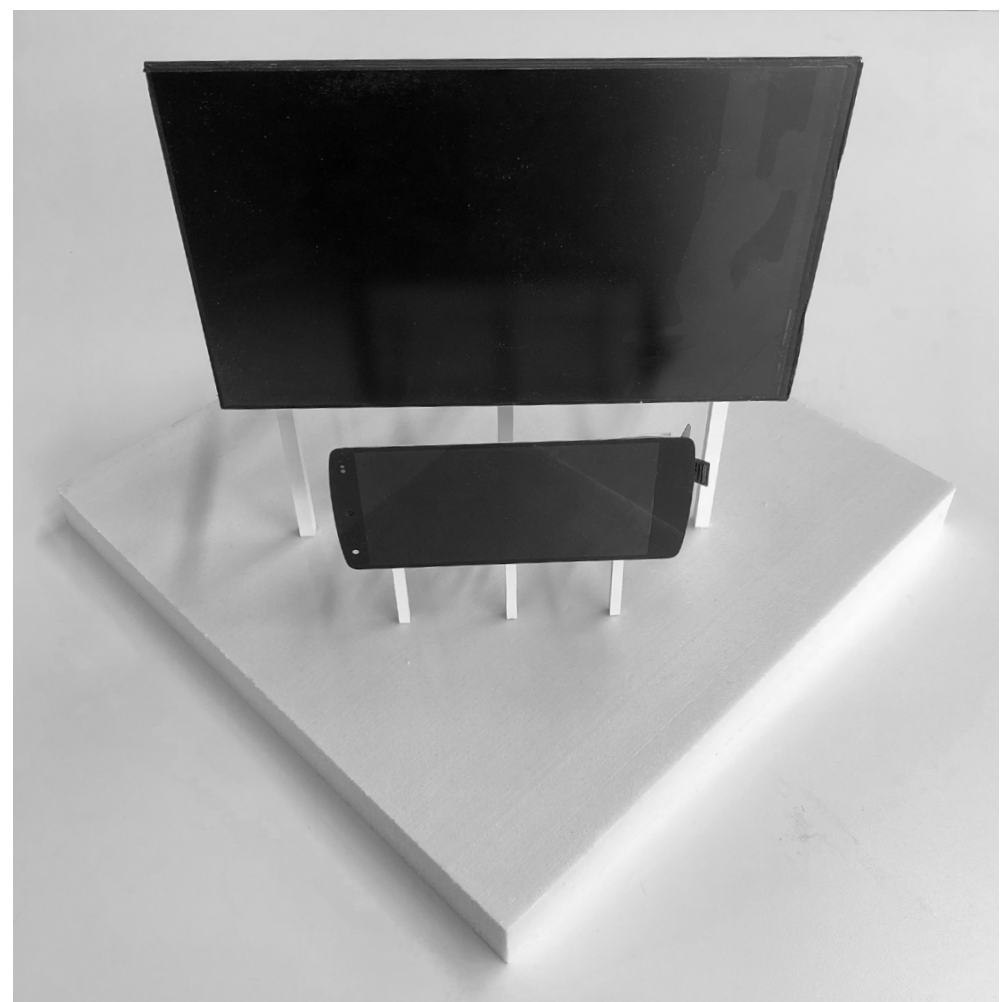

22 Design research: Exploring the electronic screen of our mobile devices as hybrid between ornamental surface, billboard sign, and building. 


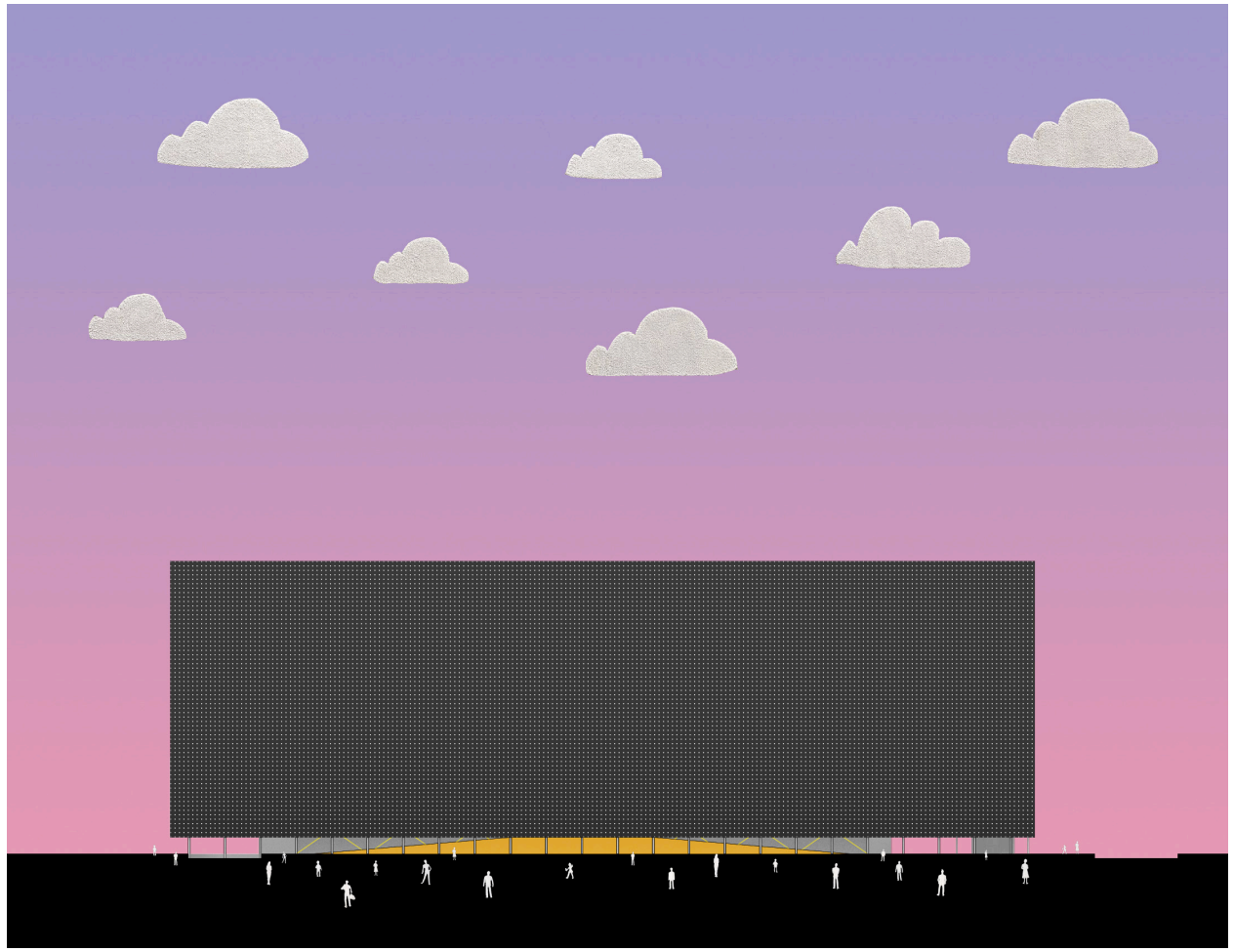

23 North Elevation: The overstated billboard building fronting Eglinton Avenue provides a generic surface to project a multiplicity of images/ornament/symbols to communicate meaning across space 


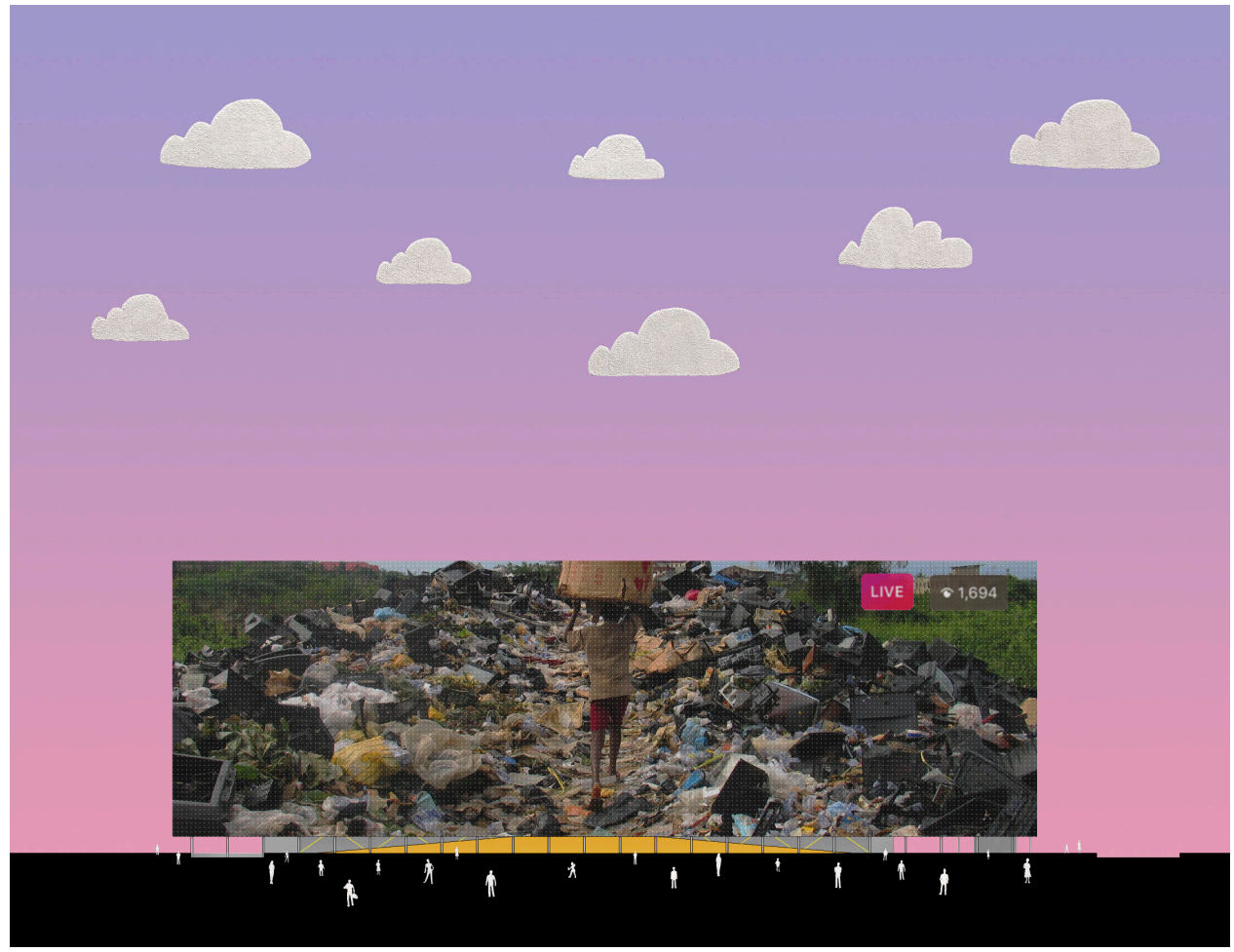

24 Image projection \#1: Live-stream of digital dump in Accra, Ghana. Collapsing the space between waste and consumption. 


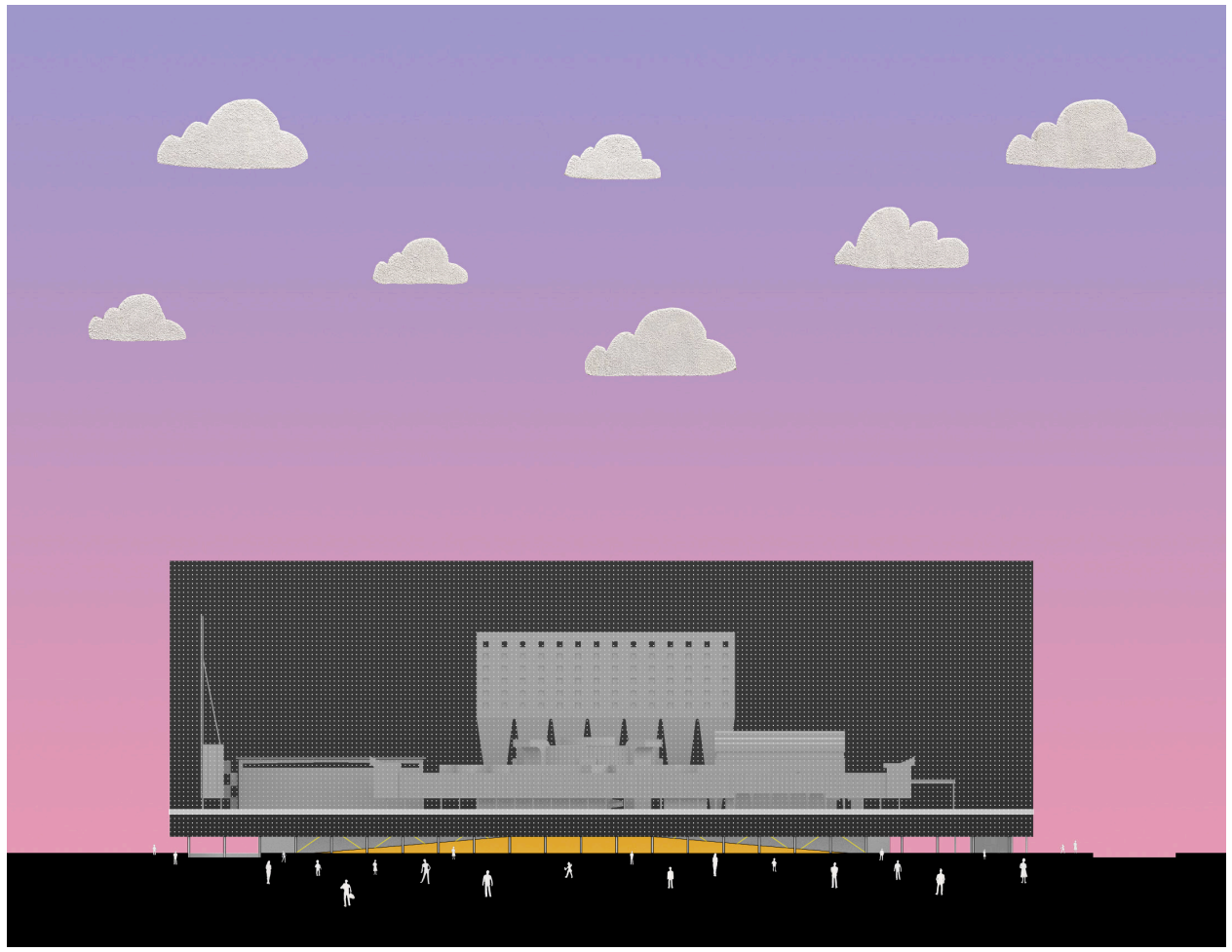

25 Image projection \#2: A live-feed of the West Elevation projected onto the North Elevation. Demonstrating a phenomenal transparency that overcomes space-time fixations to achieve a multi-perspective view. 


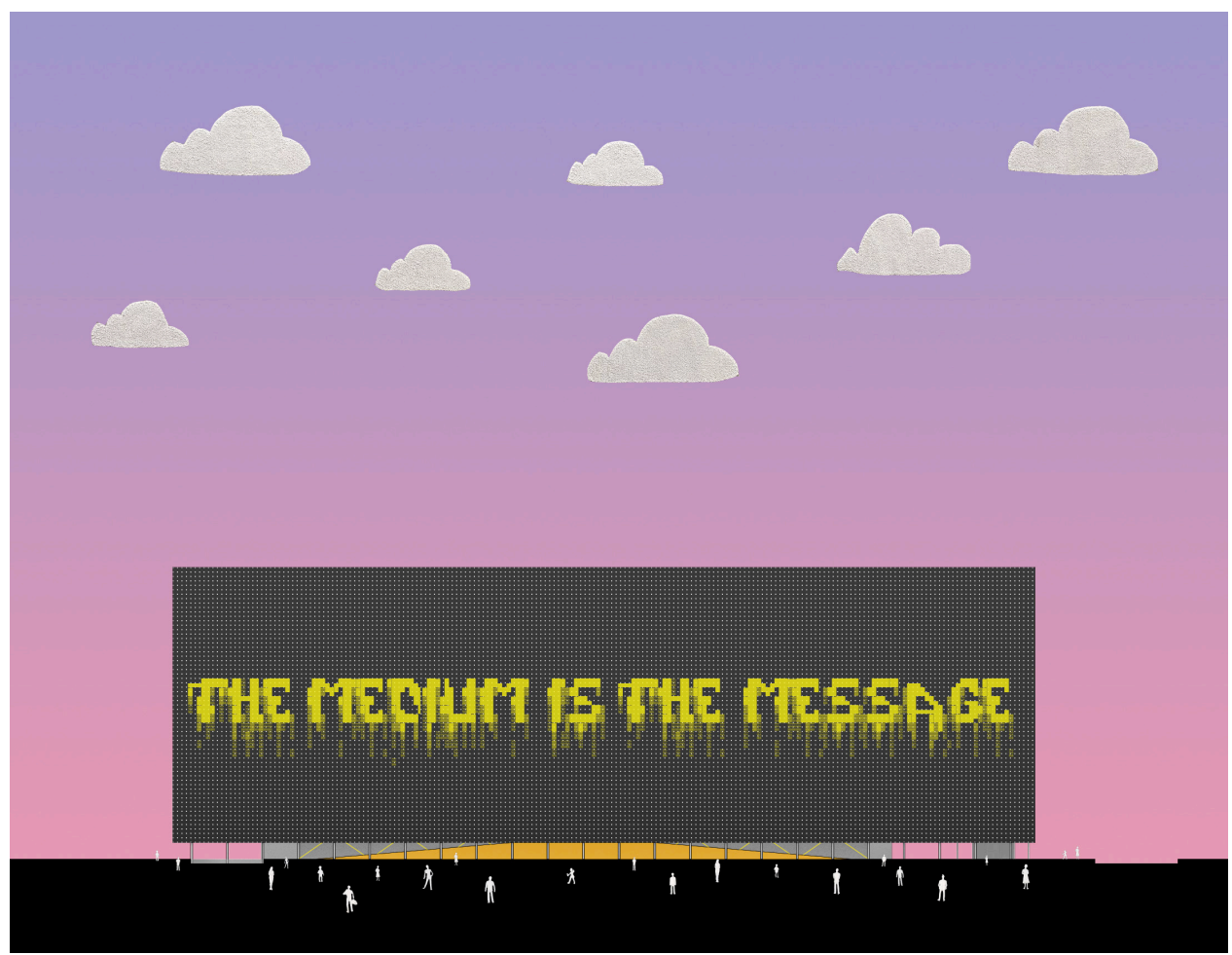

26 Image projection \#3: Traditional Use of Electronic Billboard Screen to Project Messages 

8 


\section{Collage Thinking: Un-make to Re-make}

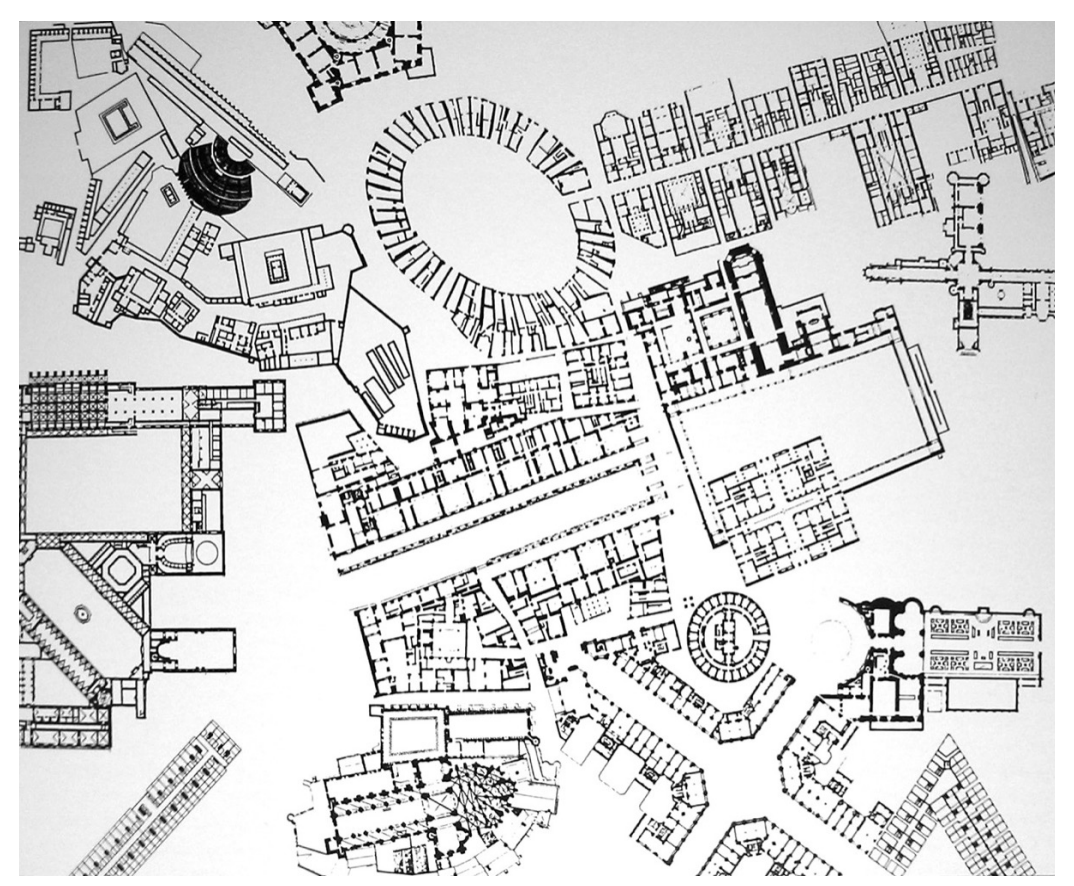

1 City of Composite Presence, MIT Press, 1978. Image by David Griffin and Hans Kolhoff.

The intention of demonstrating an iconographic transparency through signs and symbols provokes an argument for architecture to also apply the methods of collage, as a possible approach that can lead to the formation of an architectural project from the excessive accumulation of electronic waste. Electronic waste therefore becomes the source material that is found, disassembled, sampled and then reassembled to derive the architecture of an e-waste recycling facility. This type of approach that deals with electronic waste in relation to the production of space becomes an appropriate

23

Nicholson, Ben.

"Collage Making." Appliance House. The MIT Press, 1990, pp.16.

\footnotetext{
24

"Collage." Online Etymology

Dictionary, 2001, https://www. etymonline.com/ word/collage.
}

response, as the process of collage "occupies a disruptive position by using trash and deadness to form beauty."23

Collage comes from the French word, 'coller', which means, 'to glue.' ${ }^{24}$ Conceptually, a collage is a technique used in the production of art in where an assemblage of various pieces is combined to create a new whole. Within this newly assembled whole, the parts that were fragmented and taken 
from their original context retain their resemblance and are therefore still easily recognizable. However, this time the parts are distorted and slightly out of scale. Assemblages of varying parts, were taken from different sources, suggesting that the original source of the fragments were unmade, in order to be remade again.

The application of collage thinking in architecture is certainly not new. In fact, quintessential to the architect's main role is the organization of a unique whole by utilizing the conventional building elements that are available and introducing new elements when the old no longer functions as intended. ${ }^{25}$ This has been exemplified throughout the history of architecture as fragments from classical Roman vocabulary were sampled and collaged in new evolutionary architectural combinations. The architect therefore, by way of organizing fragmented parts and conventional elements, creates a meaningful context for them within what Venturi and Scott Brown characterize as the difficult whole.

Collage is an exercise in composition and the careful relationships of form and scale between objects. The figurative art of sculpture or painting is interchangeable with that of architecture and the art of construction. The still life paintings of Le Corbusier were an incessant search for "balance between the elements and harmonious relationships between parts," just as the drawings of Aldo Rossi represent a "poetic composition of autobiographical elements of the real and of the imaginary" ${ }^{26}(2,3)$. As an early design exploration, these portraits of a possible e-waste facility were created using the collage method by making architecture through the process of sampling (4).

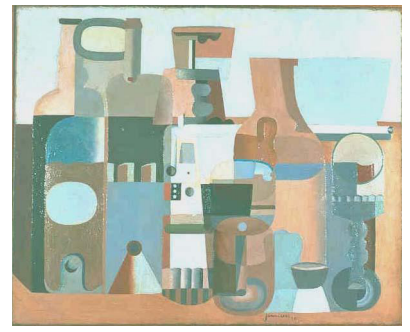

2 Still Life of the Pavilion of the New Spirit, Jeanneret, Paris, 1924. Image courtesy of Le Corbusier Foundation

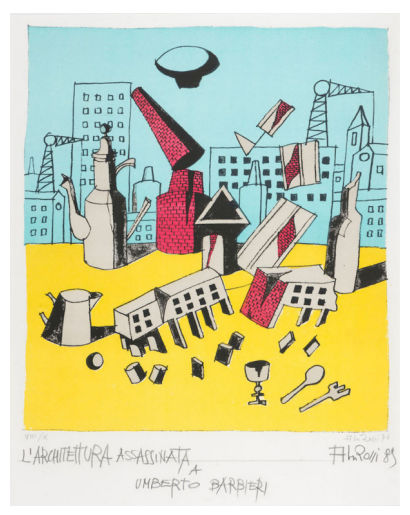

3 L'Architettura Assassinata, Aldo Rossi, 1976. Image courtesy of the private collection of Morris Adjimi.

25

Venturi, Robert and

Scott Brown, Denise.

Complexity and

Contradiction. The

Museum of Modern

Art, 1966, pp. 49

26

Nicholson, Ben.

"Collage Making."

Appliance House.

The MIT Press,

1990, pp.16. 

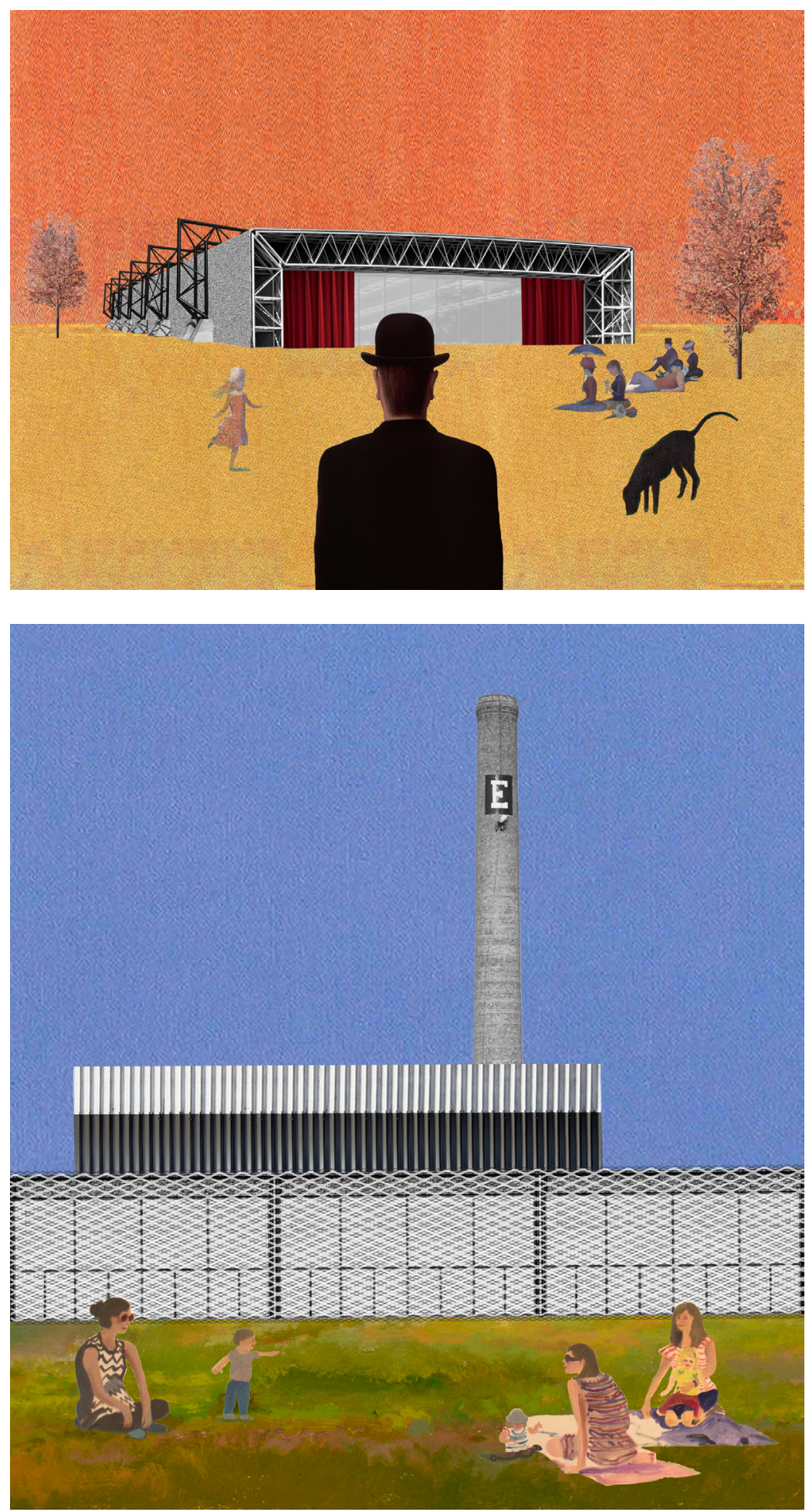

4 Portraits of a possible E-Waste Recycling Facility 
A good guiding analogy for the way that I am thinking of electronic waste in relation to the production of space is this video game called Katamari Damacy, which was released back in 2004. In Japanese, 'katamari', means 'clump, while Damacy is derivative of 'tamashii', which means 'soul'. So the literal translation of this game is "clump soul." The storyline is essentially about a King of All Cosmos, who goes on a drunken spree destroying the universe, resulting in the displacement of stuff, putting them in places where they don't belong. The premise of the game is for the hero, a small prince, to right this wrong by rolling this adhesive ball called a Katamari, around various locations, collecting enough stuff for him to remake the moon and all the stars. This interpretation may come across as a hyperbolized analysis, however the simple premise of this video game serves as a good allegory for the use of bricolage in relation to the formation of a critical architectural project from the excessive accumulation of electronic waste. In this game, waste doesn't just move through the world, but actually makes the world, demonstrating the making of space from waste in the most literal sense (26).

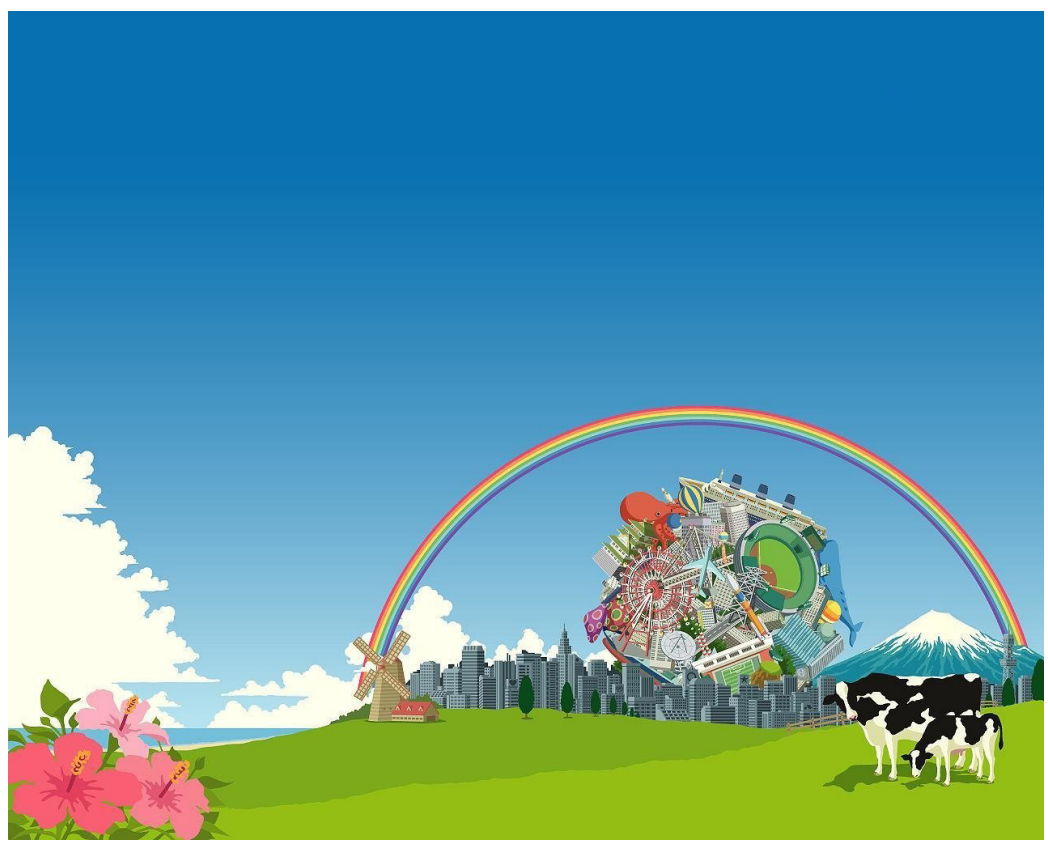

5 Box Cover Art of Katamari Damacy, Namco, 2004. Image courtesy of Namco. 


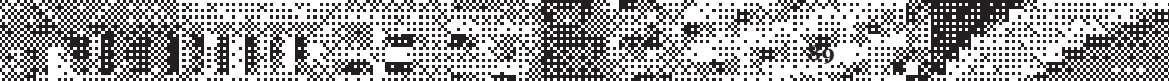
(3) (3)

) (1)

(1)

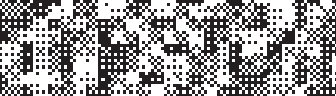

(1)

(1)

(1)

稓:

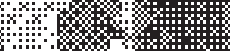

(2)

(1)

1)

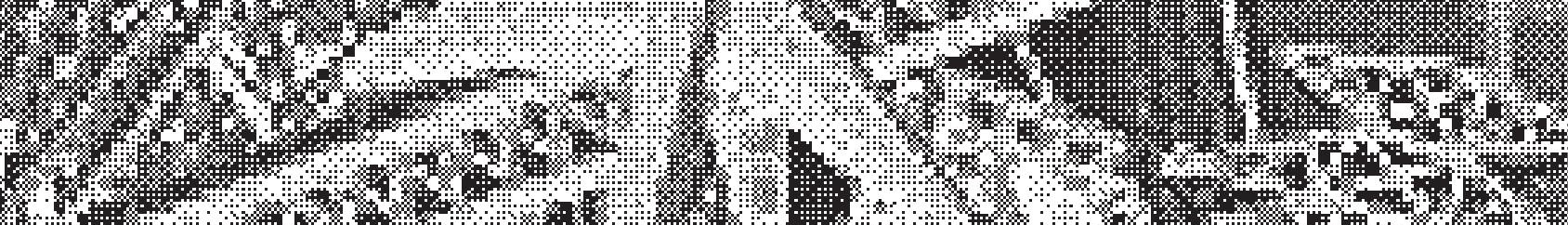

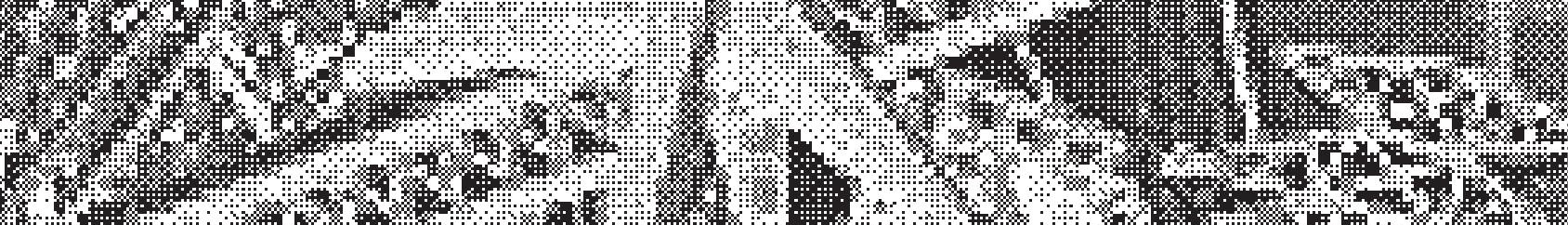
(l)

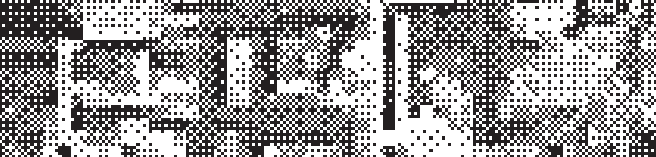

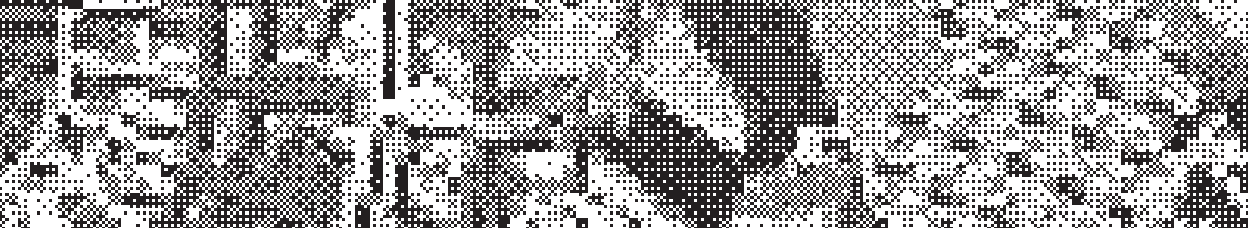

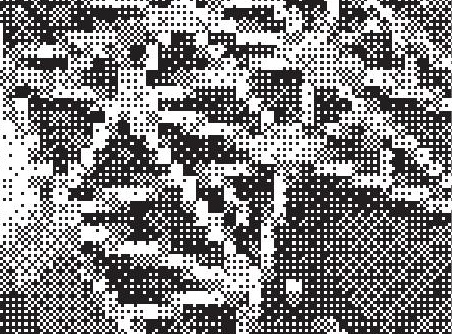
(3) (1) (3) (x) (1)

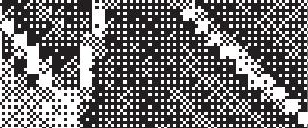
का (1) 


\section{Sampling Found Objects for Architectural Purposes}

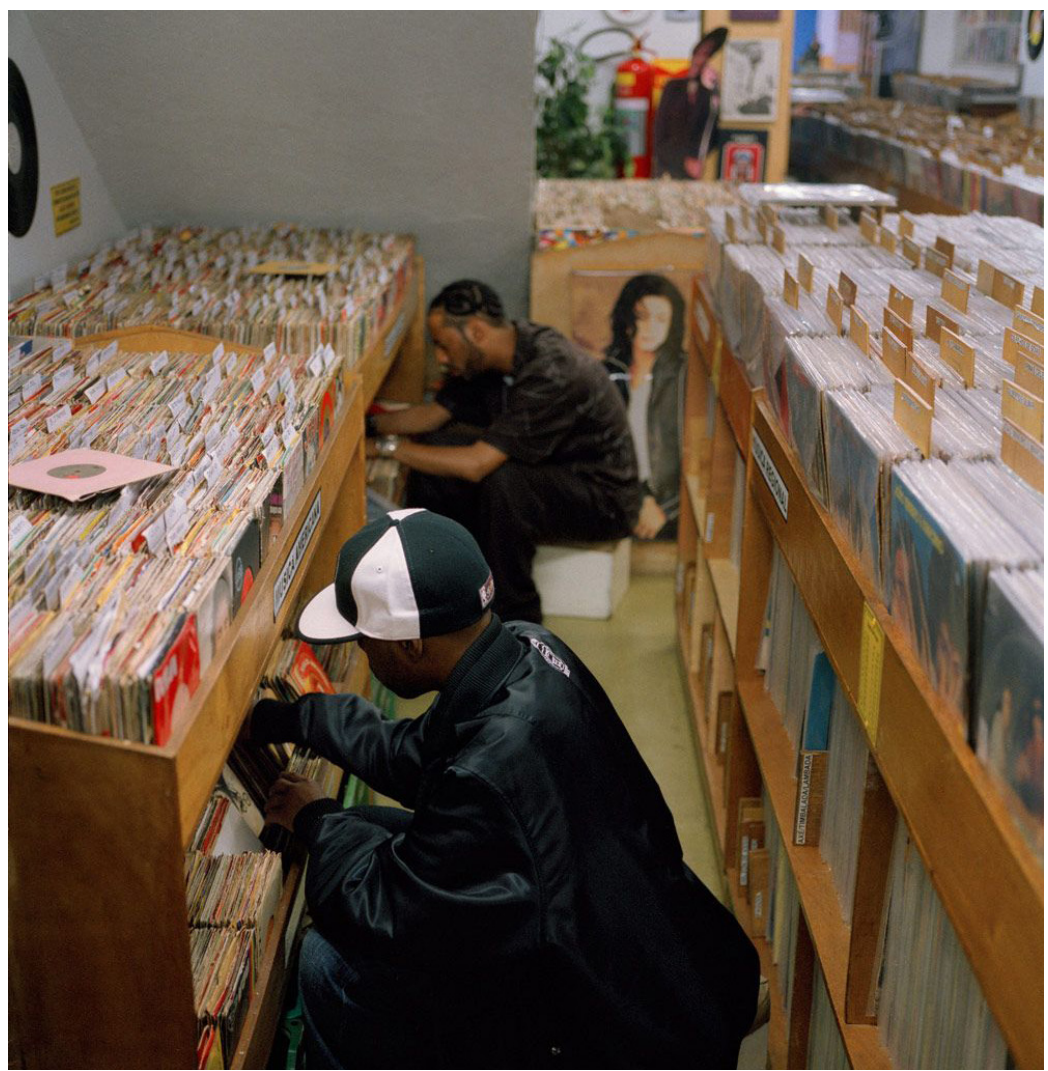

6 Madlib and J Dilla digging for records in Brazil, Stones Throw Records, 2005. Photography by Brian Cross.

The anthropogenic era, in which we find ourselves in today, has lead to the creation of millions of manufactured objects, whose sheer quantity and variety is threatening to outclass nature for diversity. How does one go about sorting through an overwhelming amount of stuff brought about by our current consumptive and material culture? Using DJ's and producers as an allegorical metaphor that can be applied to the collection, sorting and sampling of found electronic objects, these "crate diggers", as they are known in the music community, are a particular species of the modern day consumer, searching endlessly for the obscure and overlooked. Aggressively rummaging through dozens of unorganized crates of vinyl, they exhibit a great deal of patience, and a keen eye for discovering the neglected and forgotten (27). The criteria of their search is not specific or particular, but 
Kovacs, Andrew.

"10 Steps for

making architecture

from architecture."

Office of Kovacs,

https://o-k-o-k.net/

UNFOLDING-

PAVILION.

Accessed $18 \mathrm{Apr}$

2018 . rather it is motivated by the act of discovery and a desire to find records, sounds, loops, or drum breaks never before sampled. The idiosyncrasies of these musical diggers of sound prefigure a position taken in regards to sorting through found objects. To borrow the ideas of architect, Andrew Kovacs, if architecture is a way that we organize the world around us, then sampling found electronic objects is about recognizing the detritus of electronic waste and rearranging that material towards architectural purposes. ${ }^{27}$

To look upon electronic waste as lost objects that are out of place, while simultaneously viewing them through the lens of semiotics, allows one to find and rediscover its meaning (7). When the found electronic object is brought together by a logic that disturbs the status of the individual components, the collage is able to make apparent what is unapparent by re-signifying a meaning to the fragments of electronic waste.

Sampling the forms of electronic components and thinking of them as symbols, repositions these objects as an iconography that is capable of communicating an awareness about our electronics in a way that exposes and makes transparent the parts which are often hidden. Taken a step further, if these forms are distorted and scaled up to the size of a building

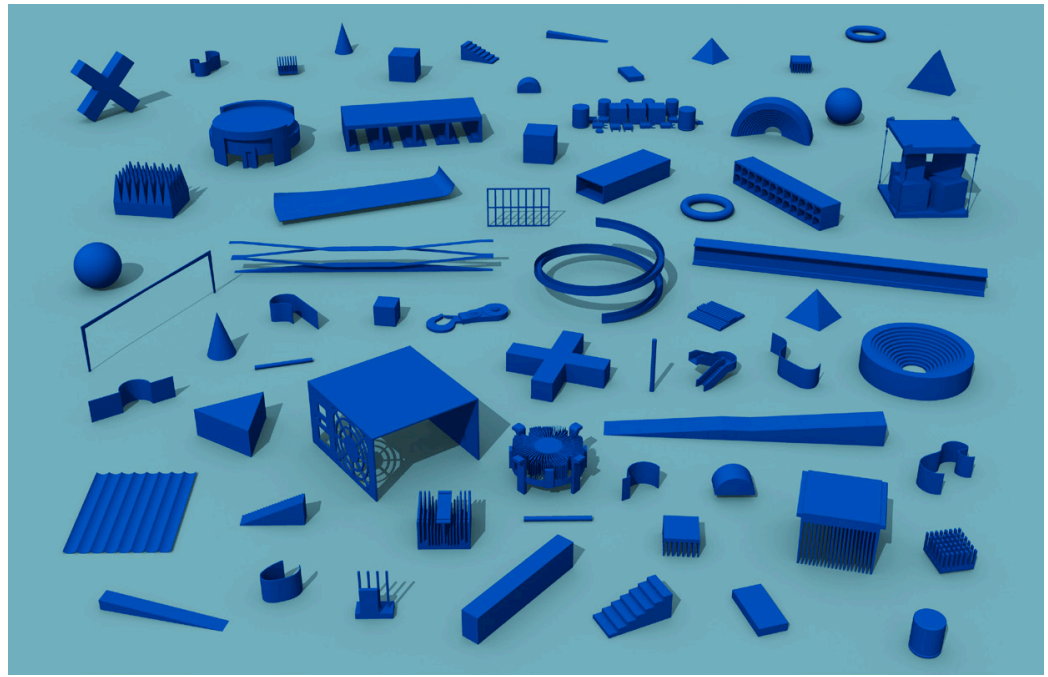

7 A collection of objects waiting to be sampled for architectural purposes. 
it changes our relationship to our electronics and gives us a better understanding of the inner workings, even if it is only achieved through the formal appearance. To quote Venturi and Scott Brown, "like all effective symbolic images, they are intended to look familiar and unfamiliar." 28

For the architect of the 21 st century, "creating the new may mean choosing from the old or existing." ${ }^{29}$ This approach to waste is not new, as pop artists are known to use juxtaposition and irony, playing between new and old associations that give us alternative interpretations of $21 \mathrm{st}$ century cultural artifacts. This is most evident in the work of Marcel Duchamp and his ready made sculptures, which challenged the authority of the art object and inspired a whole generation of modern artists $(8,9)$. If it is necessary for a pop artist to use material that is directly associated with the age in which they live, then electronic waste and all manufactured objects of our time represents a mirror world to our contemporary existence, forming an endless source that can and should be sampled for architectural purposes.

As architectural service providers we never truly own anything. We are owned by our clients and the corporations that decide how much a sheet of drywall costs and what size it comes in. So to acquire found objects for architectural purposes is a decisive action that subverts this very notion of control put upon architects, in terms of the types of building materials that we have at our disposal. This observation is not only meant to be conspiratorial of the junkspace and excessive accumulation of our material culture, but rather it is a call to recognize the unique ability of architects to turn a model into a building or a building

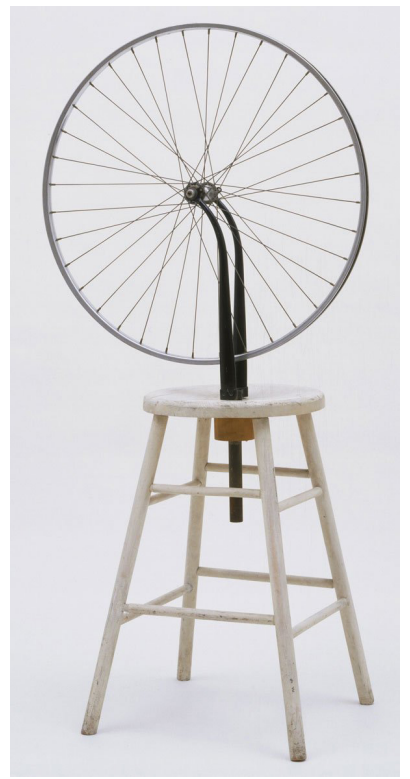

8 Bicycle Wheel, Marcel Duchamp, 1951, Museum of Modern Art. Image courtesy of MoMA.

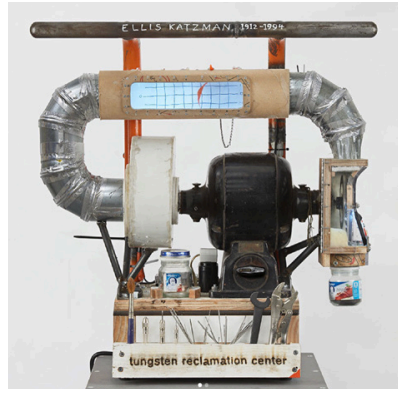

9 Tungsten Reclamation Center, Tom Sachs, 2012. Image courtesy of Tom Sachs Studio. 28

Venturi, Robert and Scott Brown, Denise. Learning From Las Vegas. The MIT Press, 1972, pp. 66.

29

Venturi, Robert and Scott Brown, Denise. Learning From Las Vegas. The MIT Press, 1972, pp. 1 
into a model. It is this shift in scale that allows one to take the fragments of electronic waste and to imagine them at the scale of a building.

The imaginary quality of electronic waste, in relation to the production of space, affords us the possibility of re-imagining an e-waste recycling facility in new and unconventional ways that are not simply pragmatic. Therefore it became necessary to diverge from conventional thinking in order to act inventively. Invention is the founding principle of the creative practice of sampling and utilizing the found object in works of art. To invent is "to find and discover lost or hidden things." 30 The ability to look at the nominal

"Invention."

Online Etymology

Dictionary, 2001,

www.etymonline.

$\mathrm{com} /$ word/invent.

31

Braghieri, Nicola.

"A Small, Portable

Lexicon." Objets

Trouves. Edited by

Phlipp Schaerer,

EPFL, 2015, pp.22. width and depth of our material culture will allow us to rediscover the detritus of our electronic waste and the objects which have been lost to the "incessant stratifications caused by the natural passage of time." ${ }^{31}$ Sampling found objects for architectural purposes is finding the force of invention which has the capacity to disassemble and reassemble the meaning between new and old, in a way that can profoundly alter our perceptions of electronic waste as, not waste, but as resource. A resource not only bounded strictly to materiality, but seen also as a source of inspiration for deriving architectural form.

The approach of sampling in architecture is fundamental to the way an artist creates using trash or the way a maker is able to makes something from what is readily available. Sampling in architecture takes a curatorial approach by first collecting, disassembling, reassembling and appropriating electronic forms through the process of collage. This method is heavily informed by the way scavengers are finding inventive ways to reuse the detritus of electronic waste in order to transform it for their own purposes. For the purpose of this thesis I am scavenging for lost and obscure electronic objects for the architectural purposes of designing a Centre for Electronic Waste and Resource Recovery. 


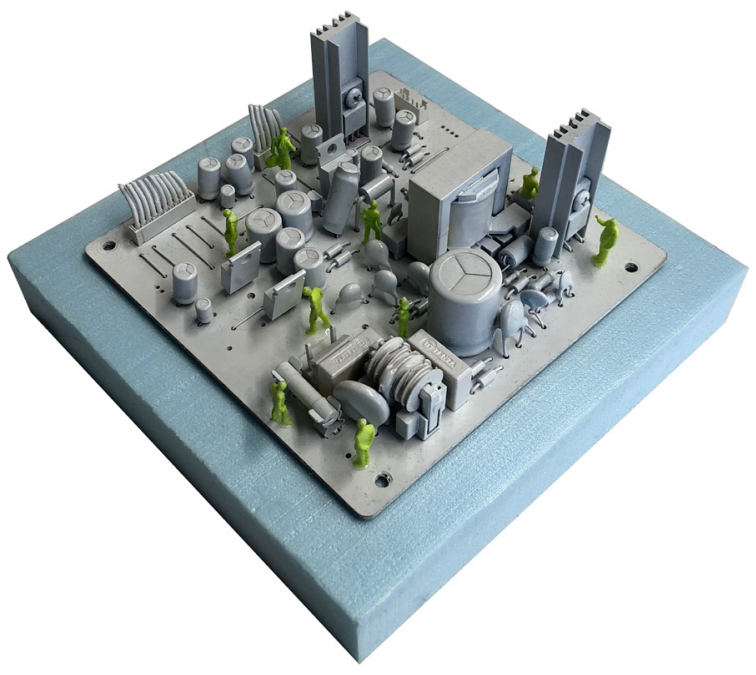

10 Proposal for motherboard factory plan

11 Salvaged Electronic Components from discarded electronics ready to be sampled and remixed for architectural purposes. 



\section{Remixing Architecture}

Sampling is very much about the process of collecting and curating found objects. However, sampling is only one step in the process of transforming found objects for architectural purposes, the true magic lies in what you do with it after. Therefore the remix is an approach that can be applied to the sampling of found objects that allows the possibilities of acting upon them inventively. Remixing extends the repetition of architectural content and form while simultaneously demonstrating alternative ways of producing space in a way that questions conventional architectural practice.

It would be naïve to think that this approach to architecture is new, which to any architectural historian, isn't. It is in fact part of a long architectural tradition, however I do feel that it is a method that has not been consciously acknowledged by the discipline, as a result of historically privileging the heroic and original. Given, our current moment in architectural time, and the ways in which we consume architecture through the endless streams of architectural content afforded by platforms such as Google Images, Tumblr, Pinterest, and Instagram, the weight felt by the extensive history of architecture from time immemorial can be, at times, difficult to comprehend, often paralyzing us from acting upon it inventively. We have reached a moment where all of architectural history is now viewed from the perspective of a flat ontology, ${ }^{32}$ where Baroque is given equal weight to Modernism when placed next to one another. It is through this recognition that I would like to put forth, within the discipline of architecture, a critical design theory that acknowledges remixing, as a legitimate approach to design as a way of acting upon the extent of architectural history, inventively. Not only learning from history, but using history to make new history.

What is interesting to note is the relationship that the remix has with modernism and post-modernism. It is at the intersection of these two movements that remixing began to be recognized and practiced as a valid 
33

Owens, Craig. The allegorical impulse: towards a theory of postmodernism. Godine, 1998, pp.223.

34

Owens, Craig. The allegorical impulse: towards a theory of postmodernism. Godine, 1998, pp.223.

35 Ibid. 36 Navas, Eduardo. "Regressive and Reflexive Mashups in Sampling Culture." Mashup Cultures. Springer Vienna Architecture, 2010, pp. 159. Sampling Culture." Mashup Cultures. Springer Vienna Architecture, 2010, pp. 159. approach to cultural production, in other creative fields. Post-modern theory signified a deconstruction and transparent awareness of history, at a moment in time when history was being questioned, as an outcome of modernisms rejection of the past. ${ }^{33}$ According to American art critic, Craig Owens, the audience is always expected to see within the work of art its history while also acknowledging the politics that lead to its creation. ${ }^{34}$ The remix pushes for autonomy, as paradoxically it is derivative and allegorical of the original. ${ }^{35}$ The extensive chopping, slicing, and recombining of the original sample starts to take on an identity of its own.

The remix is defined as a global and cultural act that comprises of a creative exchange of information made possible by digital technologies. ${ }^{36}$ The creative practice of remixing has roots in collage and is supported by the methods of sampling by way of copying and pasting, a vital feature in the development of the remix. Three Dimensional modeling software, such as Rhino, make it easy to manipulate forms through commands such as scale, rotate, mirror, extrude, intersect, union, slice... etc, in ways that defamiliarize the familiar, and extend remixing procedures that go beyond copy and paste. These new tools are the quintessential principles at play that inform the conceptual strategies for remixing found electronic objects for architectural purposes.

With the introduction of digital archives, which have made large collections of artifacts more accessible to the general public, there has been a shift made possible by the aforementioned digital technologies, where contemporary artists are embracing the possibilities and potential for re-purposing common objects and images for their own creative pursuits. The process of consciously using what already exists and appropriating it from its original context to be reinterpreted, manipulated and revised, is a way to explore the instability of objects and the volatility of their meaning. ${ }^{37}$ By using the detritus of electronic waste for the creation of an e-waste recycling facility, it undermines our perception of dysfunctional electronics as waste and 
challenges our sense of an appropriate use for these ubiquitous objects after they have been discarded. I view the digital dumps or electronic graveyards as a viable source for material resources as well as an archive. How it is used should be of no consequence, what is important is that it is used as a way to disrupt the status quo of electronic waste. We must acknowledge the possibility for a greater understanding and awareness that results when we disrupt order and challenge stability to open up a more diverse and inclusive variation on how we can re-imagine electronic waste in new and unconventional ways.

Remixing architecture is a conceptual and formal collage of past histories, ideologies, and vocabularies, which have been extended to the digital technologies and software of today. Culture is constantly being redefined by the continual flow of information in fragments. The ability to manipulate these fragments offers new possibilities that extend the activity of remixing to the evolutionary practice of architecture. Remix theory serves as a conceptual framework that has implications for the material and formal practice of recycling electronic waste. 





\section{Site of Speculation: The Golden Mile}

Considering that a majority of built projects are usually conceived in response to a design brief and/or site, I resisted the urge to immediately site my project in a real location, as a means to really investigate a symbolic transparency. However, by given this rare opportunity, I was very precise in choosing a site of speculation that would allow me to test out my theories. As a result, I chose an existing industrial site on the South-East Corner of Eglinton and Pharmacy Avenue, located in the Golden Mile.

The site is located adjacent to Eglinton Shopping Centre to the West, Wal-Mart to the North, and Big Box Smart Centres in close proximity along Eglinton Avenue. Siting the critical project in this location presented an opportunity to directly confront the spaces of consumption while also learning to co-exist. These types of infrastructural waste processing facilities are pushed to the fringes of society, out of sight from spaces of consumption. So the challenge concerning the site was its ability to stand out enough to have a public presence, but subtle enough to not disrupt the daily rituals of everyday life.

The reasons behind the selection of this site had to do with the area's unique history. The Golden Mile in the 50's was first branded as “The Golden Mile of Industry," symbolizing a post-war prosperity. This area was so prevalent in its time that in 1956, Queen Elizabeth II made a visit, for the opening of the Gold Mile Shopping Centre. By the 80's, industries began moving to less expensive properties and the area became known as the Golden Mile of Commerce, for its big-box stores and car dealerships. The context of the site provoked a strong narrative that speculated on the result of years of production and consumption in the area leading to an accumulation of electronic waste. Presenting the possibility of processing electronic waste where it was once produced and where it is currently being consumed. 


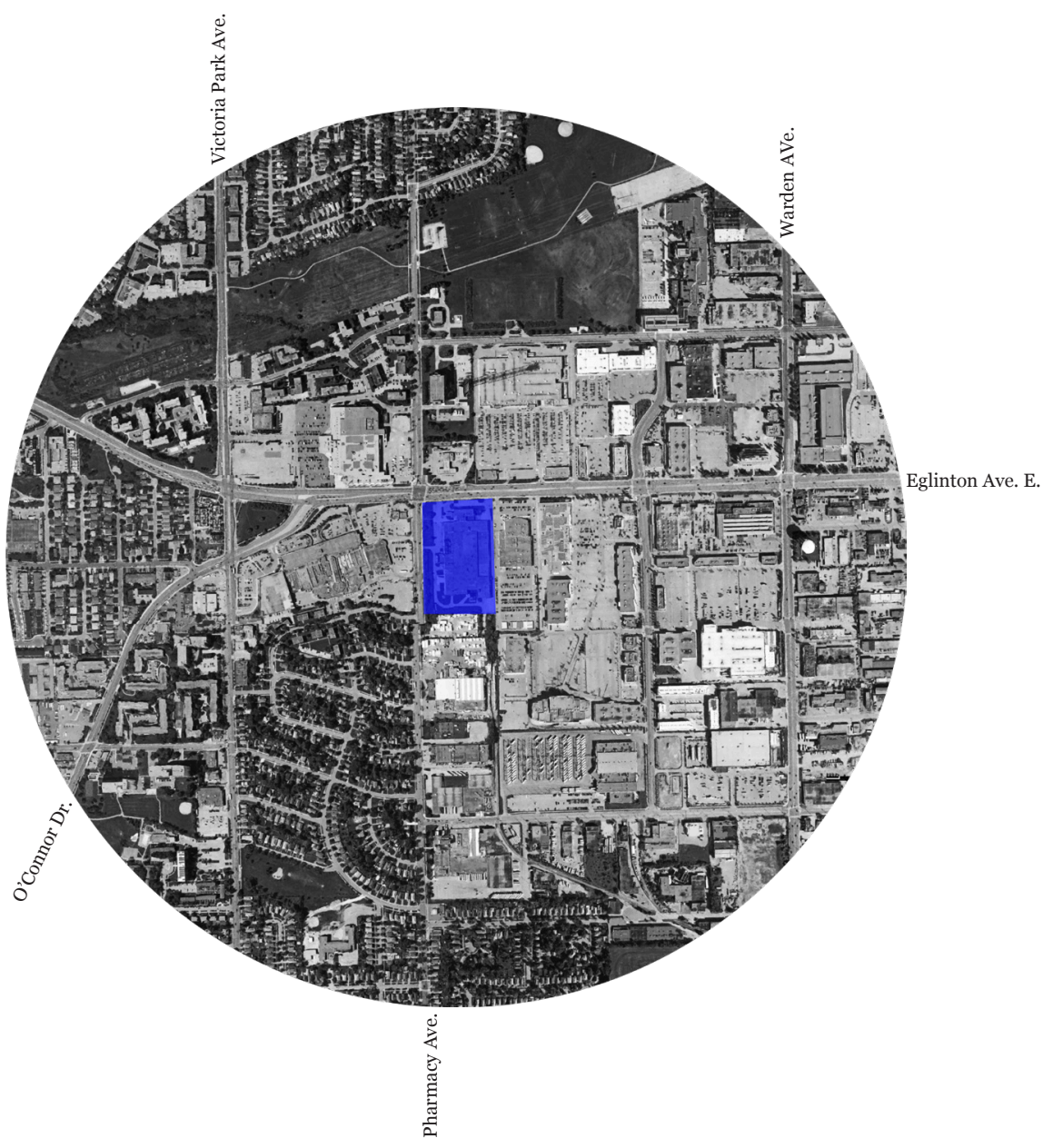

1 Site Context (1km Radius) 


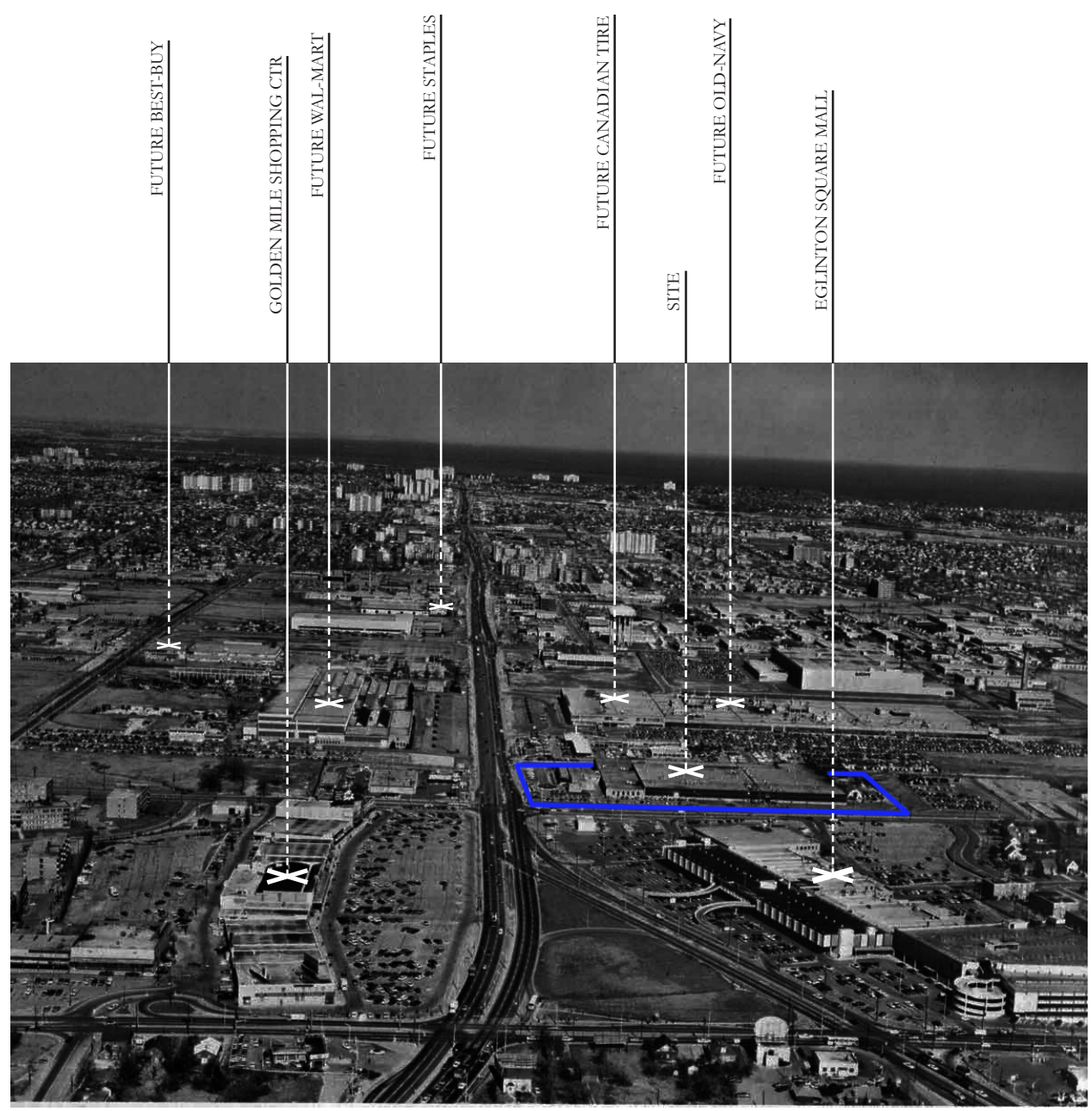




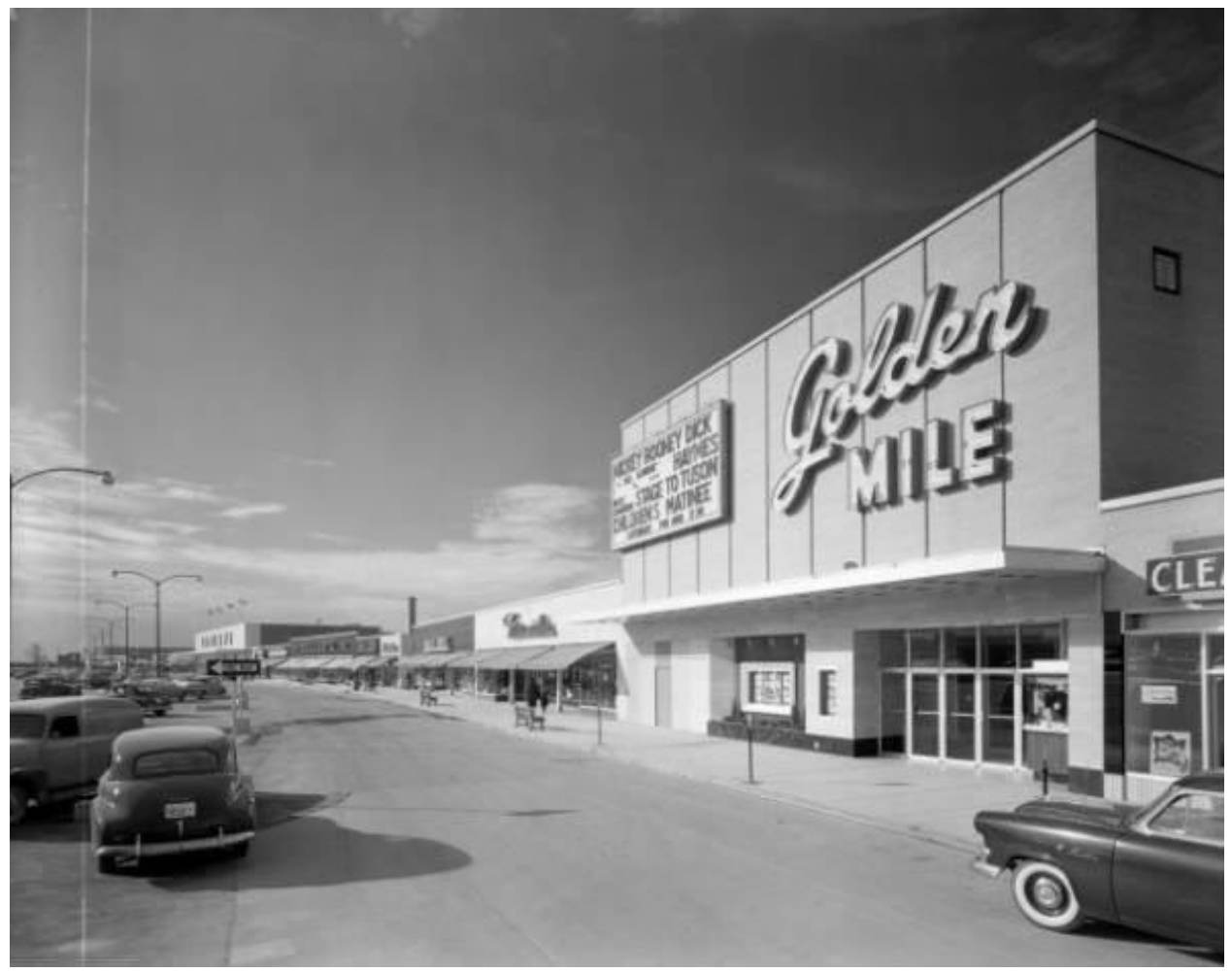

3 Golden Mile Shopping Centre 1956

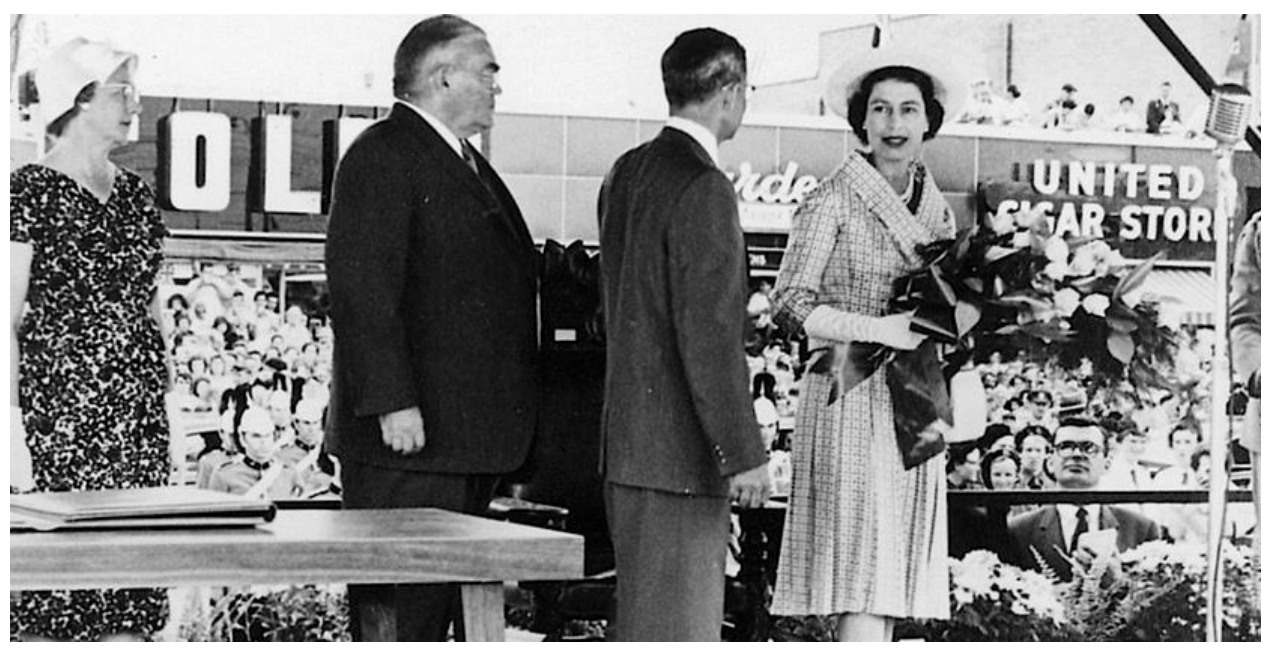

4 Queen Elizabeth II visits The Golden Mile's Opening in 1954 


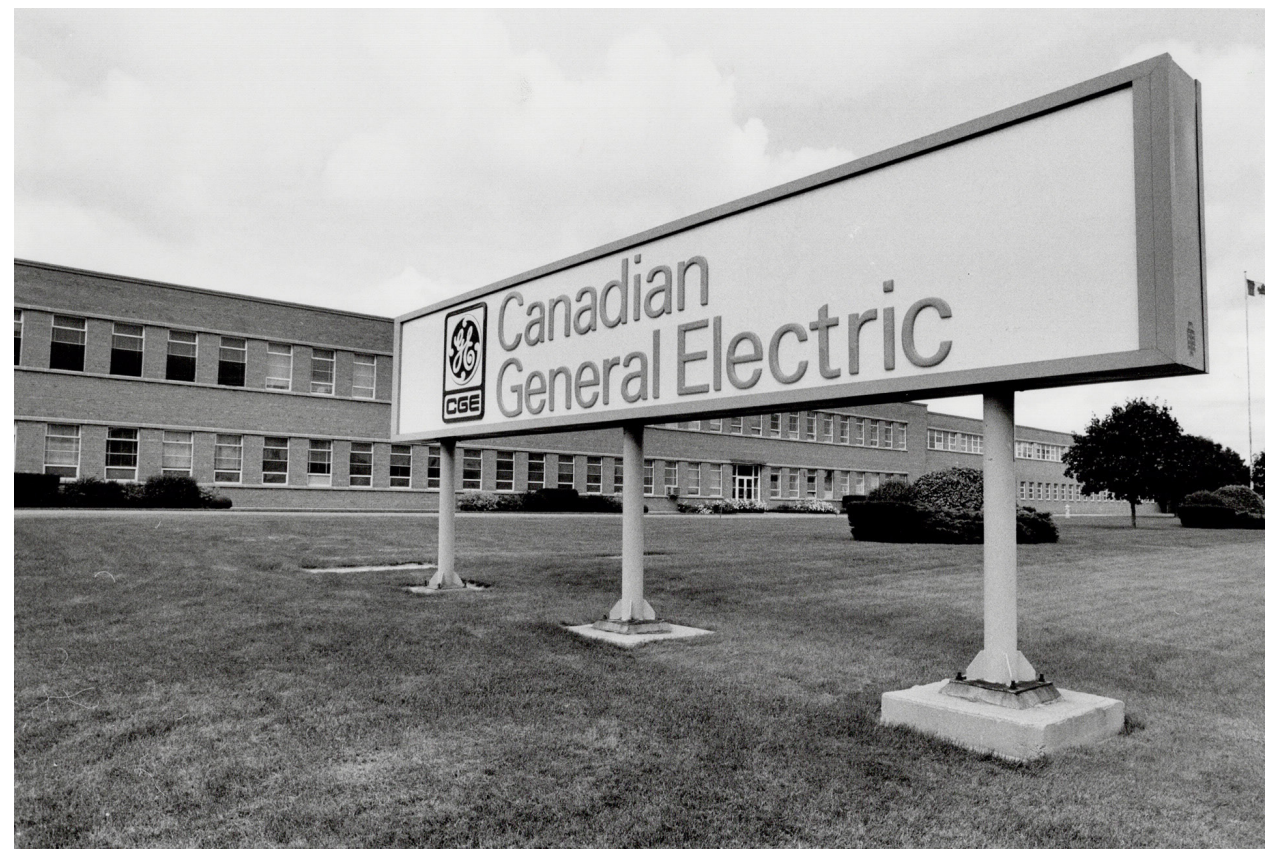

5 Canadian General Electric Closes this factory. 1983. Photograph by Jim Russell

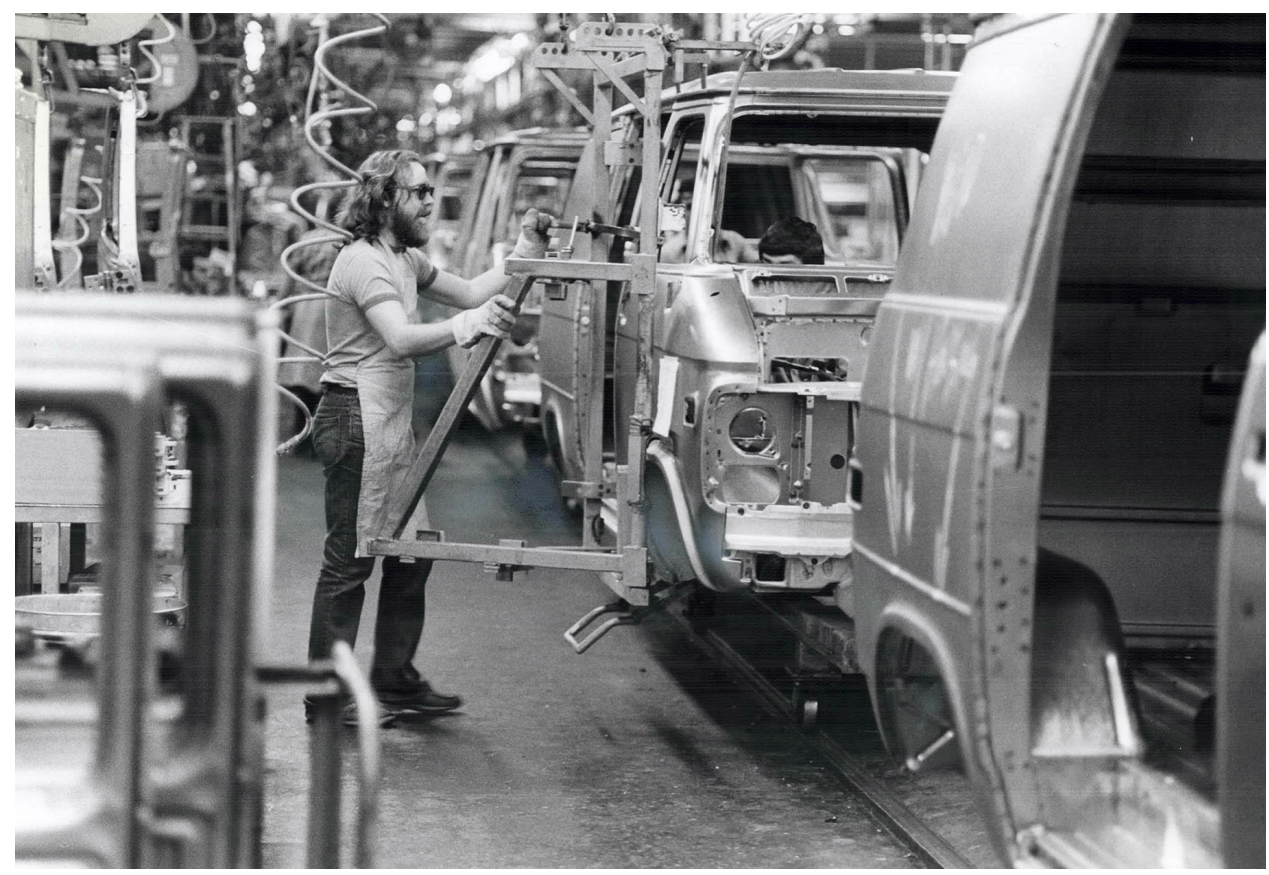

6 General Motors' van plant in Scarborough, 1981. Photopgrah by Dick Loek. 


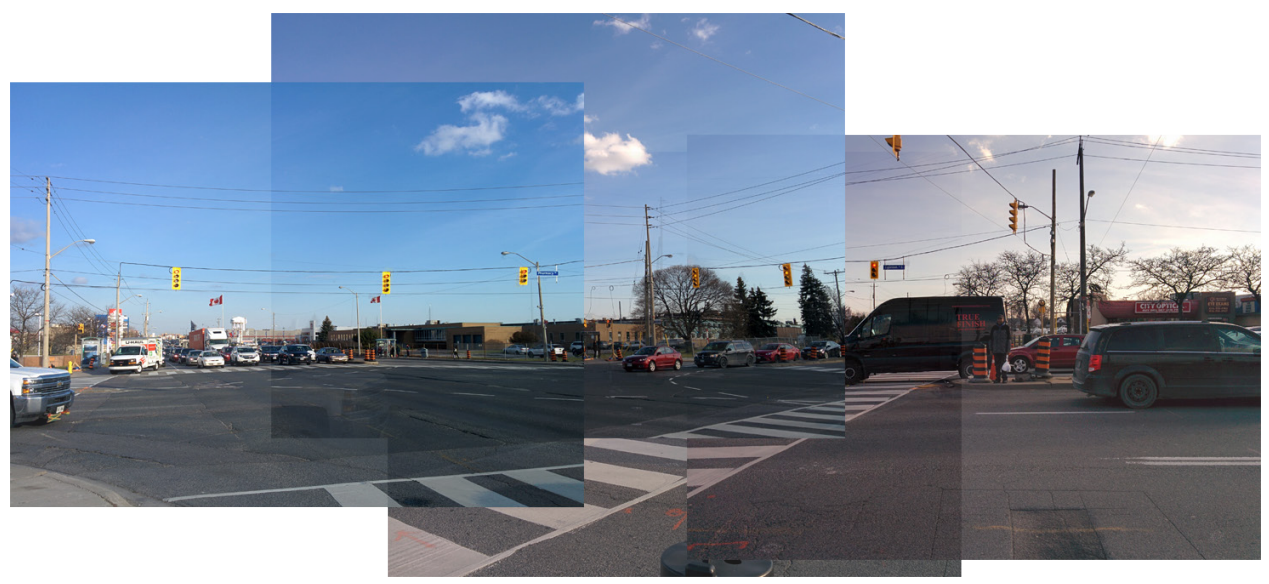

7 Street View Perspective (Standing on the North-West Corner of Eglinton \& Pharmacy Ave.)

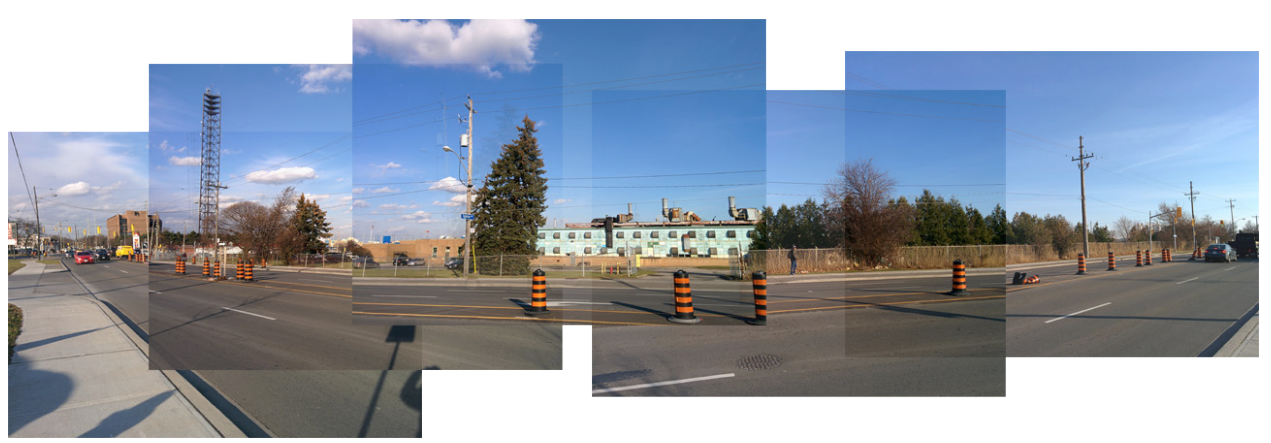

8 Street View Perspective (Standing on the West side of Pharmacy Ave.) 



\section{Centre for Electronic Waste and Resource Recovery}

The Centre for Electronic Waste is literal as well as figurative and symbolic of the discarded electronic components that have become obsolete. The emphasis on composition through the process of collage transmits meaning through the difficult whole. A claim that I contend supports a transparency through an iconography of signs and symbols as a way of responding to electronic waste while speculating on the process of sampling and remixing found electronic objects or electronic waste for architectural purpose and how this approach can be applied to the production of space.

The overstated electronic billboard screen fronting Eglinton Avenue is a direct response to the surrounding big box stores as well as the many commuters that traverse this main East-West arterial road. Subverting the use of the billboard as an architecture of commercial persuasion, this billboard is utilized to project many images onto its large surface. Images that can range anywhere from live-streaming the digital dumps of the world, collapsing the space-time fixations that separate waste and consumption, to images of the factory floor, showcasing the often invisible e-waste workers responsible for processing the electronic detritus of our digital world.

The utilization of the billboard is a fascinating proposition, in that it fuses media technologies and architecture, in a way that brings architecture back to its primitive roots of sign, symbol, and shelter. Electronic screens are ubiquitous in our daily lives, and it defines how we relate to the world around us today. There seems to be an untapped potential to expand the electronic billboard screen's use in architecture as opposed to averting our architectural gaze and dismissing it as a valid architectural element.

Behind the large billboard lies the rest of the buildings, which each serve a purpose in the processing of electronic waste. As fragmented parts of a larger whole, each building represents a testing of various possibilities of 
achieving an iconographic transparency. As part of the larger whole, the buildings are organized and composed on site as a motherboard. The layout of a motherboard represented a soon-to-be forgotten organization, or an already normalized organization shaping societies today. Either way, the critical project found a way to inventively sample electronic components for an e-waste facility.

How we deal with our waste moving forward into the future will dictate our ability to sustain. Therefore, we must view our waste as a valuable resource. And it is infrastructures such as e-waste processing facilities, combined with makerspaces that can engage communities, giving them a space that fosters their ability to re-think how we can re-use our electronic waste to make new innovations that will solve the world's problems in the later half of the $21 \mathrm{st}$ century.

The basis for the manifestation of this critical project is speculative as well as provocative, touching on many different facets and offering a critique on the capitalistic consumption of our material culture. This is a relatively new territory in architecture, and there is a richness to it that has only begun to scratch the surface. The globalization of electronic waste and its consequences is an important and very relevant discourse today, yet it is one of the least examined problems of the 21 st century. By the means of this critical project, an attempt was made at opening up a more hybrid theoretical terrain for electronic waste within architecture, which has implications for practice, that can extend beyond functionality, to embrace the social, political, and environmental issues that inform the production of space. 


\section{EIIIIII LIII UL}

HELLLLLLLLLLLLLL L

HILLLLLLLLLL L LL

땐ㄴㄴ $L^{L}, L^{L} L$ E

LIILLLLLL, HUL

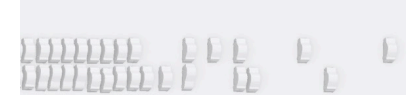
UIILLLLLLLL L L LULLLLLLLLLLL L
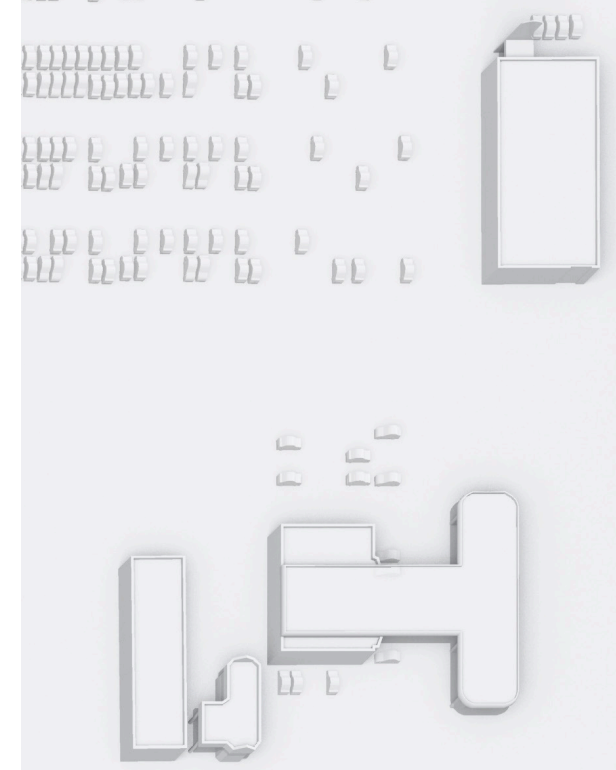

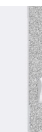

(1)
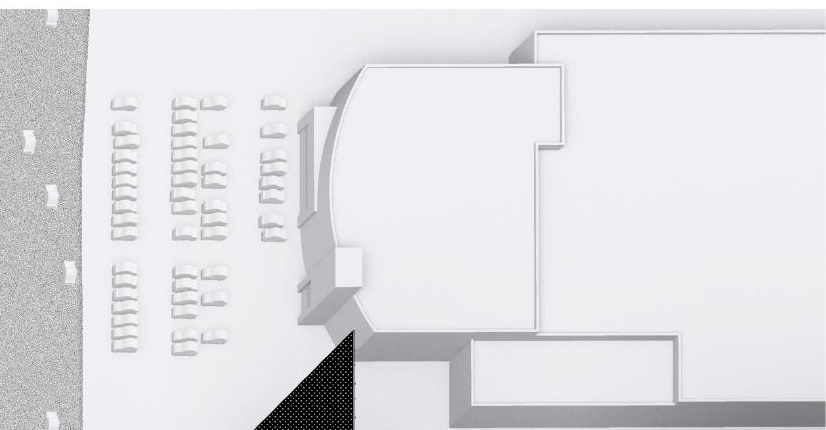


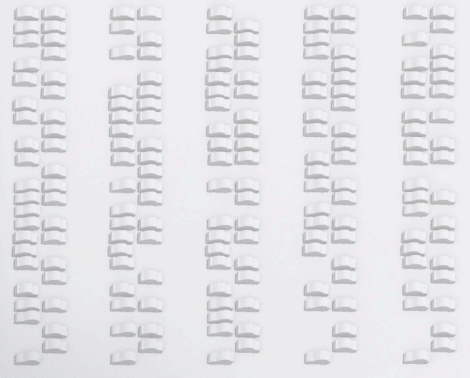
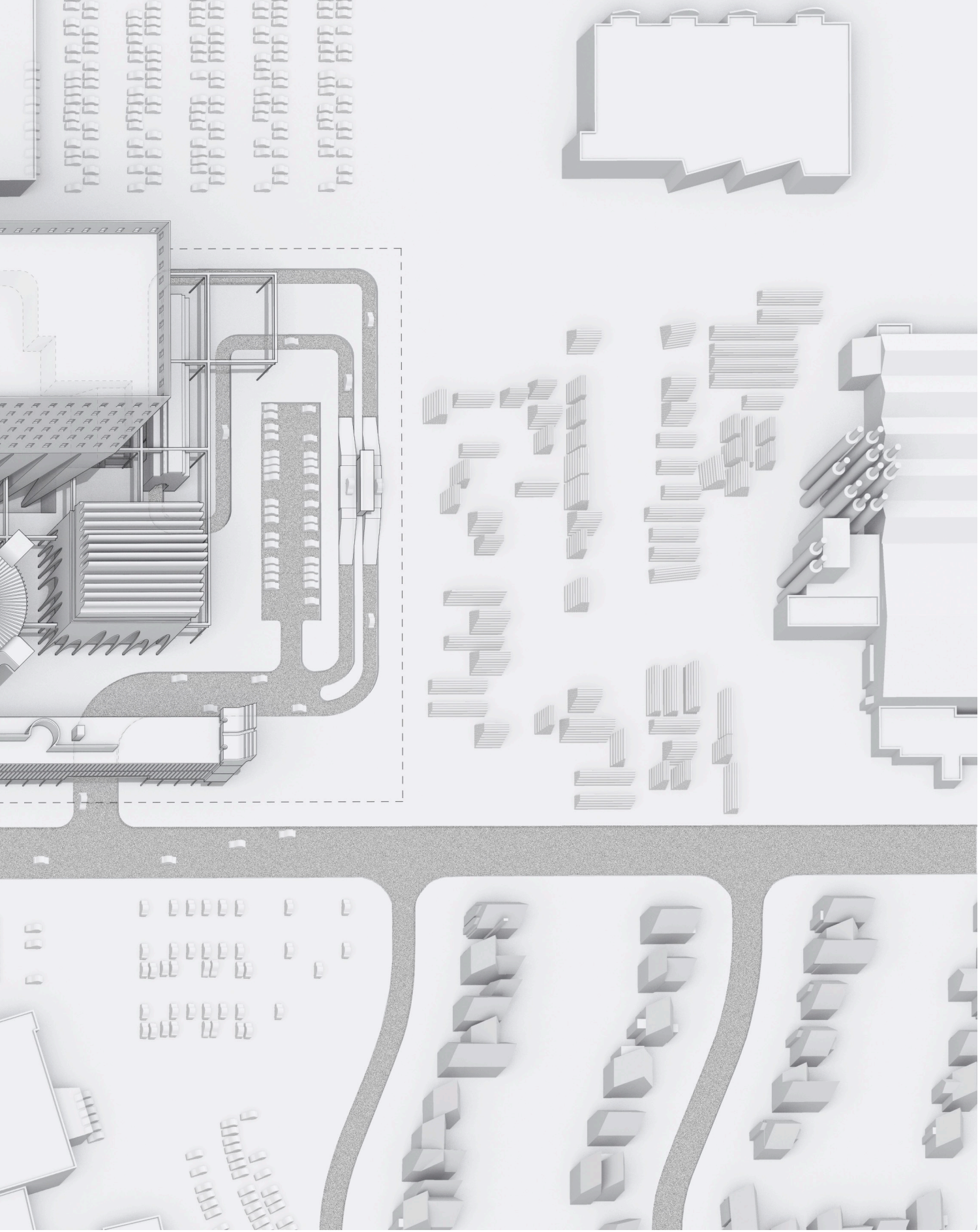

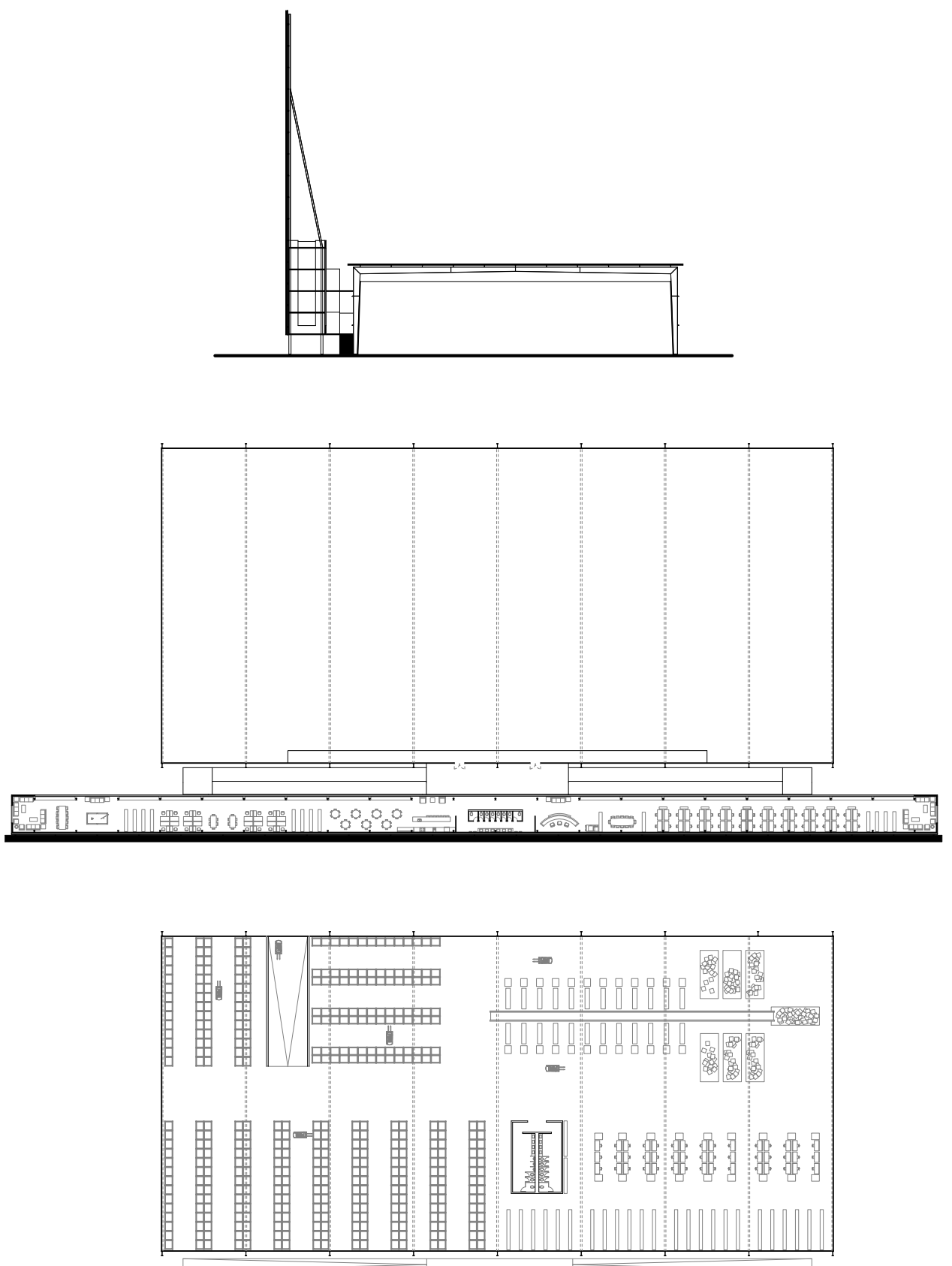


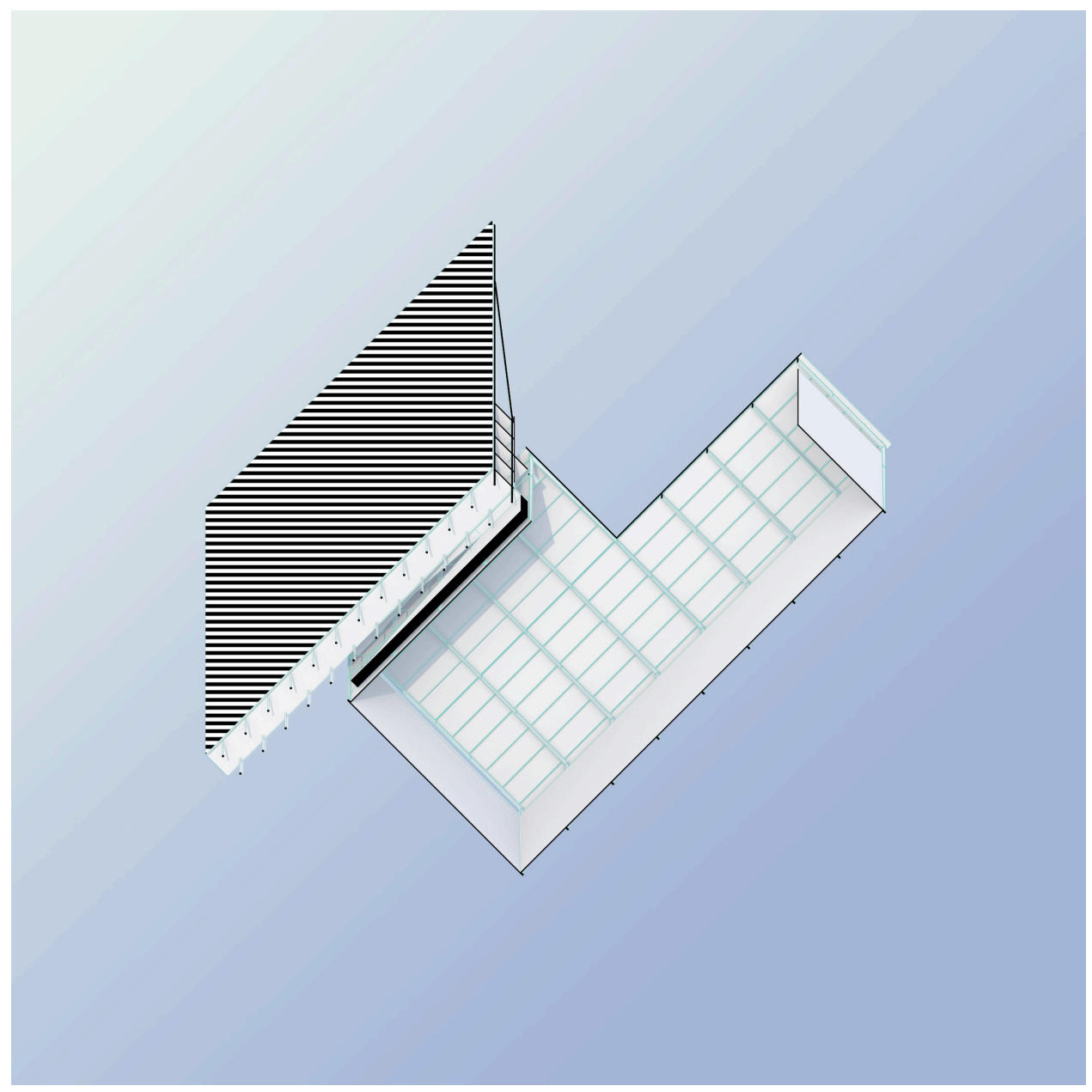



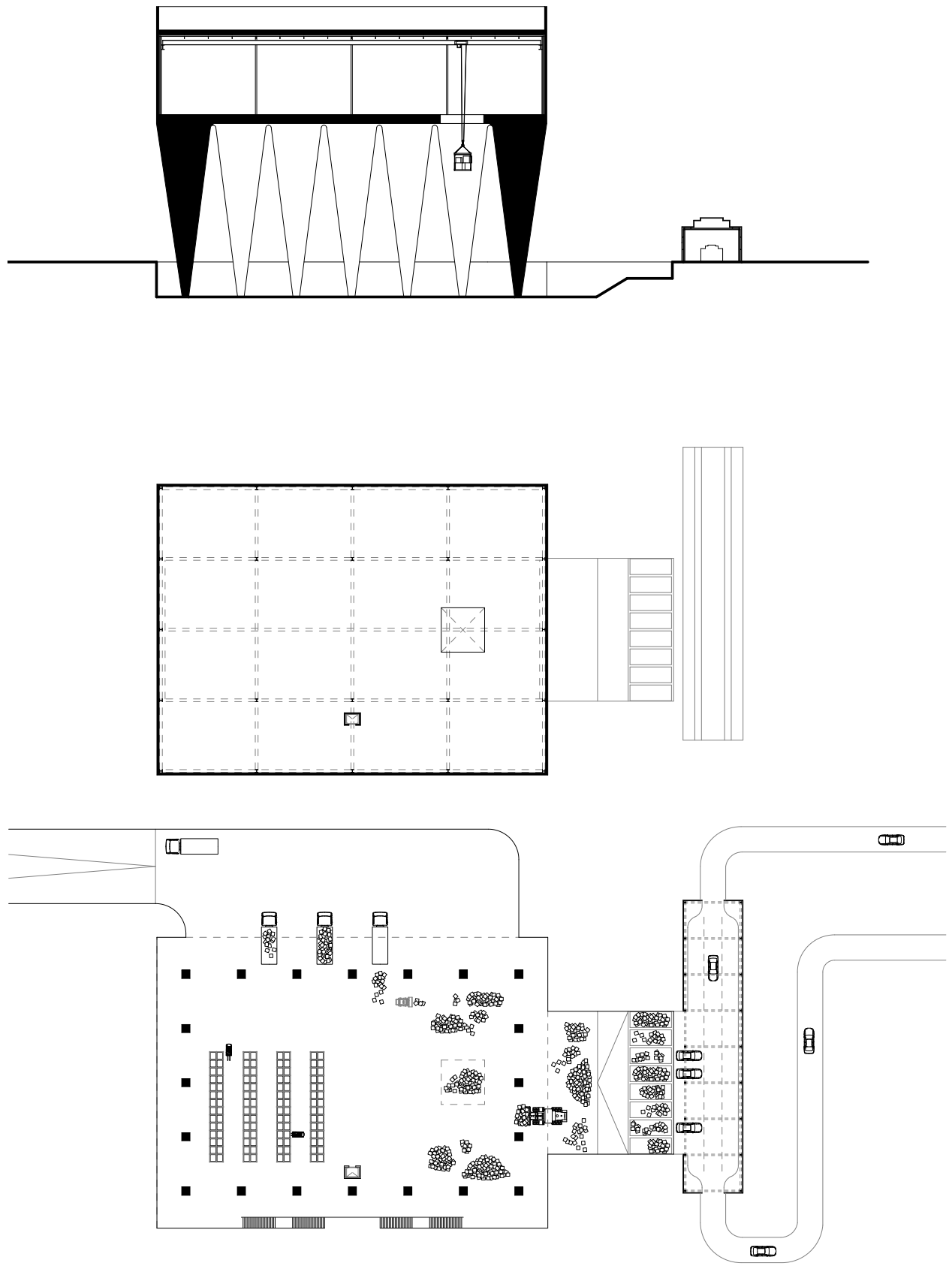

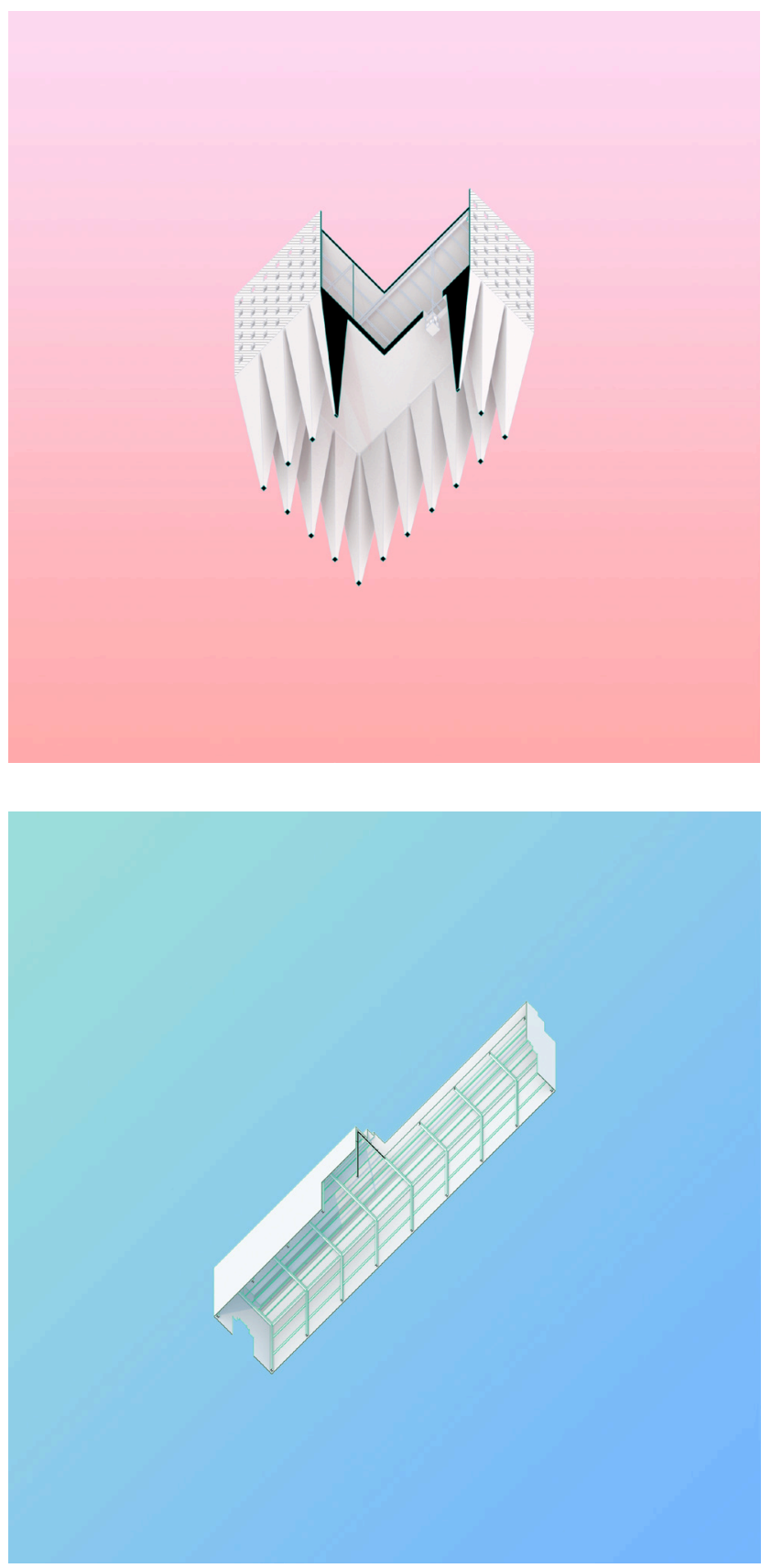

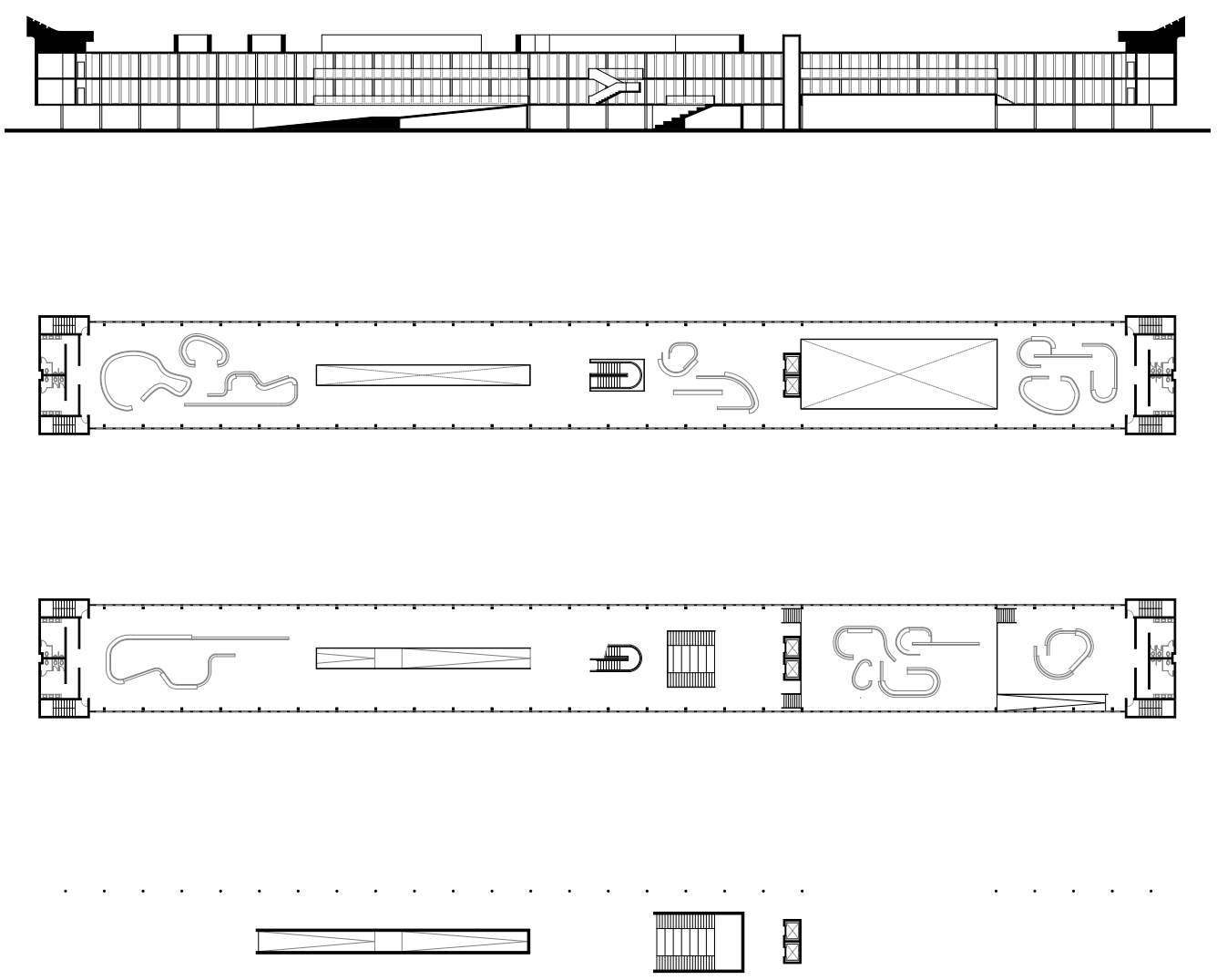


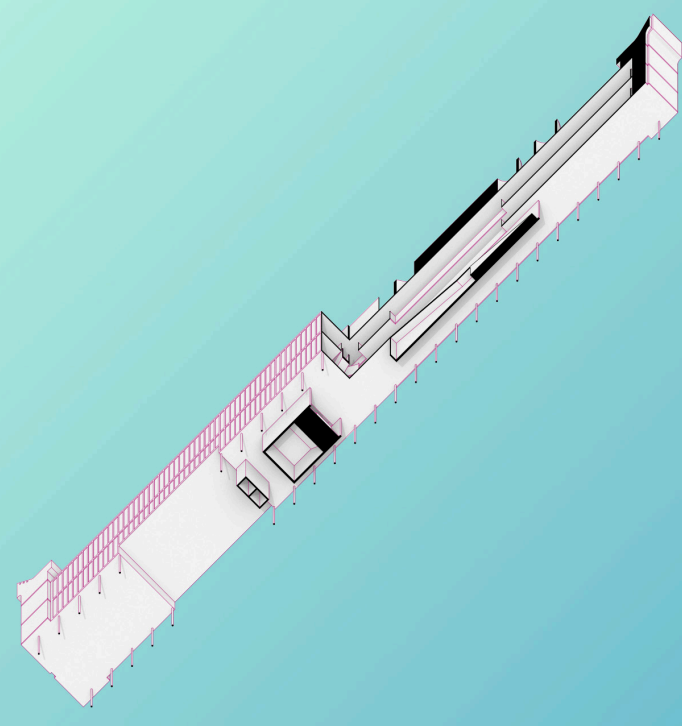

15 Marketplace for Renewed Electronics and Components: Worms Eye Axonometric 

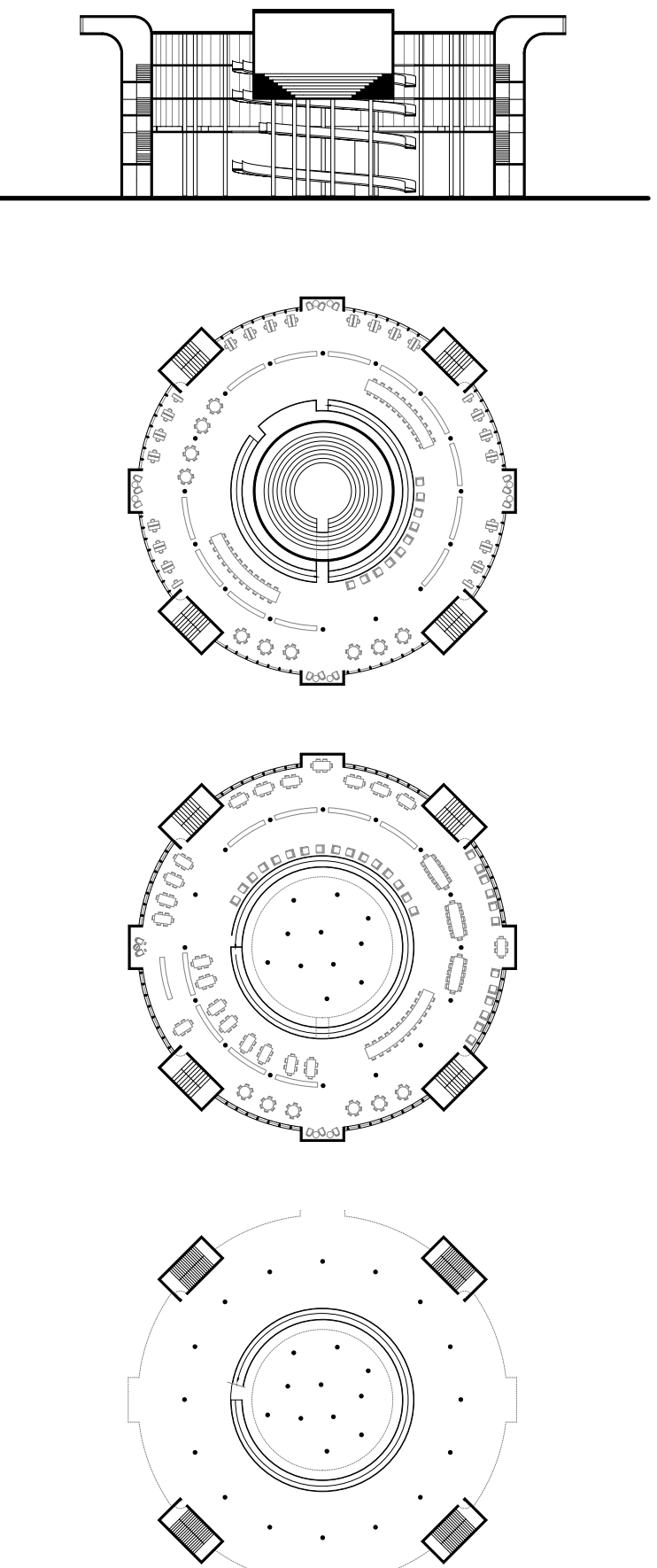


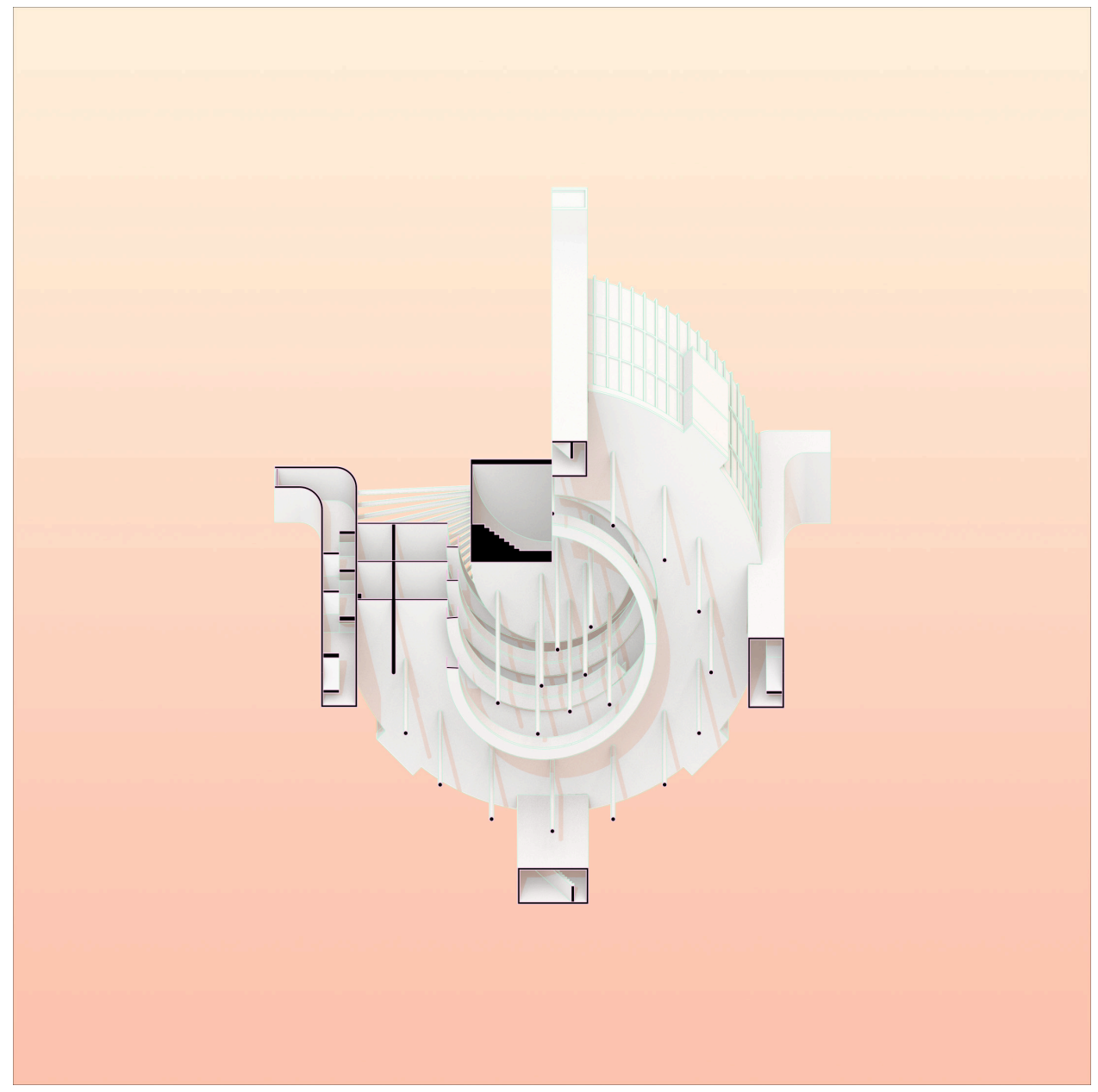



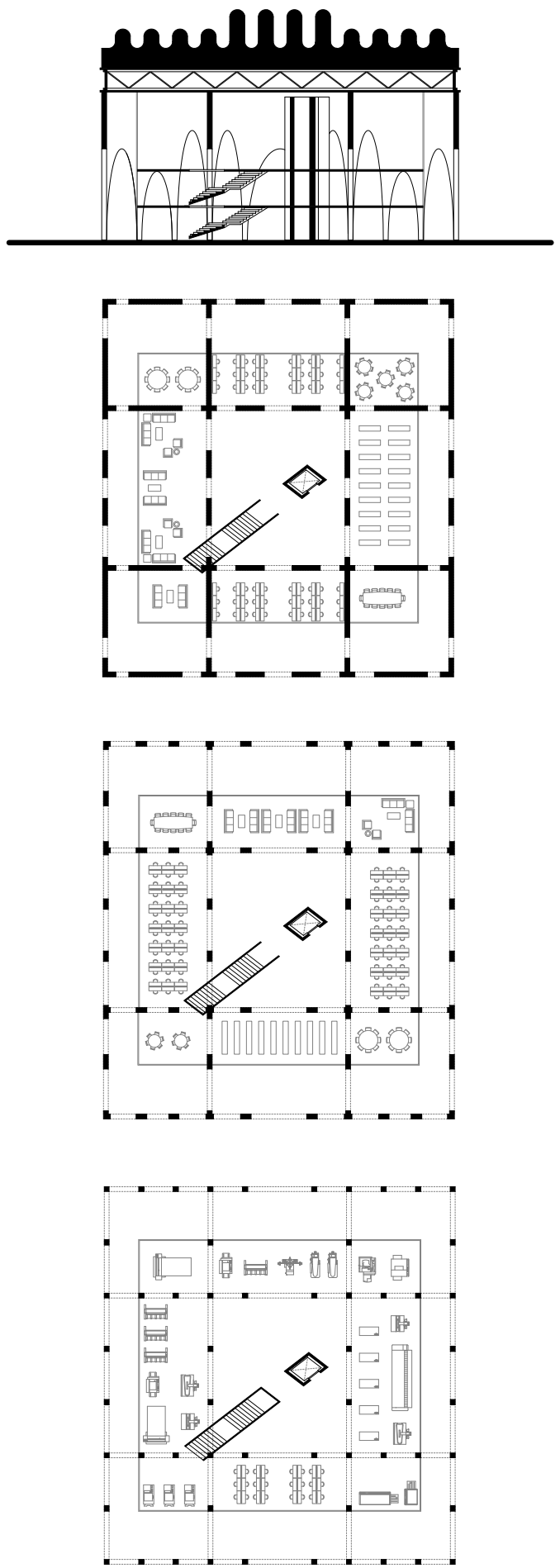


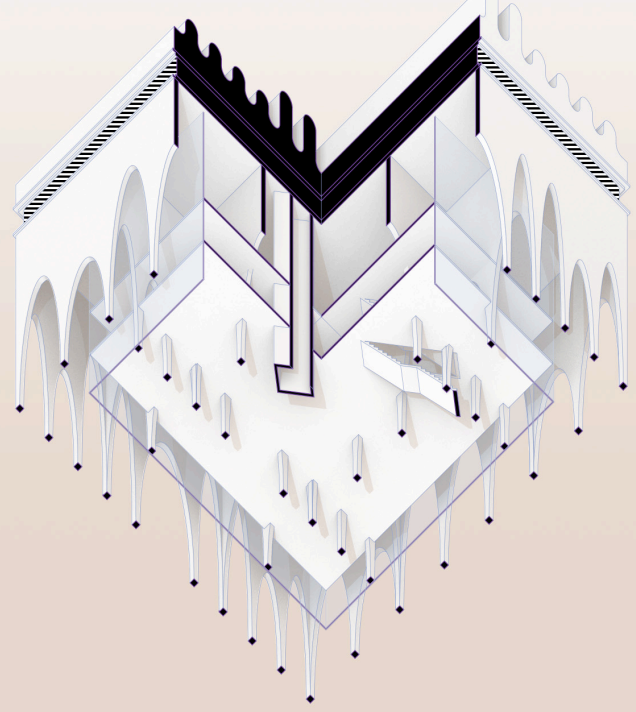




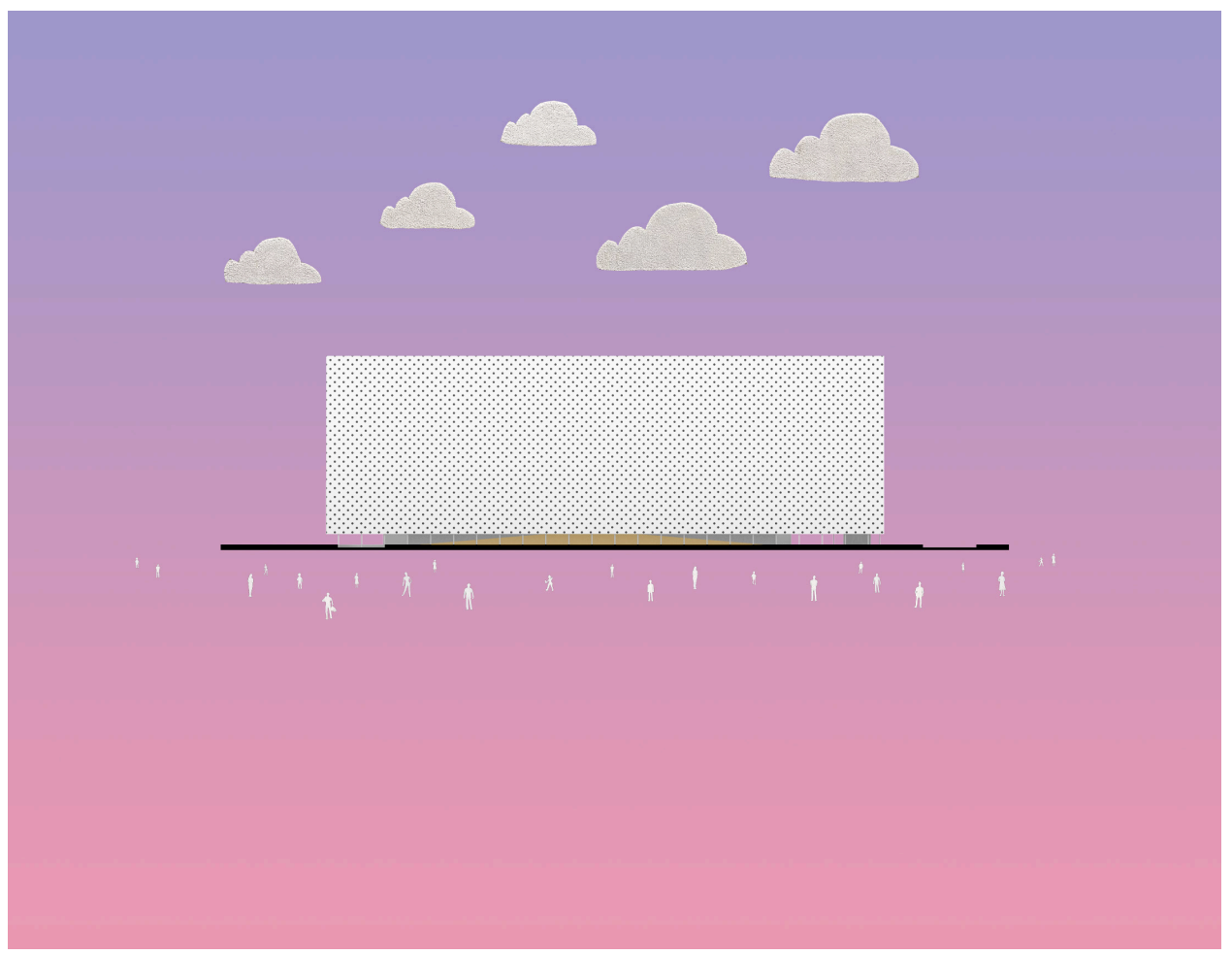

20 Site Elevation - North 


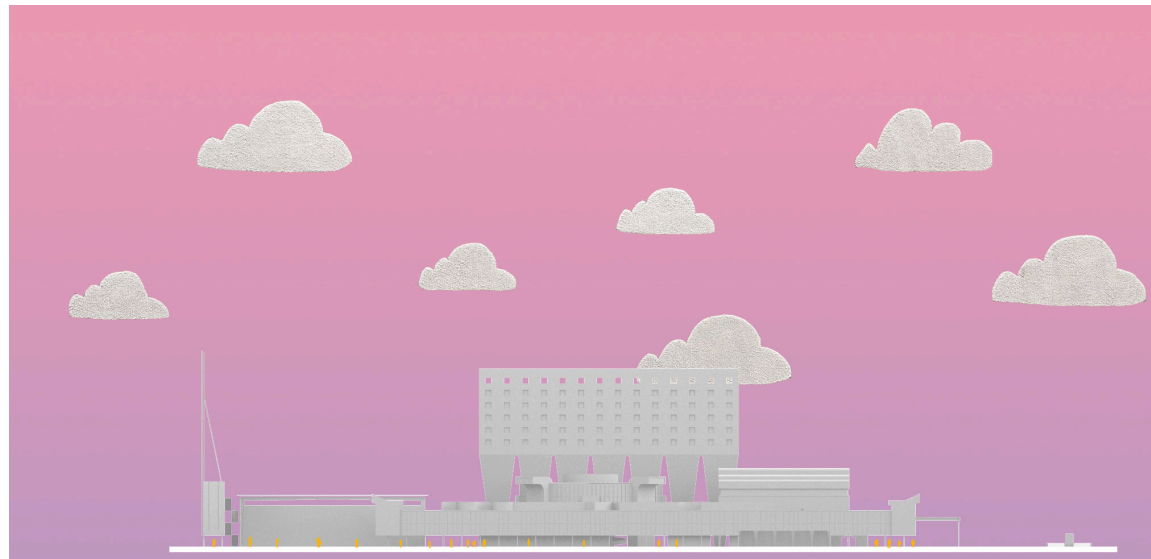

21 Site Elevation - West 


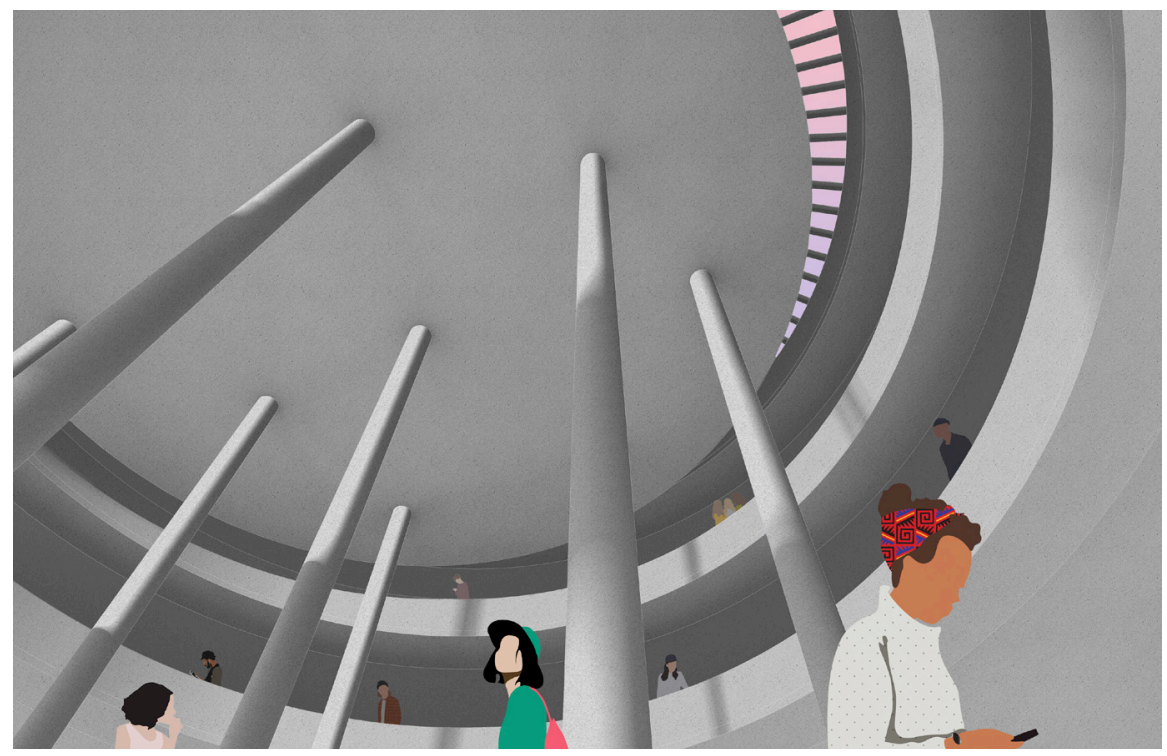

22 Research Centre

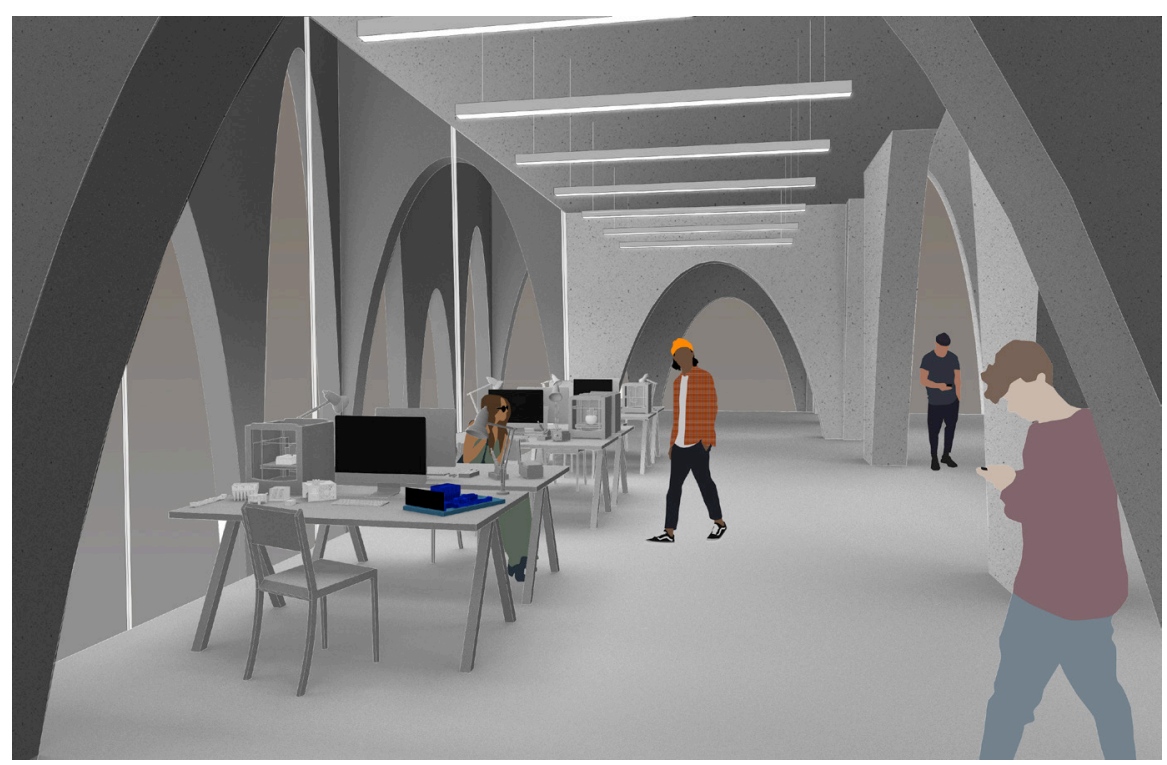

23 Makerspace 


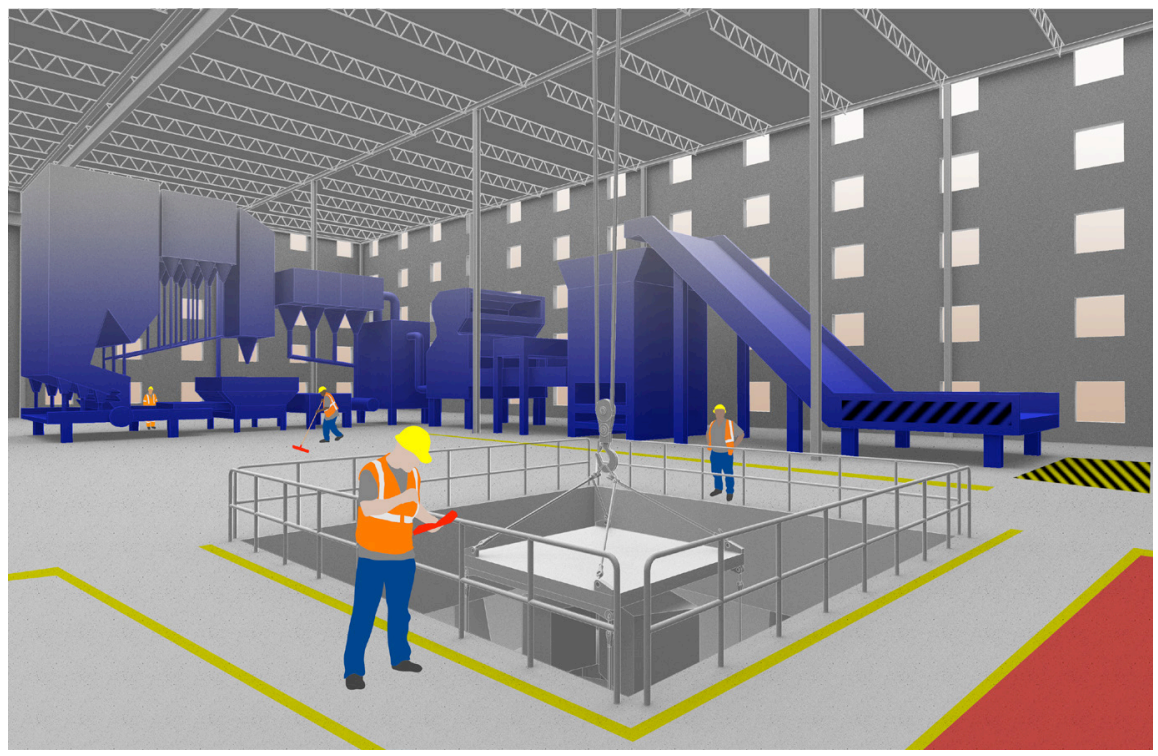

24 Mechanical Disassembly

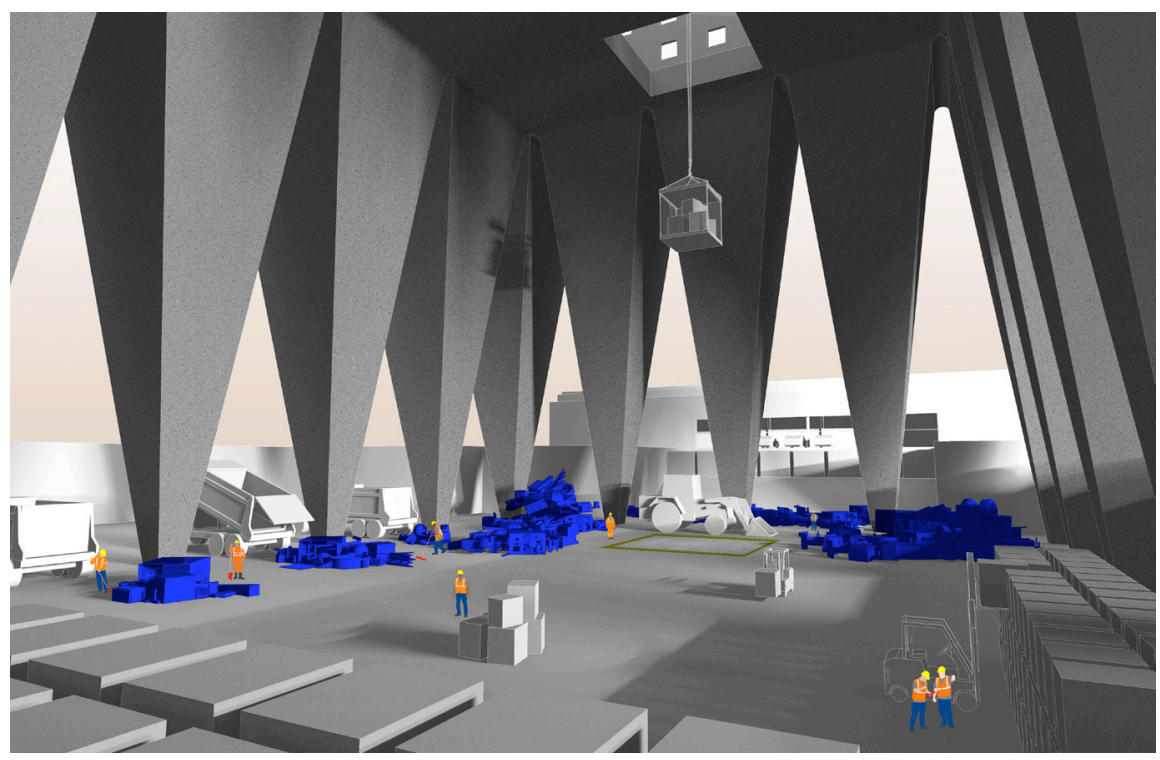

25 Tipping Floor 


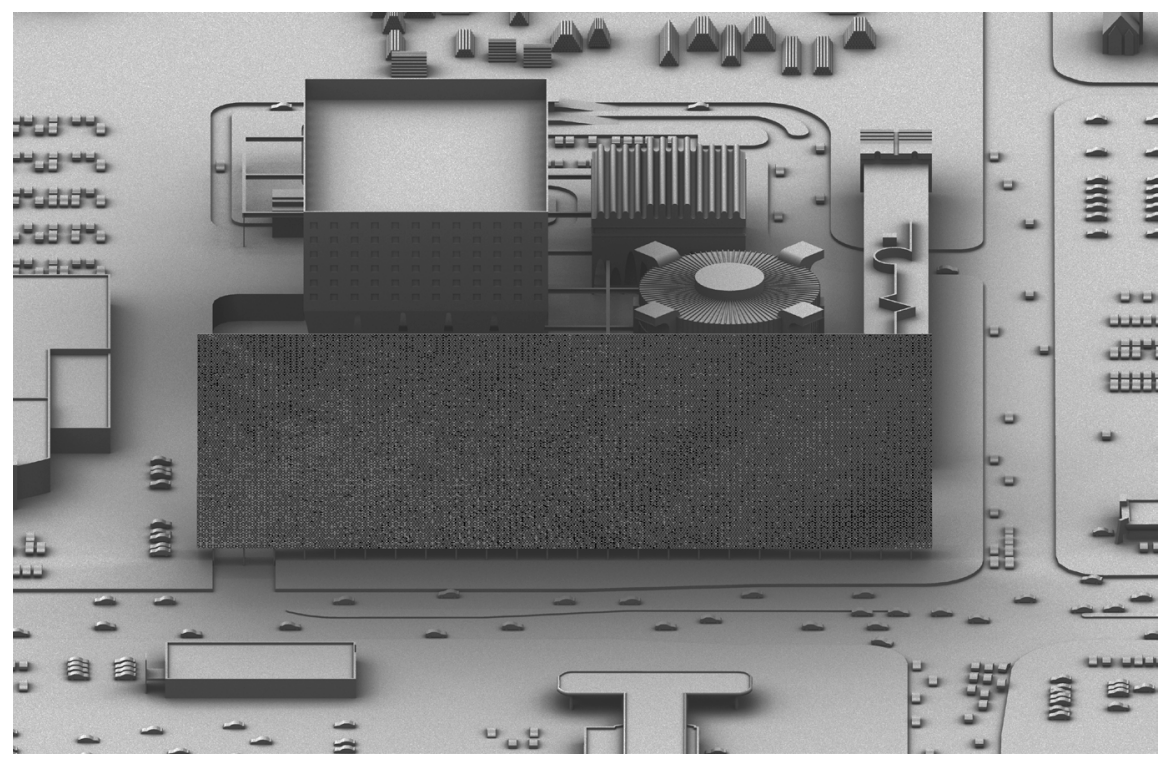

26 Front Perspective

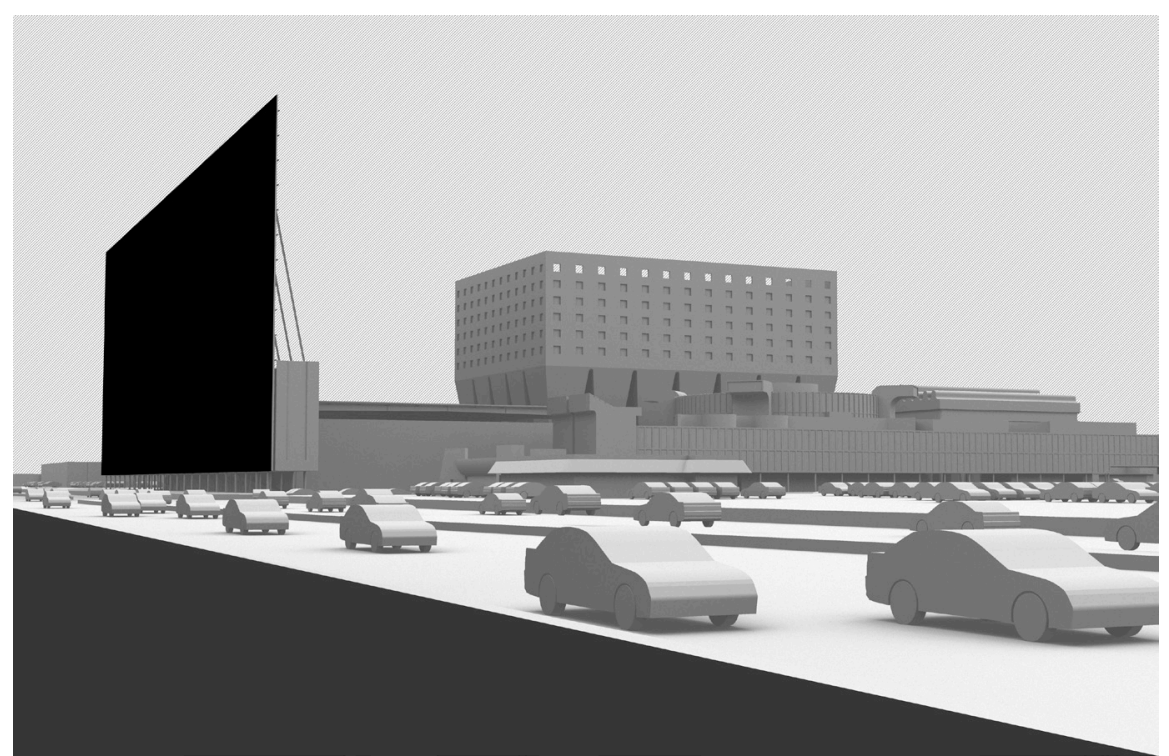

27 Streetview Looking East Along Eglinton Ave. 


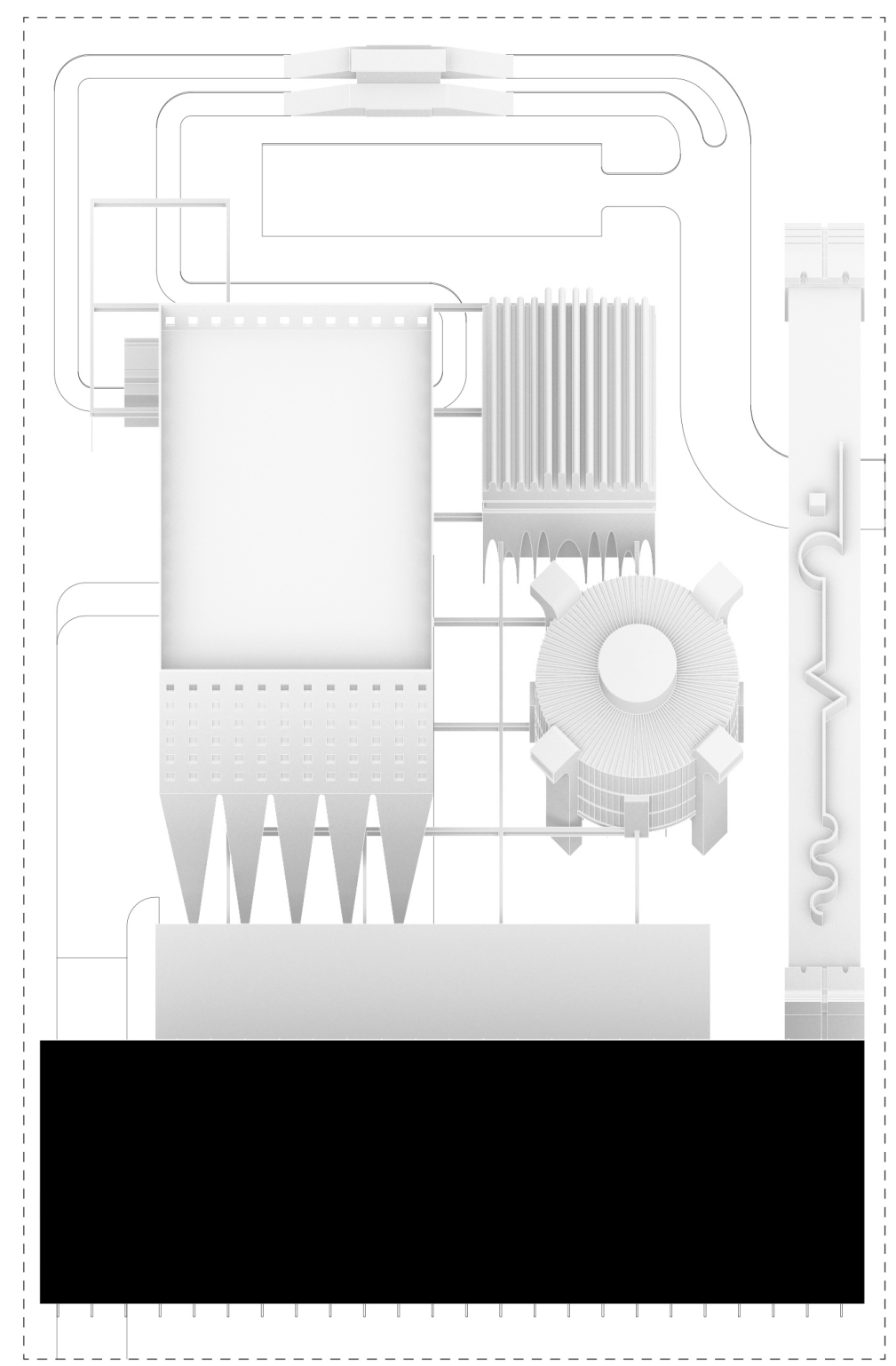

28 North Elevation - Oblique Projection 


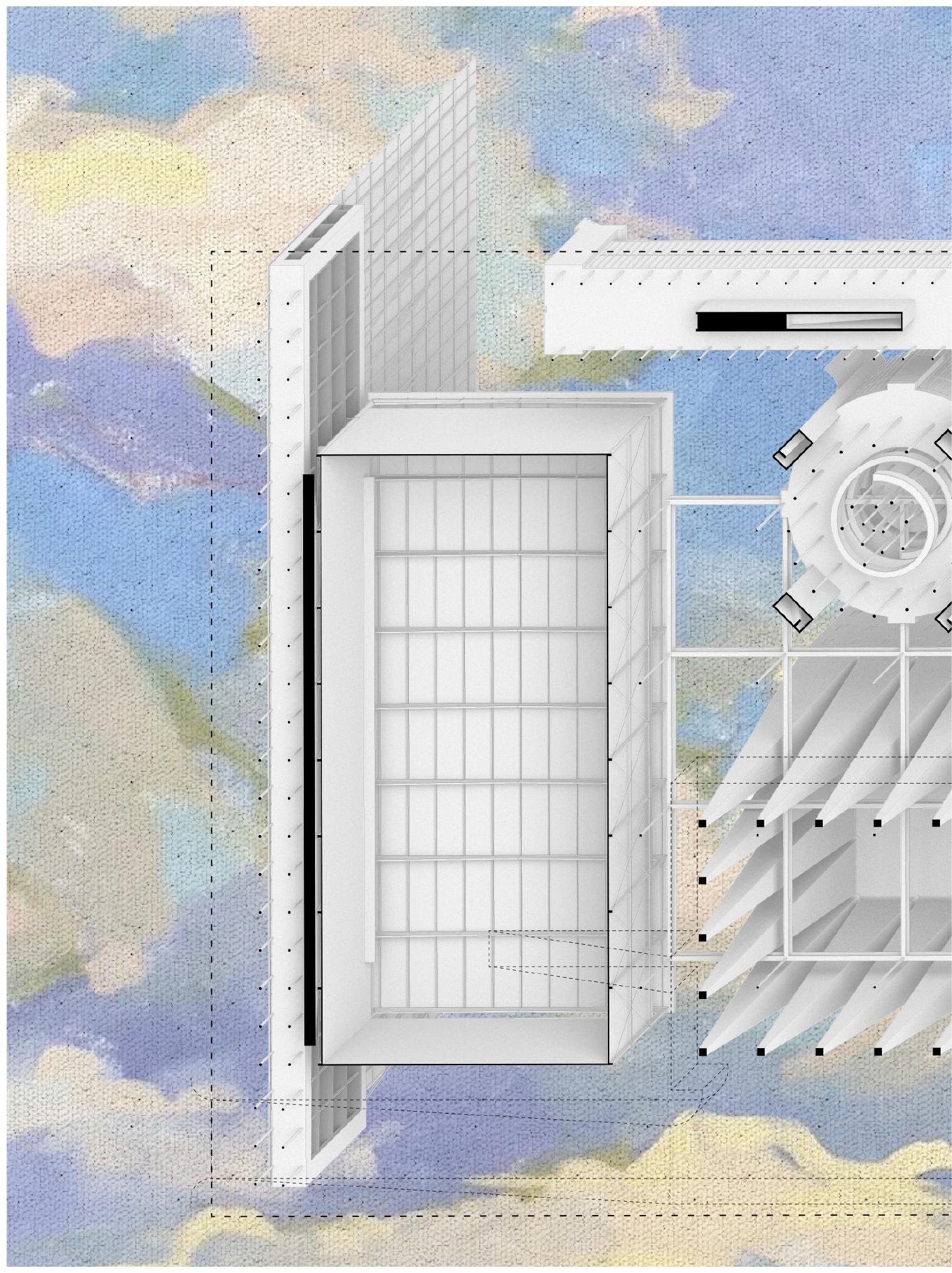




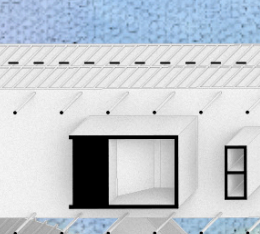




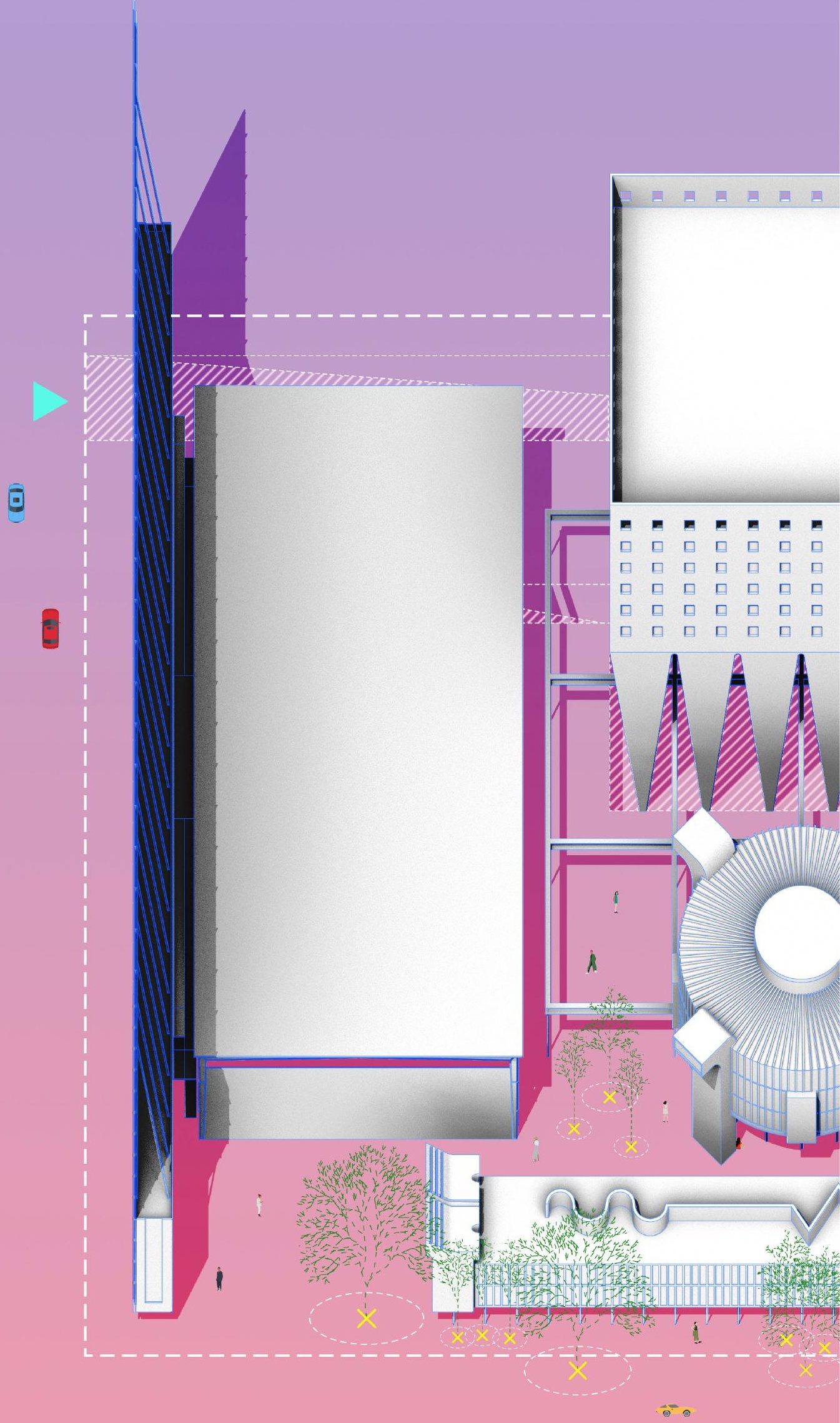




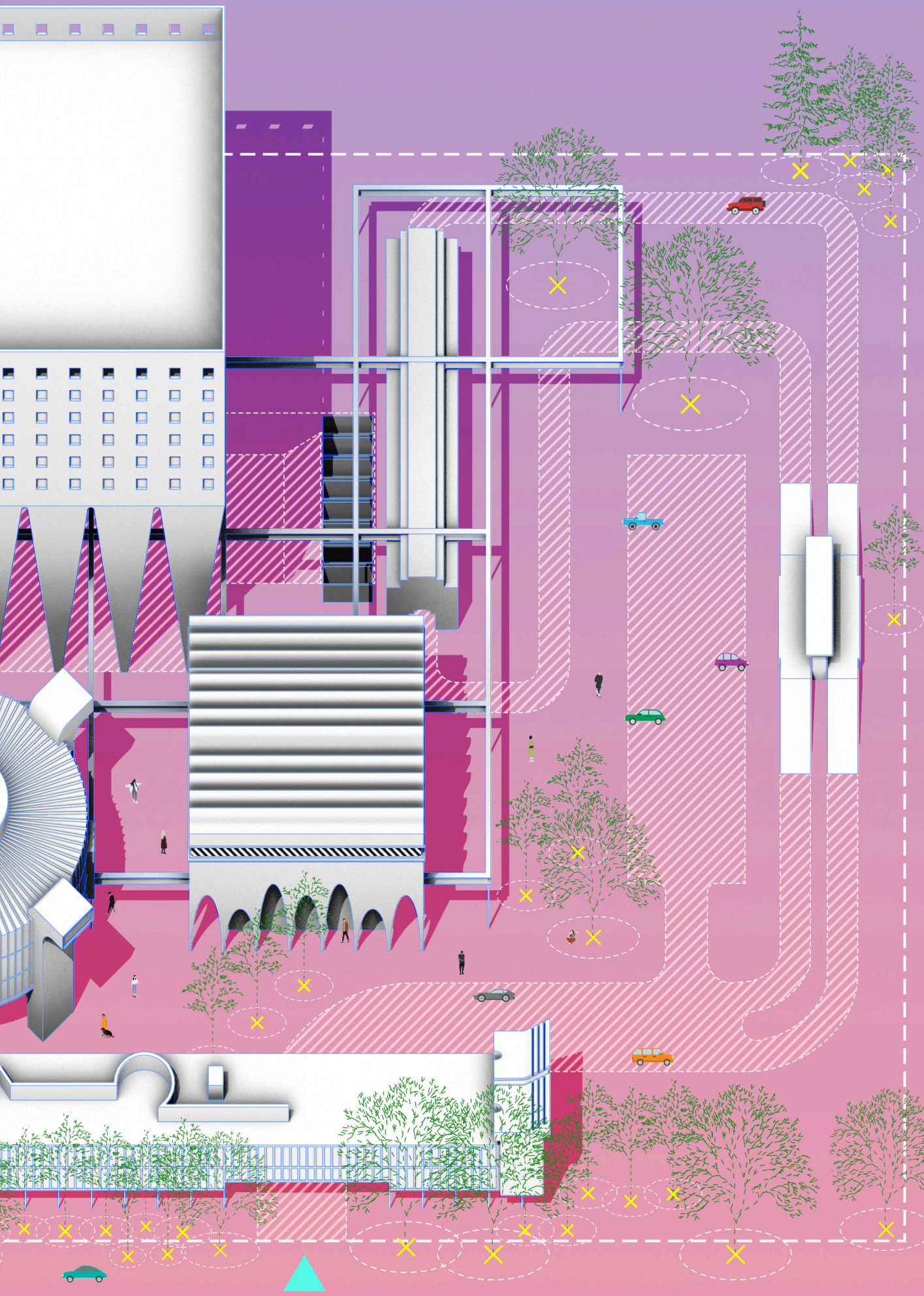



l. W.

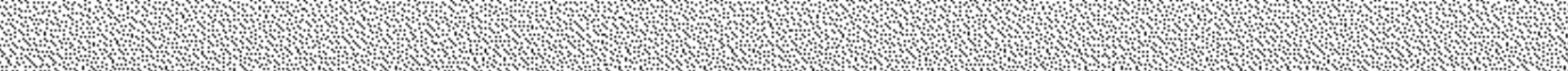

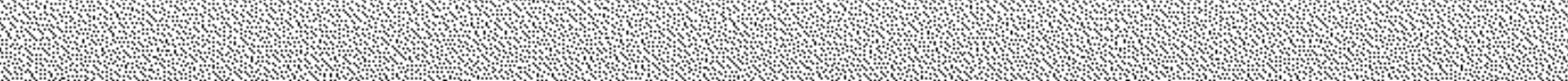


Waste is a product of capital and consumption. The economics of consumer electronics encourages disposal, as it is cheaper to buy new than to repair. People replace and dispose of their electronics with very little clarity as to where they go once they've expired and reached the end of their functional electronic lives. And so, to question the notion of waste going away is a provocation that was central to the design research of this thesis. We all know waste does not just vanish into thin air, it has to go somewhere, as made apparent with the garbage barge, Mobro 4000. Mary Douglas' statement of "Dirt is matter out of place," played a pivotal role in serving as ground zero, guiding the way I perceived electronic waste, and conducted early design explorations.

As I delved deeper into this territory of critical design research, it became apparent to me the centrality of waste's role in the processes of capitalist urbanization. The way we organize our relationship to waste is an outcome of public health. Exposure to waste is undoubtedly harmful and as such we cannot live in close proximity to the waste we produced today. However, the management of waste and its invisibility has political and social implications.

The spatial treatment of waste through zoning is inextricably linked to the spatial marginalization of people. These landscapes 
of exclusion are a result of waste management and the sociospatial mechanisms of regulation. Spaces of waste are pushed to the periphery of the city, out of sight from the more privileged spaces of consumption. Exploiting not only local communities here in Toronto, but also abroad. The hazardous waste trade is a global and ecological phenomenon that spans the entirety of the planet.

The current system of managing electronic waste remains designed to make e-waste and its by-products invisible as efficiently and quietly as possible so as to remove it from the possibility of social and political opposition. The invisibility condition associated with electronic waste, however, is a bit of a contradiction in the sense that it is premised on the fact of its visibility. By mapping the e-waste network of collectors, recyclers, transporters, and refurbishers, it reaffirmed that electronic waste is in fact spatially present in the urban fabric, despite its perception of being invisible. Therefore it became a question of how electronic waste's perceived invisibility could be made transparent and constituent of urban space. If waste is central in the processes of capitalist urbanization, then architecture can improve the condition of configuring industrial form to create an ecology between e-waste, culture, and the city. 
When analyzing the industrial big box, which is the current typology responsible for processing and recycling a majority of 'Toronto's e-waste it becomes apparent upon a closer examination that the management of e-waste exists isolated from public awareness, out of sight from spaces of consumption. These buildings are hard to access, difficult to observe, offer no alternative purpose beyond its function, no opportunities for communities to engage, and are disconnected from their surroundings. If resistance towards e-waste will only occur when the effects are felt and experienced then the big question lies in the 'how.' How can architecture address the notion of transparency to give e-waste a public value and legibility in the city?

The design theory that led to the manifestation of the critical project, was an extension of the theories of Rowe and Slutsky concerning a literal and phenomenal understanding of transparency, in conjunction with the theories of Venturi and Scott Brown, which reassessed the role of symbolism in architecture, in an attempt to formulate a symbolic transparency that is capable of communicating the consequences of electronic waste. This assertion thereby positions this critical theory as the ultimate agent in disrupting the logic of electronic waste's invisibility by bringing its consequences into greater 
visibility, making legible that which society seemingly refuses to acknowledge. Furthermore, this provocation attempts to express an electronic iconography of signs and symbols, through the confluence of form, upon a generic architecture. Bringing architecture back to its primitive roots of sign, symbol and shelter.

Adding another layer of complexity onto the provocation of a symbolic transparency is expanding the use of billboards in architecture as communication, ornamentation, and inhabitable space. Speculating on the fusion of architecture and media technology forming new hybrid possibilities. The electronic billboard screen offers yet another critical response that allows us to re-think the role of ornamentation and surface facades. Like a Roman triumphal arch, the billboard exemplifies a deliberate formula for viral appeal and becomes a site-specific message that engages the act of witnessing or monitoring. The ability for a billboard to communicate a complexity of meaning, across space and time, becomes significant when considering the spatial separation between places of waste and places of consumption.

The design method and approach in which this critical design theory is pursued is through the process of sampling the found object and remixing it for architectural purposes. This process, as speculated in writing and design research, is fundamental to 
the way artists create using trash or the way a maker is able to act inventively on the detritus of electronic waste by making something from what is readily available.

Given, our current moment in time, and the ways in which we consume architecture through the endless streams of content afforded by platforms such as Google Images, Tumblr, Pinterest, and Instagram, the weight felt by the extensive history of architecture from time immemorial can be, at times, difficult to comprehend, often paralyzing us from acting upon it inventively. We have reached a moment in architectural time, where all of architectural history is now viewed from the perspective of a flat ontology, where Baroque is given equal weight to Modernism when placed next to one another. It is through this recognition that I would like to propose, within the discipline of architecture, a critical design theory that acknowledges remixing as an approach that not only leads to a conceptual framework for dealing with the material and formal practice of recycling electronic waste, but also as a way of acting upon the extent of architectural history inventively. Not only learning from history, but using history to make new history.

In conclusion, if waste is central in the processes of capitalist urbanization then it makes it essential to open up a more hybrid 
theoretical terrain within architecture for electronic waste, which has implications for practice that can extend beyond functionality, to embrace the social, political, and environmental issues that inform the production of space. 
(r)

-

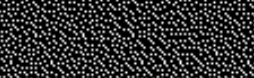

W

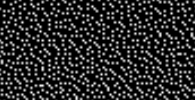

Whom

\%)

군.

1.

7.

ing

int

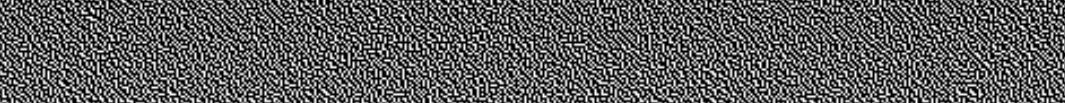

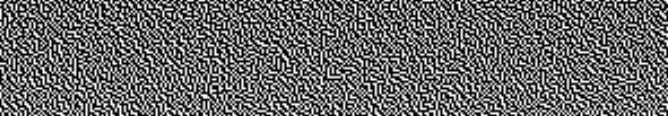

1.

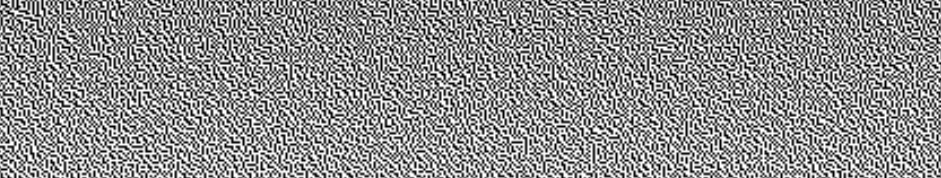

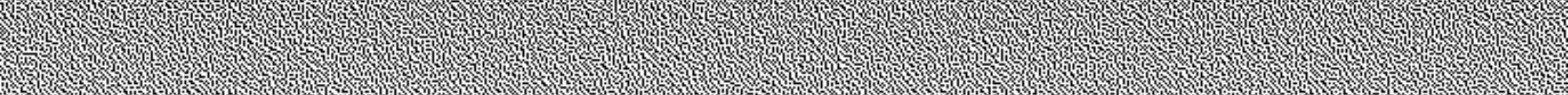

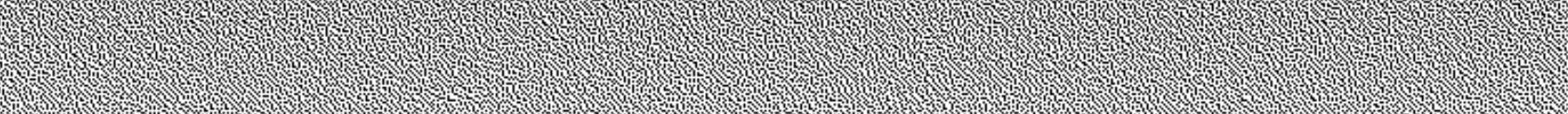

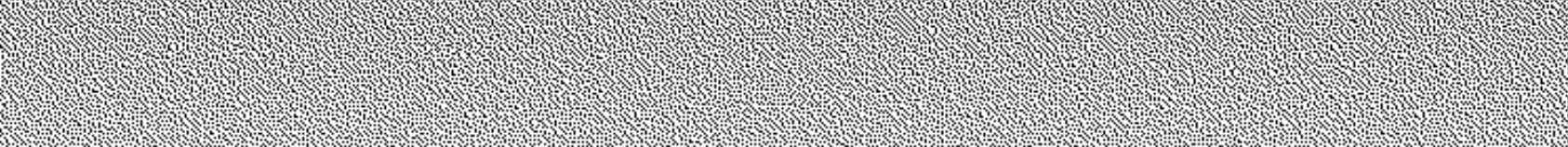

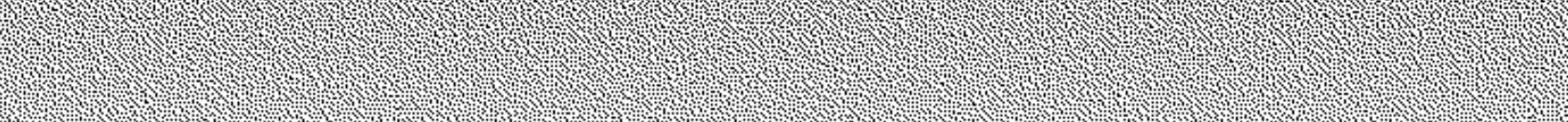
W (1. W l. l.

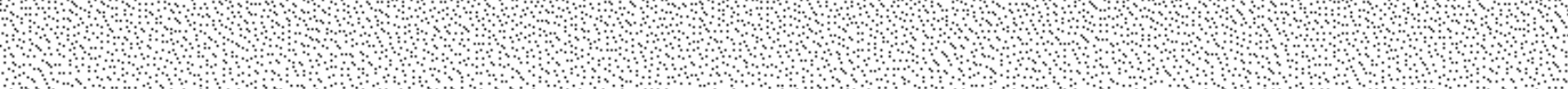





\section{Reference List}

Abramson, Daniel. Obsolescence - an architectural history. University of Chicago press, 2016.

Baldé, Kees, et al. The global e-waste monitor 2017, United Nations University, 2017.

Basel Action Network. E-trash Transparency Project, 2015, www.ban.org/trash-transparency/. Accessed 14 May 2017

Bill 151: An Act to enact the Resource Recovery and Circular Economy Act, 1st Sess, 41st Leg, Ontario, 2016.

Braghieri, Nicola. "A Small, Portable Lexicon.” Objets Trouves. Edited by Phlipp Schaerer, EPFL, 2015.

Cadbury, Deborah. Seven wonders of the industrial world. Fourth Estate, 2003, pp. 194-196.

Cheng, Em. “Observations on Drake's Billboard.” Log, no. 38, Anyone Corporation, 2016 pp. 150.

Clapham, Christopher and Nicholson, James. The concise oxford dictionary of mathematics, 4th ed., Oxford university press, 2009.

Cossu, Raffaello and Williams, Ian D. "Urban Mining: Concepts, Terminology, Challenges.” Waste Management, vol. 45, 2015, pp. 1-3, https://www.urbanmining. it/public/documents/simposio/editorial-waste-management-2015.pdf. Accessed 25 Oct 2017.

De Graaf, Reinier. “The inevitable box: architecture's main achievement and its main trauma." The architectural review, 2017, www.architectural-review.com/essays/ campaigns/notopia/the-inevitable-box-architectures-main-achievement-and-itsmain-trauma/10024071.article. Accessed 14 Feb 2018.

DeLanda, Manuel. Intensive Science \& Virtual Philosophy, Continuum, 2002.

Douglas, Mary. Purity and danger: an analysis of concepts of pollution and taboo. Routledge, 1966, pp. 36 
Gambetta, Curt. “Inside Infrastructure.” ARPA Journal, 2016, http://www.arpajournal.net/inside-infrastructure/\#note492b258020323292242ba7 3ccd5e3b6d. Accessed 28 Dec 2017

Hadhazy, Adam. "Here's the truth about the 'planned obsolescence' of tech.” BBC, 2016, www.bbc.com/future/story/20160612-heres-the-truth-about-the-plannedobsolescence-of-tech. Accessed 5 Nov 2017

Hebdige, Dick. Cut 'n' Mix: Culture, Identity and Caribbean Music. Methuen, 1987, pp.12-16.

Halliday, Stephen. The great stink of London: Sir Joseph Bazalgette and the cleansing of the Victorian capital. Sutton, 2001.

“Invention.” Online Etymology Dictionary, 2001, www.etymonline.com/word/invent.

Jencks, Charles and Baird, George. Meaning in architecture. G. Braziller, 1970.

Kepes, Gyrgy. Language of Vision. Dover Publications, 1995

Kara, Hanif, et al. “The Missing Link: Architecture and Waste Management.” Harvard Design Magazine, no. 40, 2015.

Koolhaas, Rem. “Junkspace.” October, vol. 100, The MIT Press, 2002.

Kovacs, Andrew. “10 Steps for making architecture from architecture." Office of Kovacs, https://o-k-o-k.net/UNFOLDING-PAVILION. Accessed 18 Apr 2018.

Le Corbusier. Towards a new architecture. Dover Publications, 1986.

Lepawsky, Josh. "The changing geography of global trade in electronic discards: time to rethink the e-waste problem.” The Geographical Journal, vol. 181, no. 2, 2014, pp. 147-159. Wiley Online Library, doi.org/10.1111/geoj.12077. Accessed 9 Sept 2017.

Loos, Adolf. "Ornament and Crime.” Crime and Ornament: The arts and popular culture in the shadow of Adolf Loos, edited by Bernie Miller and Melony Ward, YYZ Books, 2002, pp.29-36.

Matthews, Chris. "This Innovative West African Lab Is Turning E-Waste into 3D Printers and Robots.” Motherboard, 2 May 2014, https://motherboard.vice.com/en_us/ article/mg7bwa/upcycling-e-waste-into-3d-printers-and-robots-at-togos-woelab. 
Millar, Laura. Mashup: The Birth of Modern Culture. Vancouver Art Gallery. Archivaria, 2016, https://archivaria.ca/index.php/archivaria/article/view/13591. Accessed 18 July 2018 pp. 186-189.

McCluhan, Marshall. "The medium is the message." Understanding media: the extensions of man, McGraw-Hill, 1964.

“Mason White E-Waste.” YouTube, Uploaded by urbanNext, 29 Jan 2018, www.youtube.com/watch?v $=\mathrm{LcO} 5 \mathrm{zKqUhtQ} \& \mathrm{t}=35 \mathrm{~s}$.

Magalini, Fredrico. Interview by Angela Chen. "Why Failing to recycle electronics leaves gold mines untapped." The Verge, https://www.theverge. com/2018/4/23/17270960/electronic-waste-urban-mining-materials-recycling. Accessed 15 May 2018.

Moholy-Nagy, Laszlo. Vision in Motion, Theobald, 1947.

Muller, Simone M. "Here it is toxic, there it is not." Youtube, Uploaded by the Canadian Centre for Architecture, 22 Mar 2017, https:/ /www.youtube.com/watch?v=NhWthyiHuJo.

Munari, Bruno. “A Language of Signs and Symbols.” Design as Art, Penguin, 2008,

Navas, Eduardo. "Regressive and Reflexive Mashups in Sampling Culture.” Mashup Cultures. Springer Vienna Architecture, 2010, pp. 159.

Nicholson, Ben. “Collage Making.” Appliance House. The MIT Press, 1990.

Owens, Craig. The allegorical impulse: towards a theory of postmodernism. Godine, 1998, pp.223.

"Planned obsolescence pervasive in digital age.” CBC News, 2013, www.cbc.ca/news/technology/planned-obsolescence-pervasive-in-digital- age1.2479281. Accessed 29 May 2018.

Powell, Betsy. "Toronto's advertising sign companies push hard for digital billboards." The Toronto Star. 2013, www.thestar.com/news/city_hall/2013/10/07/ torontos_advertising_sign_companies_push_hard_for_digital_billboards. html. Accessed 14 May 2018. 
Puckett, J., \& Smith, T. (Eds.). (2002). Exporting harm the high-tech trashing of Asia. 5. Retrieved October 4, 2017, from http://archive.ban.org/E-waste/ technotrashfinalcomp.pdf

Rathje, William. Rubbish! The archaeology of garbage. HarperCollins, 1992.

Rathje, William and Murphy, Cullen. "Poor, misunderstood garbage.” New York Times, 1992, pp. 21. Proquest, http:/ / ezproxy.lib.ryerson.ca/login?url=https:/ / searchproquest-com.ezproxy.lib.ryerson.ca/docview/108845812?accountid=13631. Accessed 7 June 2018.

Rowe, Colin and Slutsky, Robert. "Transparency: Literal and Phenomenal." Perspecta, vol. 8, MIT Press, 1963.

Schopf, Heidy. "The Leslie Street Spit: Urban wilderness and cultural heritage landscape." Ontario Association of Landscape Architects, 2009, oala.ca/ground_ issue/ground-35-edges/leslie-street-spit-urban-wilderness-culturalheritage-landscapes/. Accessed 5 November 2017.

Scott Brown, Denise and Venturi, Robert. Complexity and Contradiction. The Museum of Modern Art, 1966, pp.23

Scott Brown, Denise and Venturi, Robert. Learning From Las Vegas. The MIT Press, 1972.

Slutsky, Robert. “Aqueous Humor.” Oppositions, vol. 19/20, 1980

Smith, Christopher. "The Economics of E-Waste and the Cost to the Environment." Natural Resources \& Environment, vol. 30, no. 2, 2015.

Stoner, Jill. Towards a minor architecture. MIT Press, 2012.

“Transparency.” The Merriam-Webster Dictionary, 11th ed., 2005

Vaughn, Charles. "New Park: Do we want wall-to-wall boats?” The Globe and Mail, 1977, pp.7.

Venturi, Robert. Iconography and Electronics Upon a Generic Architecture. The MIT Press, 1996.

Webster, Ken. The circular economy: a wealth of flows. Ellen MacArthur Foundation, 2015. 



